\title{
A review of the SCOSTEP's 5-year scientific program VarSITI-Variability of the Sun and Its Terrestrial Impact
}

\author{
Kazuo Shiokawa ${ }^{1 *}$ (D) and Katya Georgieva ${ }^{2,3}$
}

\begin{abstract}
The Sun is a variable active-dynamo star, emitting radiation in all wavelengths and solar-wind plasma to the interplanetary space. The Earth is immersed in this radiation and solar wind, showing various responses in geospace and atmosphere. This Sun-Earth connection variates in time scales from milli-seconds to millennia and beyond. The solar activity, which has a 11-year periodicity, is gradually declining in recent three solar cycles, suggesting a possibility of a grand minimum in near future. VarSITI—variability of the Sun and its terrestrial impact—was the 5year program of the scientific committee on solar-terrestrial physics (SCOSTEP) in 2014-2018, focusing on this variability of the Sun and its consequences on the Earth. This paper reviews some background of SCOSTEP and its past programs, achievements of the 5-year VarSITI program, and remaining outstanding questions after VarSITI.
\end{abstract}

Keywords: VarSITI, Variability of the Sun and its terrestrial impact, Sun, Heliosphere, Inner magnetosphere, lonosphere, Thermosphere, Middle atmosphere, Climate change, Space weather

\section{Introduction}

The Sun, our home star, is a variable star. Its activity is due to the action of the solar dynamo, maintaining the solar magnetic field. The solar wind-the everexpanding solar atmosphere-drags the magnetic field throughout the whole heliosphere and carries transients like coronal mass ejections and high-speed solar wind streams. The Earth, together with the other planets in the solar system, is immersed in the solar wind and interacts with the plasma and magnetic fields originating from the Sun. The Sun also emits radiation in all wavelengths, with sporadically superposed contributions by solar flares, and modulates the flux of galactic cosmic rays. All these solar agents vary on time-scales from milli-seconds to millennia and beyond. Consequently, their impact on the terrestrial system also varies. The variations of the Sun and the geoeffective solar agents,

\footnotetext{
* Correspondence: shiokawa@nagoya-u.jp

${ }^{1}$ Institute for Space-Earth Environmental Research (ISEE), Nagoya University,

Furo-cho, Chikusa-ku, Nagoya, Aichi 464-8601, Japan

Full list of author information is available at the end of the article
}

and their varying impacts on the Earth, were studied by the SCOSTEP's program VarSITI-Variability of the Sun and Its Terrestrial Impact.

\subsection{What is SCOSTEP}

SCOSTEP, the Scientific Committee on Solar-Terrestrial Physics, was originally established as the Inter-Union Commission on Solar-Terrestrial Physics (IUCSTP) by the XIth General Assembly of the International Council of Scientific Unions (ICSU; now the International Science Council, ISC) in January 1966. At its XIVth General Assembly in September 1972, ICSU reorganized IUCSTP as a special committee with responsibility for interdisciplinary solar-terrestrial physics programs of finite duration. The designation of SCOSTEP took effect in September 1973 after the ratification of a new Constitution by the ICSU Executive Board and General Committee. At the XVIIth ICSU General Assembly in September 1978, SCOSTEP became a Scientific Committee of ICSU charged with the long-term responsibility to promote international interdisciplinary programs in 
solar-terrestrial physics (https://scostep.org/). Under the International Science Council (ISC), SCOSTEP is the only organization to deal with the Sun-Earth connections.

\subsection{Previous SCOSTEP's programs 1.2.1 Early programs}

The early SCOSTEP's programs were mostly focused on separate parts of the solar-terrestrial system: International Magnetospheric Study (IMS: 1976-1979), Solar Maximum Year (SMY: 1979-1981), Middle Atmosphere Program (MAP: 1982-1985), and three parallel programs during 1998-2002: International Solar Cycle Study (ISCS), Planetary Scale Mesopause Observing System (PSMOS), and Equatorial Processes Including Coupling (EPIC). Meanwhile, the first attempts were made to incorporate all these into an end-to-end program aiming at improving our understanding of the linked solar-terrestrial system-the Solar-Terrestrial Energy Program (STEP: 1990-1997), followed by its continuation STEP-Results, Application and Modeling Phase (S-RAMP) program (1998-2002). (https://scostep. org/programs/).

Research in the framework of these programs had led to significant improvements in understanding the physical processes within each of the Sun-Earth domains: Sun, heliosphere, magnetosphere, thermosphere/ionosphere, middle atmosphere, lower atmosphere, and climate. Some cross-disciplinary progress was also achieved during STEP and S-RAMP in understanding the domain as a whole.

\subsubsection{CAWSES (2004-2008)}

In 2000, the SCOSTEP's Long Range Planning Committee was constructed with the purpose to define future research programs. This group came up with a new approach for solar-terrestrial physics that led to a new paradigm-end-to-end study of scientific "problems" within the system as a whole on both short and long time-scales. The program was named CAWSES-Climate and Weather of the Sun-Earth System. This new program was intended to enable researchers in various disciplines to work together to understand the effects of the Sun on the Earth's environment.

The fundamental problems for CAWSES as formulated by the Planning Committee were (Schmieder et al. 2004):

- Can we link the end-to-end processes that produce geoeffective coronal mass ejections, facilitate their transfer through the heliosphere, their interaction with the magnetosphere, and the production of geomagnetic storms that affect the atmosphere?
- Can we identify evidence for long-term variations of solar luminosity related to solar activity and resultant impacts on global change, compared with other climate change mechanisms?

- Can we reconcile apparent responses of the middle and lower atmosphere to solar activity, identify the physical mechanisms, in comparison with anthropogenic influences, and estimate future ozone changes?

- To what extent are the magnetosphere and ionosphere-thermosphere systems modulated by solar activity on long time scales, including the solar cycle, and how do variations driven by different processes interact with dynamical and radiative forcing processes from below?

To answer these questions, four projects were defined by the CAWSES Science Steering Group: solar influences on climate, space weather: science and applications, atmospheric coupling processes, and space climatology.

1.2.2.1 Theme 1: Solar influence on climate The aim of this project was to investigate the effects of solar variability on the climate of the lower and middle atmosphere. Evidences were accumulated that solar activity indeed influences climate. Using cosmogenic radionuclides which are primarily produced by the galactic cosmic rays whose intensity is modulated by the open solar magnetic field, the strength of the interplanetary magnetic field (IMF) was reconstructed for the past 10,000 years. The close relationship between the strength of the IMF and the total solar irradiance (TSI) found during the modern space era allowed TSI in turn to be reconstructed in the past from the reconstructed IMF. TSI was compared with selected climate records, and a relationship was found between solar variability and climate (Beer and McCracken 2009). Considerable evidence was also found that solar variability on decadal timescales does influence climate; however, it was noted that the solar signal is not uniformly distributed over the globe. Some mechanisms were suggested for the amplification of the solar signal, as summarized by (Haigh 2009 and the references therein). Among then, the so called "Bottom-up" mechanism works in the tropical oceans where there is less cloud and variations of solar irradiance have more sensible effects. It includes changes in atmospheric circulation associated with anomalies in horizontal temperature gradient of the sea surface. The basis of the "Top-down" mechanism connecting the stratosphere to the underlying tropospheric climate is the spectral solar irradiance (SSI) variability which is much greater than the TSI variability. Other possible mechanisms are related to modulation of El Niño by solar activity through 
a change in ocean circulations induced by longitudinally asymmetric changes in sea surface temperatures, etc.

1.2.2.2 Theme 2: Space weather-science and applications "Space weather" is known as the shortterm variations of the Sun, propagation of energetic particles, and electro-magnetic emissions through interplanetary space, and their effects in the magnetosphere, ionosphere, and thermosphere that can influence the performance and reliability of space-borne and groundbased technological systems and can endanger human life or health. The goals of this project were to develop dependable, robust deterministic end-to-end models that predict conditions in geospace from a quantitative understanding of the observed phenomena.

In addition to Interball, Geotail, Cluster, SOHO, ACE missions, new spacecraft were launched during CAWS ES like Hinode, RHESSI, Solar-B, and STEREO. They allowed to study in unprecedented detail processes on the Sun responsible for solar flares, energetic particles, and geoeffective transients in the solar wind. The observed properties of CMEs and ICMEs were summarized, with an emphasis on those properties that determine the ability of CMEs in causing space weather. On the applied side, special attention was paid to the effects of solar events on satellite missions in near-Earth orbit.

1.2.2.3 Theme 3: Atmospheric coupling processes Solar and magnetospheric inputs propagate downward through the atmosphere while tropospheric effects propagate upward to the thermosphere-ionosphere system. This project sought to gain greater understanding of atmospheric coupling processes by means of observations, theory, and modeling. Global observing campaigns were conducted to characterize tides and their influence from the troposphere to the thermosphere, gravity waves and turbulence, solar and galactic cosmic rays influence on minor constituents, and layers at the extra-tropical summer mesopause. In the framework of the new topic "Equatorial atmosphere coupling processes," low latitude ionospheric disturbances associated with geomagnetic activity and electrodynamic coupling of equatorial $\mathrm{F}$ region with conjugate $\mathrm{E}$ regions were studied. A project was dedicated to atmospheric wave interactions with the winter polar vortices.

1.2.2.4 Theme 4: Space climatology Climatology includes a description and understanding of the average properties and regular variations of the system and is concerned with the long-term effects (e.g., longer than the solar rotation period). The goal of this project was to provide the data necessary to study the climatology of the Sun-Earth system with an emphasis on both a critical review of the original observations and their interpretations. Two composites of total solar irradiance measurements (PMOD and ACRIM) were updated, and a third composite (IRMB) was additionally presented (Fröhlich 2009). New geomagnetic indices [e.g., the Inter-Hour Variability (IHV), the Inter-Diurnal Variability (IDV), and Polar Cap Potential (PCP)] were devised from which the long-term variations of the solar wind parameters can be derived (Svalgaard and Cliver 2007). Special attention was paid to the long-term changes and trends found in the upper atmosphere at heights above $50 \mathrm{~km}$, i.e., in the mesosphere, thermosphere, and ionosphere (Laštovička, Akmaev and Emmert 2009).

A summarizing CAWSES symposium was held in Kyoto in 2007, and selected papers from the symposium were gathered in the monograph "Weather of the SunEarth System (CAWSES): Selected papers from the 2007 Kyoto Symposium" (Tsuda et al. 2009) which is freely available online at https://www.terrapub.co.jp/ onlineproceedings/ste/CAWSES2007/index.html.

In summary, the first phase of CAWSES led to a significant improvement in our understanding of the solar influence on climate changes, effects of sporadic solar events on the terrestrial system and satellite missions in near-Earth orbit, and the coupling of atmospheric layers through dynamical, electromagnetic, and photochemical processes. It was recognized, however, that there was still much that needs to be achieved, and therefore, the SCOSTEP endorsed the continuation of the CAWSES program as CAWSES II during 20092013.

\subsubsection{CAWSES II (2009-2013)}

CAWSES II had four task groups: solar influences on Earth's climate, geospace response to altered climate, short-term solar variability and geospace, and geospace response to variable inputs from the lower atmosphere. Additional activities were related to capacity building and E-science and informatics, including the creation of scientific databases and their effective utilization in solar-terrestrial physics research. Below is a brief summary of the overview of the achievements by the CAWS ES II working groups mostly based on Tsuda et al. (2015).

1.2.3.1 TG1: Solar influences on Earth's climate An important contribution of TG1 was the highlighting of the role of the spectral solar irradiance in the solar influences on climate. Before CAWSES II, the total solar irradiance (TSI) was the only factor considered to quantify the solar influences on climate change. In addition to the "bottom-up" mechanism relying on the influence of the TSI on the tropical sea surface temperature with resulting changes in the circulation 
(Meehl et al. 2008), the "top-down" mechanism was proposed highlighting the role of the spectral solar irradiance (SSI) forcing on chemical-dynamical coupling via its interactions with atmospheric ozone and connecting the stratosphere to the underlying tropospheric climate (Gray et al. 2010). A major development during the CAWSES-II period for studies of energetic particle precipitation effects on the middle and upper atmosphere was the shift of focus from the previously dominant topic of solar proton events (SPE) to investigations including energetic electron precipitation (EEP). These two topics together defined as energetic particle precipitation (EPP). In the high latitude atmosphere, the enhanced ionization from EPP leads to the production of HOx and NOx which have an important role in middle atmosphere ozone balance, thus providing a potential link to dynamics and regional climate (Rozanov et al. 2012). Significant advances were also made in the field of cosmic rays. An extensive review on the results of TG1 is given by Seppälä et al. (2014).

Solar influence on climate is now accepted as an important contribution to climate variability, particularly on regional scales. During CAWSES II, the main focus has moved not only from TSI towards understanding SSI variations and their impact, but as well shifting from the global responses to more regional responses. With better understanding of SSI, the importance of the topdown stratospheric UV mechanism has been widely accepted. Improved measurements of both TSI and SSI became available leading to more reliable solar cycle variation estimates, and a new lower value for TSI was recommended for the IPCC AR5 climate simulations (Kopp and Lean 2011).

\subsubsection{TG2: Geospace response to altered climate} The main focus of TG2 was on the effect of anthropogenic emissions of greenhouse gases (GHG) on the geospace-the region of the atmosphere between the stratosphere and several thousand kilometers above ground where atmosphere-ionosphere-magnetosphere interactions occur. GHG cause warming in the troposphere but cooling in the upper atmosphere.

GHG are not the only driver of long-term changes and trends in the upper atmosphere and ionosphere. A regionally important driver is the secular change of the main magnetic field of the Earth. Model simulation showed that the secular variation of the Earth's magnetic field may be the dominant cause of trends in the Atlantic region ionosphere (Cnossen and Richmond 2013). In the mesosphere and lower thermosphere, important additional drivers appear to be stratospheric ozone, changes in $\mathrm{CH}_{4}$, and mesospheric water vapor concentration, though the modelled changes are much higher than the observed (Qian et al. 2011). The poorly known trends in atmospheric circulation and particularly in atmospheric wave activity with predominantly tropospheric sources (one of potential trend drivers) remained key open question in the upper atmosphere and ionosphere trends (Laštovička et al. 2014).

A sufficient amount of information had made it possible to create a first scenario of global change in the mesosphere, thermosphere, and ionosphere (Laštovička et al. 2006). During CAWSES-II period, this scenario had been continuously improved and updated (e.g., Laštovička et al. 2012; Danilov 2012; Laštovička 2013). The derived trends qualitatively agree with model simulations that show that they are the consequences of the enhanced greenhouse gases. However, some of the trends are still controversial or discrepant. The key challenges now are to improve the accuracy of various parameters and to reduce the differences in trends between models and observations.

A summary of the CAWSES-II TG2 achievements is given by Laštovička et al. (2014).

1.2.3.3 TG3: Short-term solar variability and geospace Towards the understanding of the origin and emergency of solar magnetism, the development of improved mean field solar dynamo models that take into account physical ingredients such as mutli-cellular and/ or time varying meridional circulation, magnetic pumping, North-South asymmetry, irregularity in the cycles, or improved source function for the poloidal field, has been accomplished (e.g., Gopalswamy et al. 2015a, b, c). The first self-consistent models were developed for generation of magnetic wreaths at the base of the convection zone that have become unstable and started to rise to the top (surface) of the numerical domain (Nelson et al. 2011, 2013, Nelson 2013). Three-dimentional MHD numerical simulations successfully explained the dynamics of several CMEs and the associated shock waves (Shen et al. 2011).

The International Study for Earth-Affecting Solar Transients (ISEST) program was newly created within the frame of CAWSES Task Group 3. It continued during the VarSITI program, with the focused objective of improving the scientific understanding of the origin and propagation of solar transients and developing the prediction capacity of these transients' arrival and potential impact on the Earth.

1.2.3.4 TG4: Geospace response to variable inputs from the lower atmosphere The Task Group 4 focused on the geospace response to variable inputs from the lower atmosphere. This contains atmospheric waves generated by meteorological disturbances, their interaction with the background mean flow in the middle atmosphere and with the ionospheric plasma, and their 
relation to competing disturbances in the thermosphere and ionosphere generated by energy inputs from the magnetosphere. A comprehensive summary of Task Group 4 is given by Oberheide et al. (2015).

The major scientific findings during CAWSES-II Task Group 4 are for impacts from lower atmosphere to the middle and upper atmosphere and ionosphere through various atmospheric waves, i.e., gravity waves with periods from 5 min to a few hours; tides with periods of 6 , 8,12 , and $24 \mathrm{~h}$; and planetary waves with periods of days. Vadas and Crowley (2010) showed the features of the penetration of gravity waves generated from convective plume to the middle atmosphere and ionosphere. Tsugawa et al. (2011) reported clear concentric waves in ionospheric total electron content (TEC) map generated by catastrophic Tohoku earthquake and Tsunami on 11 March 2011. This event provided a strong visual evidence of gravity wave penetration to the ionosphere. The wavenumber 4 structure observed in the equatorial ionosphere by Immel et al. (2006) was recognized as a result of penetration of atmospheric tides to the E- and F-region ionosphere and electromagnetic coupling between E- and F-region ionosphere (e.g., England 2012). After the discovery of response of ionospheric TEC to the stratospheric sudden warming (SSW) induced by planetary wave collapse by Goncharenko and Zhang (2008), many evidences of planetary wave penetration to the thermosphere and ionosphere have been reported during the CAWSES-II period.

A summarizing CAWSES-II symposium was held in Nagoya in 2013, and selected papers from the symposium were gathered in the special issue of Earth Planets and Space at https://www.springeropen.com/collections/ ICS (overview: Yamamoto et al. 2016). Review papers of the four task groups and overall CAWAES-II (overview: Tsuda et al. 2015) were published in the special issue of Progress in Earth and Planetary Science which is freely available online at https://www.springeropen.com/ collections/cawses2reviewcollection.

\section{VarSITI (2014-2018)}

CAWSES coincided with the prolonged period of very low solar activity between sunspot cycles 23 and 24 . CAWSES II started in 2009, the long-awaited beginning of cycle 24, and covered the rising phase of the cycle. It was even subtitled "Towards solar maximum." However, that solar maximum was a surprise to most of the community.

Both CAWSES and CAWSES II were mainly focused on the Earth's atmosphere: how it is affected by solar activity on short and long time scales, how anthropogenically induced changes in the atmosphere affect climate, how the solar effects in the atmosphere depend on a changing climate, and how upper atmospheric levels are influenced by lower levels.

Due to the observed decline in solar activity which puts an end to the Modern Grand Maximum, as shown in Fig. 1, by the time of the start of the next SCOSTEP's scientific program, more attention was directed to the Sun: are we facing the next grand minimum in solar activity or will this be just a regular secular minimum? In either case, what are the most extreme solar events that we can expect, and how will they affect the Earth's system and its technological infrastructure? In a period of low solar activity, what are the characteristics of geoeffective solar agents, and how does the terrestrial system respond to them?

Basically, all we know about the Sun and the geoeffective solar transients from space-borne and in situ measurements is for the period of the "space era," coinciding with the period of the grand maximum of solar activity in the second half of the twentieth century. The question arises whether the mechanisms and models based on these observations will hold true in a period of lower activity.

The definition of the VarSITI program was a community effort (Gopalswamy 2013). The primary input was a set of nine white papers received from the community spanning the interests of all the scientific unions and interdisciplinary bodies of ICSU represented in the SCOSTEP Bureau. Community input was also received during the International Symposium on Solar-Terrestrial Physics in Pune India in 2012 when a panel discussion was held on the next scientific program. After a thorough discussion among the Bureau members, a set of 30 experts from the SCOSTEP community was invited to a brainstorming forum organized by the International

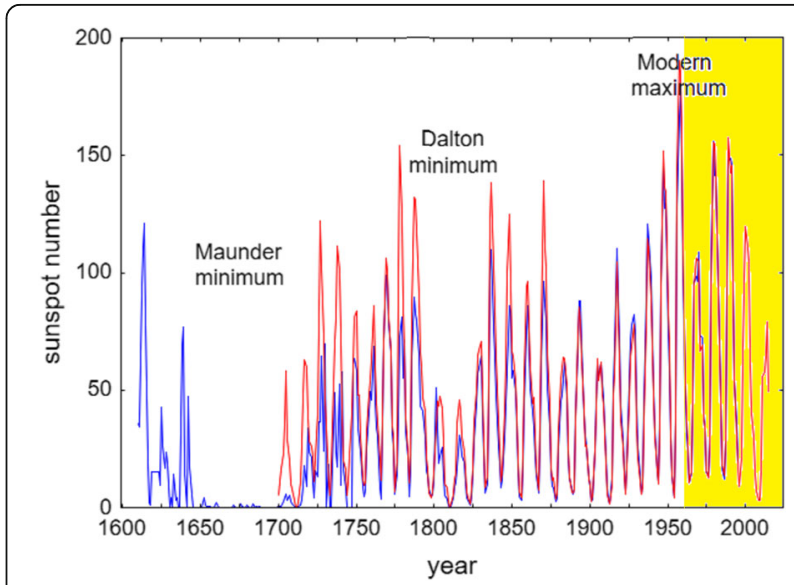

Fig. 1 Instrumental sunspot observations: group sunspot number (Hoyt and Schatten 1998) - blue line and international sunspot number (Clette et al. 2007)—red line. The shaded area indicates the "space era" which started with the launching of the first artificial satellites of the Earth for in situ measurements in the outer space 
Space Science Institute (ISSI) in Bern, Switzerland, during May 7-8, 2013. The participants were the authors of the white papers, the SCOSTEP Bureau, and international scientists. The 9 white papers and the community input were synthesized into four projects:

(i) Solar Evolution and Extrema (SEE)

(ii) International Study of Earth-affecting Solar Transients (ISEST/MiniMax24)

(iii) Specification and Prediction of the Coupled InnerMagnetospheric Environment (SPeCIMEN)

(iv) Role Of the Sun and the Middle atmosphere/ thermosphere/ionosphere In Climate (ROSMIC).

The name VarSITI (Variability of the Sun and Its Terrestrial Impacts) was proposed and accepted at the ISSI Forum. Further community input was received during the CAWSES-II Symposium in Nagoya in 2013 and the VarSITI Town Hall during the AGU 2013 fall meeting in San Francisco.

\section{Selected results from VarSITI}

\subsection{Project SEE: Solar Evolution and Extrema}

During CAWSES II, physical models based on the solar dynamo theory, together with other approaches (statistics, precursors, correlations, neural networks, etc.), were employed for the first time in predicting the following sunspot cycle 24. A set of predictions of the amplitude of Solar Cycle 24 accumulated in 2008 ranged from very low to unprecedented high levels of solar activity (Fig. 2). The predictions formed an almost normal distribution, centered on the average amplitude of all preceding solar cycles (Pesnell 2012). The wide range of the predicted amplitudes, even derived using the same methods, demonstrated that at the time of the completion of CAWSES II, we were still far from understanding the physics of the solar cycle.

The goal of the project SEE was to answer the following questions:

1. Are we at the verge of a new grand minimum? If not, what is the expectation for cycle 25?

2. For the next few decades, what can we expect in terms of extreme solar flares and storms, and also absence of activity? Another Carrington event? What is the largest solar eruption/flare possible? What is the expectation for periods with absence of activity?

3. Does our current best understanding of the evolution of solar irradiance and mass loss resolve the "Faint Young Sun" problem? What are the alternative solutions?

\subsubsection{Forecasting solar activity}

One of the main focuses of VarSITI program was the end of the modern grand maximum of solar activity and what we can expect after it. Different approaches are employed to forecast the future sunspot cycles: extrapolations and statistical relations between some characteristics of the average sunspot cycle and between consecutive cycles, precursor methods, data-driven fluxtransport simulations, machine learning, neural network, autoregressive models, etc. All prediction methods can be generically divided into three broad groups, including the majority of the above classifications: statistical or extrapolation methods, precursor methods, and modelbased methods. Extensive reviews of the prediction methods and some early forecasts of cycle 25 are given by Petrovay (2020).

It should be noted here that a major event occurred during the VarSITI program though it was not part of it. After a series of "Sunspot Number Workshops" (http:// ssnworkshop.wikia.com/wiki/Home), on July 1, 2015, the Sunspot Index Data Center in Brussels terminated the more than 400 years long data series of the International relative sunspot number $R_{Z}$ and replaced it by a new entirely revised data series $S_{N}$ (Cliver et al. 2013; Clette et al. 2014). In this revised data series $S_{N}$, the overall level of solar activity was significantly increased as compared to $R_{Z}$. In the future solar activity forecasts, some authors still use the original $R_{Z}$ series, others use the new $S_{N}$ series, and the comparison of the predictions for cycle 25 , as well as between cycle 24 and the predictions for cycle 25 is not straightforward. To avoid misunderstanding, for each forecast, we will indicate which series is used: V1 for the original $R_{Z}$ (Clette et al. 2007) or V2 for the recalibrated $S_{N}$ (Clette et al. 2014).

The statistical and extrapolation methods include linear regression techniques (e.g., Chae and Kim 2017; Werner and Guineva 2020), multivariate regression (Sabarinath and Anilkumar 2018), neural networks (Covas et al. 2019), deep learning (Pala and Atici 2019), and non-linear prediction algorithms (Sarp et al. 2018).

Extrapolation methods can theoretically yield very long-term predictions. An attempt to make a superlong-term forecast was made by Popova et al. (2018), where it is stated that two fundamental dependences were found for a solar dipole and a quadrupole, on the basis of which one can make a forecast for many cycles ahead. This forecast was an example of the methods based on spectral analysis in which it is assumed that the sunspot time series is a superposition of periodicities. This article was criticized by Usoskin (2018), which the authors disagreed with Zharkova et al. (2018).

Most of the predictions based on statistical and extrapolation methods are for a low cycle 25, similar 


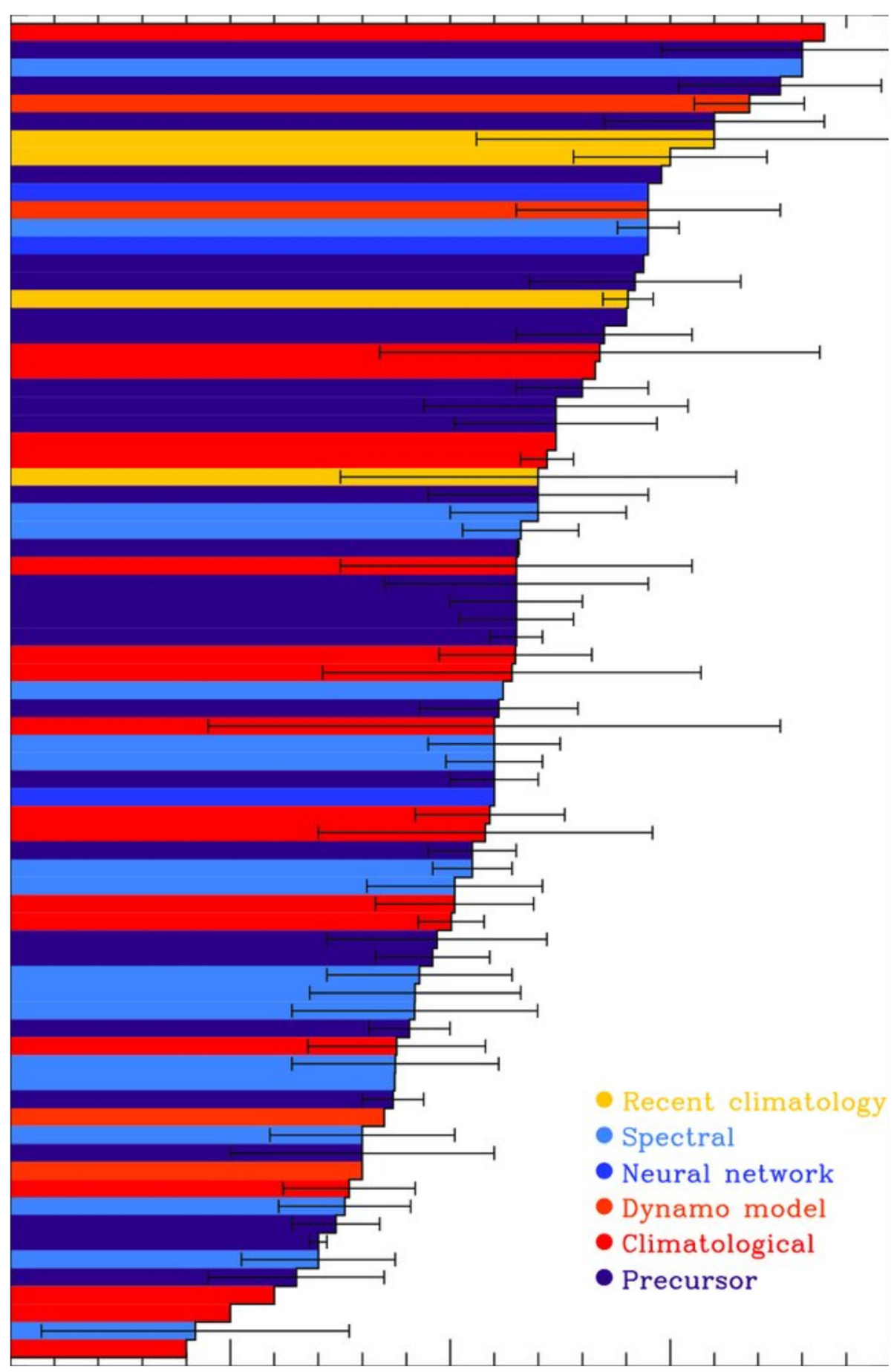

Fig. 2 Forecasts of solar cycle 24 (From Pesnell 2012)

(possibly somewhat higher of somewhat lower) to cycle 24. Some studies predict a very weak cycle (e.g., Covas et al. 2019), a cycle stronger than cycle 24 (Sarp et al. 2018), or stronger than both cycles 23 and 24 (Pala and Atici 2019).

In the precursor methods, the future sunspot maximum is predicted using its correlations with other heliophysical parameters observed before this maximum ("precursors"). Helal and Galal (2013) used a correlation between the number of spotless days and the upcoming solar maximum to estimate that Solar Cycle 25 will have $R_{z}=118.2(\mathrm{~V} 1)$, peaking 4.0 years after the solar minimum. Yoshida (2014) used correlations between $R_{z}$ before minimum with the upcoming solar maximum, using 
the symmetries of the even/odd cycles to derive the prediction: $R_{z}=115.4 \pm 11.9$ (V1). Based on the empirical correlation between the dipole moment during solar minimum and the strength of the subsequent cycle, Cameron et al. (2016) suggest that Cycle 25 will be of moderate amplitude, not much higher than cycle 24 . Kirov et al. (2018) show that both the maximum sunspot number of a solar cycle and the minimum of geomagnetic activity preceding it can be predicted from the maximum value of the solar dipole magnetic field of the previous cycle which is observed well before the sunspot minimum. They estimated that the minimum geomagnetic activity between cycles 24 and 25 as quantified by the geomagnetic $a p$-index will be about 5 , and the maximum sunspot number for cycle 25 about 50-55 (V1). Petrovay et al. (2018) focused on the rush-to-the-poles (RTTP) phenomenon in coronal green line emission. Considering various correlations between properties of the RTTP with the upcoming solar cycle, they found a correlation between the rate of the RTTP and the time delay until the maximum of the next solar cycle. On the basis of this correlation and the known internal regularities of the sunspot number series, they predict that, following a minimum in 2019, cycle 25 will peak in late 2024 at an amplitude of about 130 (V2). This slightly exceeds the amplitude of cycle 24, but it would still make cycle 25 a fairly weak cycle. Gopalswamy et al. (2018) used polar and low-latitude brightness temperatures from the Nobeyama Radioheliograph at $17 \mathrm{GHz}$ as proxies to the polar and active region magnetic fields, respectively, and the locations of prominence eruptions as a proxy to the filament locations to study their time variation. They showed that the polar microwave brightness temperature is highly correlated with the polar magnetic field strength and the fast solar wind speed, and that the polar microwave brightness in one cycle is correlated with the lowlatitude brightness with a lag of about half a solar cycle. They used this correlation to predict the strength of the solar cycle 25: the smoothed sunspot numbers (V2) in the southern and northern hemispheres can be predicted as 89 and 59, respectively. These values indicate that cycle 25 will not be too different from cycle 24 in its strength. Gopalswamy et al. (2018) also combined the rush-to-thepole data from Nobeyama prominences with historical data going back to 1860 to study the north-south asymmetry of sign reversal at solar poles. They find that the reversal asymmetry has a quasi-periodicity of $3-5$ cycles.

The model-based methods are based on the theory of solar dynamo. A very recent review of dynamo models of the solar cycle is presented by Charbonneau (2020). The flux-transport mechanism allows predictions by assimilating the observed magnetic field on the surface. Since the emergence of sunspot groups has random properties, making it impossible to accurately predict the solar cycle and strongly limiting the scope of cycle predictions, Jiang et al. (2018) developed a scheme to investigate the predictability of the solar activity over one cycle. When a cycle has been ongoing for more than 3 years, the sunspot group emergence can be predicted along with its uncertainty during the rest time of the cycle. The method gives maximum strength of cycle 25 in the range $125 \pm 32$ ( $2 \sigma$ uncertainty range, V2), which is about $10 \%$ stronger than cycle 24 based on the mean value. Using an Advective Flux Transport (AFT) model, Hathaway and Upton (2016) predicted that cycle 25 will be similar in strength to the cycle 24 , with an uncertainty of about $15 \%$. AFT also predicted that the polar fields in the southern hemisphere would weaken in late 2016 and into 2017 before recovering. After two more years of observations, Upton and Hathaway (2018) examined the accuracy of the 2016 AFT prediction and found that the new observations track well with AFT's predictions for the last 2 years. The updated prediction for cycle 25 was that it will be slightly weaker than cycle 24 , making it the weakest cycle on record in the last hundred years. As weak cycles are preceded by long extended minima, we may not reach the cycle24/ 25 minimum until 2021. Bhowmik and Nandy (2018) coupled 2D flux transport model to a 2D kinematic dynamo model and sequentially calculated the polar field of one cycle and the number of sunspots in the next cycle. They predicted the maximum of cycle 25 in 2023-2025 with the height of 109-139 (V2).

The general conclusion is that the beginning of the twentyfirst century will be characterized by one or two cycles with a fairly low or just low intensity. A more serious, Maunder-type decline of activity cannot be ruled out either, but in the next few decades, the level of solar activity is expected to be either average (more likely) or of the type of the Dalton minimum (less likely).

A review of the recent results on predicting the future solar activity in the framework of VarSITI program is given by Nandi et al. (this issue).

\subsubsection{Extreme solar events}

Extreme can be considered events on the tail of a distribution-for example, a CME with speed or magnetic field exceeding certain thresholds that very few observed so far events have exceeded (Gopalswamy 2018). From the terrestrial point of view, extreme are solar events leading to disturbances in the terrestrial system that very few observed so far events have caused. It should be noted that there is no direct correspondence between the two types of extreme events: extreme geomagnetic storms are nearly always, but not always, produced by extreme solar events, and extreme solar events do not necessarily cause extreme geomagnetic storms (Schmieder 2018).

The ability of a solar active region to produce an extreme event depends of the maximum possible magnetic 


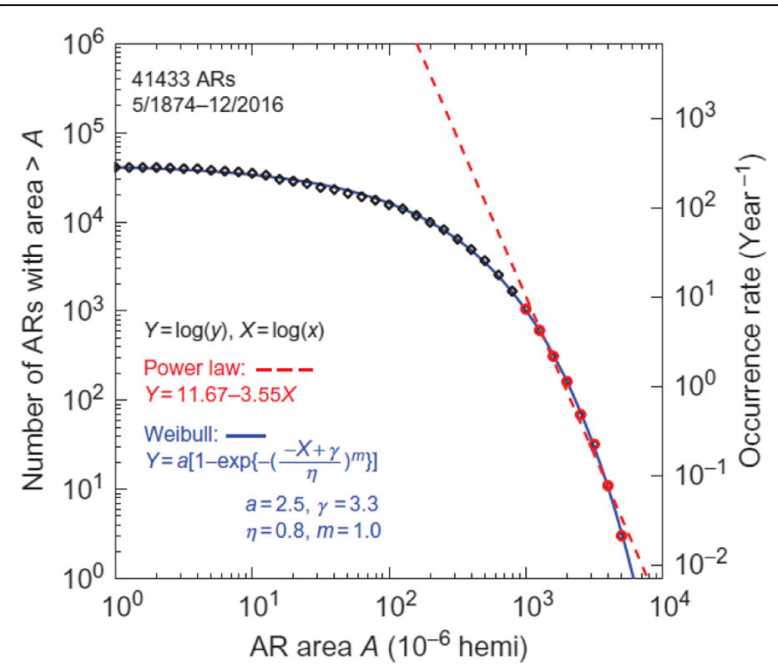

Fig. 3 Cumulative number $N$ of active regions' (sunspot groups') areas $A$ from 1874 to 2016. $A$ is expressed in msh (millionths of solar hemisphere). The left-hand $Y$-axis gives the total number of active regions with area $>A$, and the right-hand $Y$-axis-the occurrence rate $N$ per year (taken from Gopalswamy 2018)

potential energy that can be converted into magnetic kinetic energy. The visual indicators of active regions are sunspots.

The number and area of sunspots reflect the intensity of the solar magnetic fields in the solar active regions (Houtgast and van Sluiters 1948). Therefore, using historical data of active regions' areas, estimations can be made of the active regions' magnetic fields, respectively,

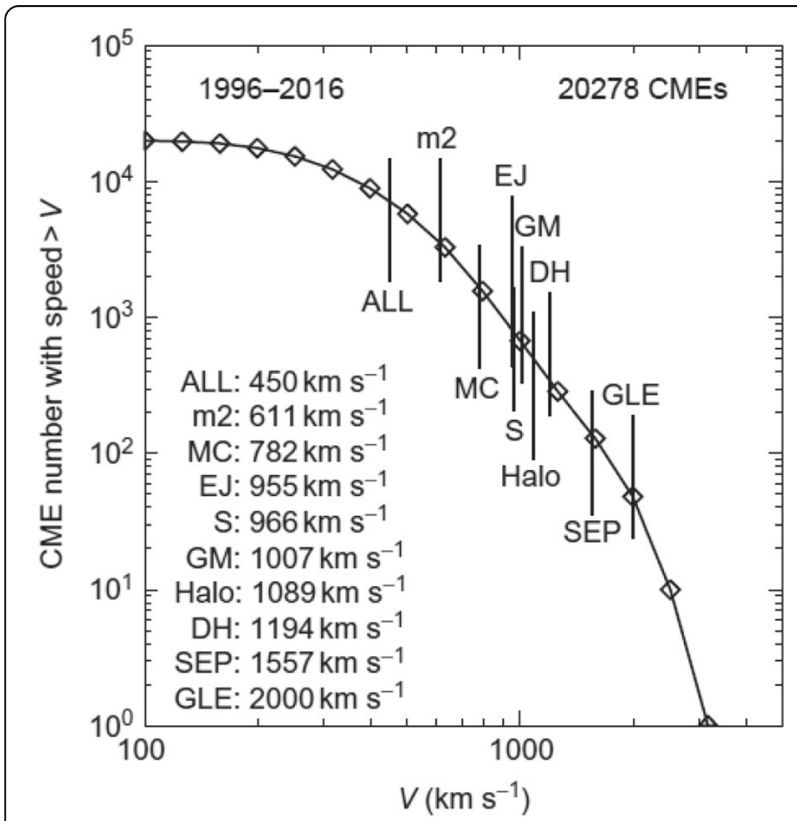

Fig. 4 Cumulative distribution of CME speed (V) from SOHO/LASCO with the average speeds of the various CME populations (taken from Gopalswamy 2016) of the magnetic potential energy, and of the ability of the solar active regions to produce extreme events. Figure 3 shows the cumulative distribution of the active regions' areas $A$ for the period 1874-2016 (Gopalswamy 2018). The cumulative number decreases slowly until the area reaches $\sim 1000 \mathrm{msh}$ (millionths of solar hemisphere) and then decreases rapidly. The overall distribution can be fit to the Weibull's function, and its high area tail-also to a power law. An extreme active region (once in 100 years) has an area of $7000 \mathrm{msh}$ according to the power law and $6000 \mathrm{msh}$ according to the Weibull function.

3.1.2.1 Coronal mass ejections Figure 4 presents the cumulative distribution of CMEs' speed from $\mathrm{SOHO} /$ LASCO (https://cdaw.gsfc.nasa.gov) with the average speeds of the various CME populations marked on the plot: metric type II radio bursts $\left(\mathrm{m}^{2}\right)$; magnetic clouds (MC); ejecta (EJ)-ICMEs lacking flux rope structure; interplanetary shocks (S) detected in the solar wind; geomagnetic storms (GM) caused by CME magnetic field or shock sheath; halo CMEs (Halo) that appear to surround the occulting disk of the coronagraph and propagating Earthward or anti-Earthward; decameter-hectometric (DH) type II bursts indicating electron acceleration by CME-driven shocks in the interplanetary medium; SEP events caused by CME-driven shocks; and ground level enhancement (GLE) in SEP events indicating the acceleration of $\mathrm{GeV}$ particles.

The fastest CME observed by SOHO/LASCO occurred on November 10, 2004, with an average speed in the coronagraph field of view of $3387 \mathrm{~km} / \mathrm{s}$, and there are very few CMEs with speeds exceeding $\sim 3000 \mathrm{~km} / \mathrm{s}$. Figure $5 \mathrm{a}$ illustrates the occurrence frequency of CMEs with speeds exceeding certain values. From the Weibull distribution, once in 100 years an event may occur with $V>3800 \mathrm{~km} / \mathrm{s}$, and once in 1000 years-an event with $V$ $>4700 \mathrm{~km} / \mathrm{s}$ (Gopalswamy 2018).

Figure 5b gives the cumulative distribution and occurrence frequency of the CMEs' kinetic energy. The once in 100 years and once in 1000 years events have kinetic energies $4.4 \times 10^{33}$ and $9.8 \times 10^{33} \mathrm{erg}$, respectively, which are not much higher than the highest reported values. The CME with the highest kinetic energy of 4.2 $\times 10^{33}$ erg was observed by SOHO/LASCO on September 9, 2005 (Gopalswamy 2018).

3.1.2.2 Flares As in the case of CMEs, the extreme solar flares are defined as one in 100 years and one in 1000 years events. Figure 6 is the cumulative distribution of all flares recorded by various GOES satellites since 1969 in the $1-8 \mathrm{~A}^{\circ}$ energy band.

For the flare intensity, the Weibull and the power law distributions give almost identical results: the 100-year 


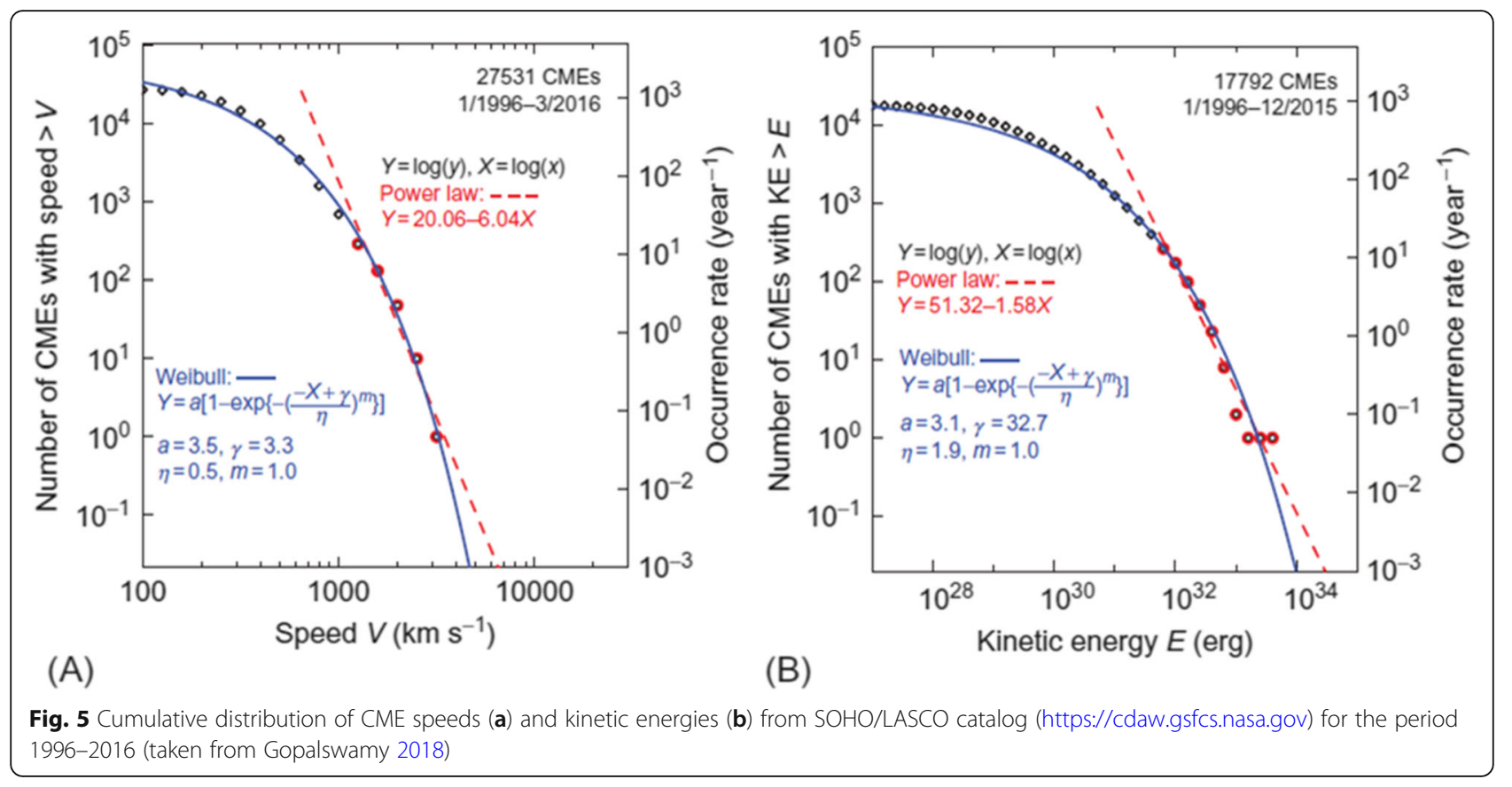

and 1000-year event sizes are X43.9 and X101, respectively, according to the Weibull distribution, and X42 and X115 according to the power law distribution (Gopalswamy 2018). As mentioned above, the largest flare during the space age was registered by the GOES satellite on November 4, 2003, but as the GOES X-ray sensor saturated at a level of X17.4 for about $12 \mathrm{~min}$ during this event, it was suggested that the flare size should have been in the range X34-X48, with a mean

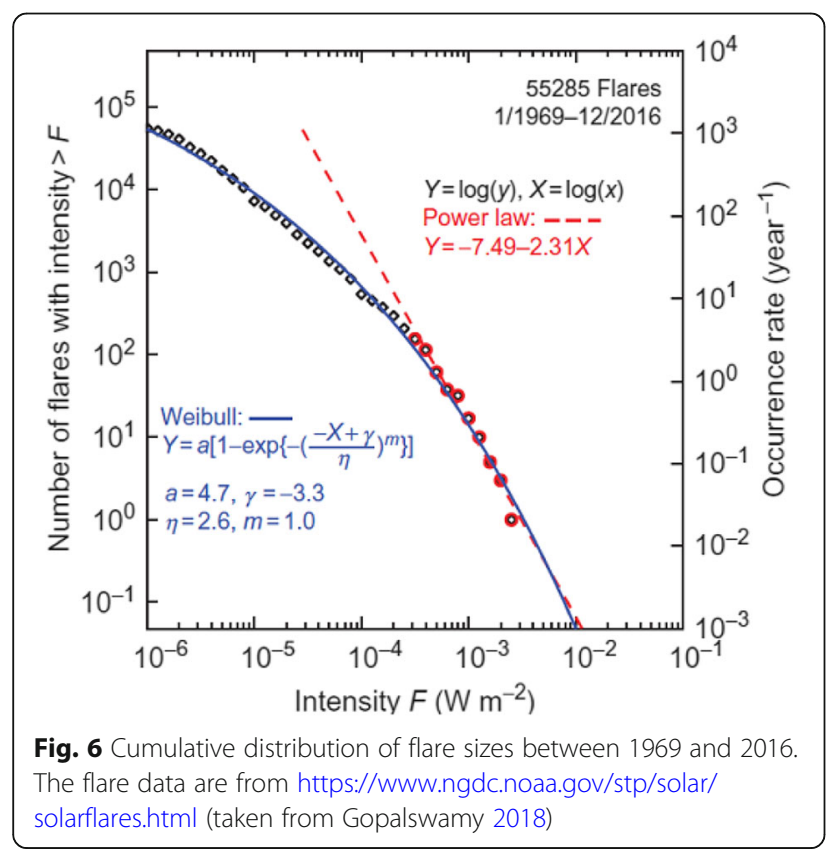

value of X40 (Brodrick et al. 2005). Therefore, it is about the size of the 100-year maximum.

The bolometric energy (the energy emitted across the whole electromagnetic spectrum) corresponding to an $\mathrm{X} 100$ flare is $10^{33} \mathrm{erg}$ (see e.g., Benz 2017). Flares with bolometric energies $>10^{33}$ erg are considered super flares.

There is no agreement about how extreme a solar flare can be, and how often extreme flares can occur. The period of instrumental observations of the Sun is only 400 years which is far from good statistics. However, we can complement these observations with observations of solar-like stars. Superflare stars are generally characterized by larger chromospheric emissions than other stars, including the Sun, but superflare stars with activity levels lower than, or comparable to, the Sun do exist, suggesting that solar flares and superflares most likely share the same origin (Karoff et al. 2016). Therefore, if we observe 10,000 solar type stars (slowly rotating G-type main sequence stars with surface temperatures between 5600 and $6000 \mathrm{~K}$ ) for 1 year, we can get the data similar to the data obtained from 10,000 years' observations of the Sun. Maehara et al. (2012) using Kepler satellite data, which include observations of 80,000 solar type stars, found 365 superflares with total bolometric energy from $10^{33}$ to $10^{36}$ erg on 148 solar type stars. Superflares of $10^{34} \mathrm{erg}$ on Sun-like stars were estimated to occur once every 800 year, and those of $10^{35} \mathrm{erg}$-once every 5000 year. This is much more frequently than implied by Fig. 3 where the tail of the flare-size distribution suggests that super flares $\left(>10^{33} \mathrm{erg}\right)$ can occur on the Sun once in a millennium, and a $10^{34}$ erg flare-only once in 125,000 years (Gopalswamy 2018). Besides, historical surveys of 
bright or oddly colored Sun, short intense heat waves, or low-latitude auroras indicate that the Sun has likely not had any superflares in the last two millennia (Schaefer et al. 2000).

Aulanier et al. (2010, 2013) used a dimensionless numerical 3D MHD simulation for solar eruptions. When the model is scaled to the strongest measured sunspot group's area and magnetic field $(6000 \mathrm{msh}$ and $3.5 \mathrm{kG}$, respectively), it can be used to calculate the size of the sunspot pair that is required to generate the solar flares of various energies. Further, observations show that large sunspots groups are always fragmented into several spots and are never involved in a given flare as a whole, only one bipole will be involved in the flare. Aulanier et al. (2013) estimated that only $30 \%$ of the area of a given sunspot group can be involved in a flare. Figure 7 from Schmieder (2018) illustrates the size of the sunspot group needed to host a bipole which can produce a flare of a given size. With these scalings, a superflare of $10^{36}$ erg requires a very large single pair of spots, whose extent is $48^{\circ}$ in longitude/latitude, at the surface of a Sun-like star. Such spots have never been reported on the Sun (Aulanier et al. 2013).

These scalings resulted in a maximum solar flare energy of $\sim 610^{33} \mathrm{erg}$ which is only about six times that of the strongest-ever directly observed flare of Nov. 4, 2003. Aulanier et al. (2013) argued that superflares of $10^{34}$ erg are unrealistic for the Sun because of the observed fragmentation of the magnetic flux in the active regions. However, Toriumi and Takasao (2017) demonstrated that even one of the largest, highly fragmented sunspot groups, such as the one numbered 14585 by the Royal Greenwich Observatory (RGO), produced a flare eruption leaving AR-sized, gigantic flare ribbons (on July $25,1946)$, which may point to the possibility that even larger ARs could occur and cause a superflare. For the largest sunspot group on 1947 April 8, RGO 14886 with a maximum spot area of $6132 \mathrm{msh}$, Toriumi and Wang (2019) estimated its total flux to be $2.0 \times 10^{23} \mathrm{Mx}$, leading to a flare with energy $1.5 \times 10^{34} \mathrm{erg}$. This is more than twice larger than the maximum possible energy estimated by Aulanier et al. (2013), and in the energy range of the weak superflares reported by Maehara et al. (2012) for numerous slowly rotating and isolated Sunlike stars, but is several orders of magnitude smaller than that of strong stellar superflares.

An open question is whether the current solar dynamo can produce much larger sunspot groups as required to produce stronger flares.

3.1.2.3 Terrestrial perspective From the terrestrial perspective, a crucial question is how extreme geomagnetic storms the solar extreme events can produce. The Dstindex is available since 1957, and since then, there has been only one storm with Dst $\leq 500 \mathrm{nT}$. It had an intensity of Dst $=-589 \mathrm{nT}$ and happened on March 13-14, 1989. Another very intense magnetic storm, reaching almost the level of a superstorm with Dst $\leq 490 \mathrm{nT}$, occurred on November 20, 2003. Only these two events can qualify as possible superstorms since the Dst-index is available.

Before the Dst-index became available, the geomagnetic storms can be estimated from magnetic field data from the Colaba and Alibag Observatories operating since 1841. The strongest geomagnetic storm since then is the famous Carrington event on September 1, 1859 (Lakhina and Tsurutani 2018). The depletion of the horizontal component of the magnetic field measured in the Colaba observatory in Mumbai, India, was $1600 \mathrm{nT}$. The transit time of the ICME from the Sun to the Earth

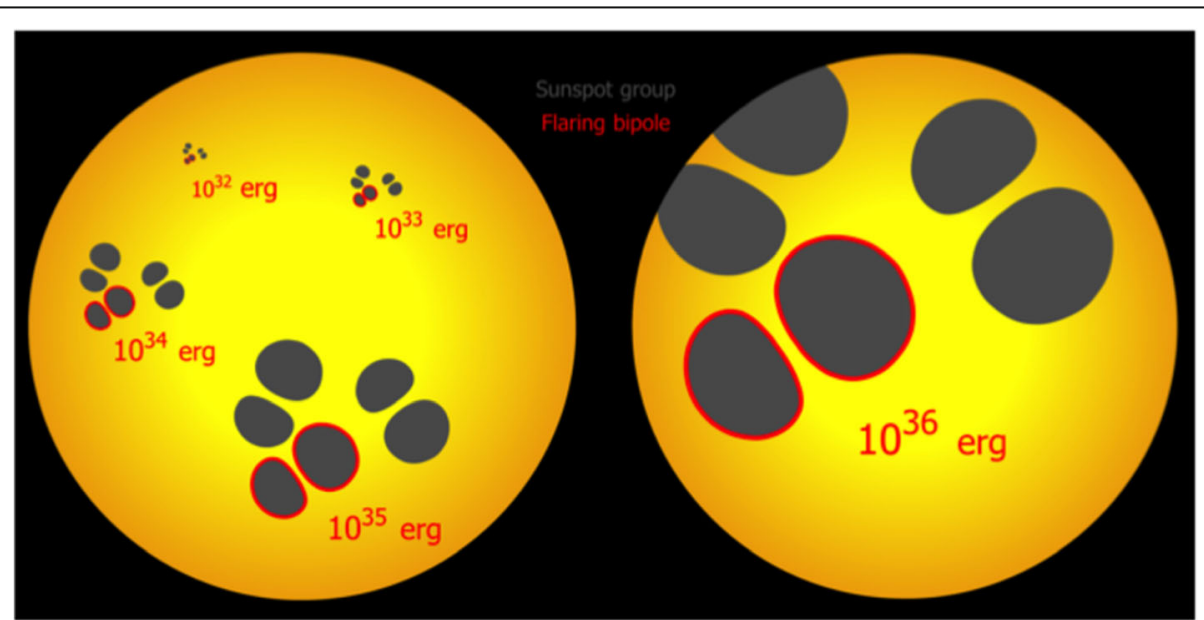

Fig. 7 Schematic representation of several modeled sunspot groups on the solar disk, with their corresponding modeled flaw energies computed with the Aulanier et al. (2013) simulation. A sunspot group consists of several pairs of sunspots. In each group, a pair of sunspots (surrounded by red curve) representing $30 \%$ of the sunspot group area is modeled in the simulation (taken from Schmieder 2018) 
was $17 \mathrm{~h}$ and $40 \mathrm{~min}$, so the average shock transit speed is found to be $2380 \mathrm{~km} / \mathrm{s}$, and the estimated speed at Earth's orbit was estimated to have been $1850 \mathrm{~km} / \mathrm{s}$. Based on the empirical relation between the speed and magnetic field of the ejecta (Gonzalez et al. 1998), the magnetic field magnitude was calculated to have been 90 $\mathrm{nT}$ at $1 \mathrm{AU}$. Finally, from the empirical expression for the dependence of the Dst-index of the speed and magnetic field of the ejecta, the Dst-index of the Carrington event was estimated as - $1760 \mathrm{nT}$ (Tsurutani et al. 2003).

Tsurutani and Lakhina (2014) and Lakhina and Tsurutani (2018) estimated the maximum possible intensity of a superstorm. They assumed a maximum CME speed close to the Sun of $3000 \mathrm{~km} / \mathrm{s}$, and a $10 \%$ decrease on the way to the Earth, or a speed $2700 \mathrm{~km} / \mathrm{s}$ at $1 \mathrm{AU}$. This would give shock transit time from the Sun to the Earth of $\sim 12.0 \mathrm{~h}$ (for comparison, the fastest ever recorded event on August 1972 took $14.6 \mathrm{~h}$ and the Carrington event $17.6 \mathrm{~h}$ ). This would mean Alfvén Mach number of $\sim 63$ and magnetosonic Mach number of $\sim 45$. The largest magnetosonic Mach number of the shock observed so far is $\sim 28$ and that is for the shock associated with the extreme ICME of July 23, 2012 (Riley et al. 2016). The ram pressure of the maximum intensity superstorm downstream of the ICME shock was calculated to be $244 \mathrm{nPa}$, which would cause the magnetopause to be pushed inward from its quiet time position of $\sim 11.9 \mathrm{RE}$ to a new subsolar position at $\sim 5.0 \mathrm{RE}$ from the center of the Earth, where RE is an Earth radius $(6371 \mathrm{~km})$. So far, the lowest magnetopause position detected is at 5.2 $\mathrm{RE}$ for the August 1972 storm. Using the empirical relationship between the speed and magnetic field strength of the ICME at $1 \mathrm{AU}$ (Gonzalez et al. 1998), the magnetic cloud field strength of $127 \mathrm{nT}$ was estimated by Tsurutani and Lakhina (2014). This yields a maximum strength of the interplanetary electric field of $340 \mathrm{mV} / \mathrm{m}$, and if we accept a linear dependence of the intensity of all magnetic storms on the interplanetary electric field (Burton et al. 1975; Echer et al. 2008), the maximum possible intensity of a superstorm is expected to be twice the intensity of the Carrington storm, that is, Dst $\sim 3500 \mathrm{nT}$.

Figure 8 shows the cumulative distribution of geomagnetic storms with Dst $<100 \mathrm{nT}$. According to the Weibull distribution which fits better the data points, a 100 -year event has a size of $603 \mathrm{nT}$, and a 1000-year event has a size of $845 \mathrm{nT}$. The 100-year event is consistent with the March 1989 event, while the 1000-year event is half the estimated size of the Carrington storm. It should be noted, however, that some authors argue that the $-1760 \mathrm{nT}$ of the Carrington event is an overestimation and suggest a Dst around - $900 \mathrm{nT}$ as a nominal value for it (Gopalswamy 2018).

Yermolaev et al. (2018), assuming power law, calculated the tails of distributions in the area of moderate and strong storms (from - 150 to $-300 \mathrm{nT}$ ) where statistics of

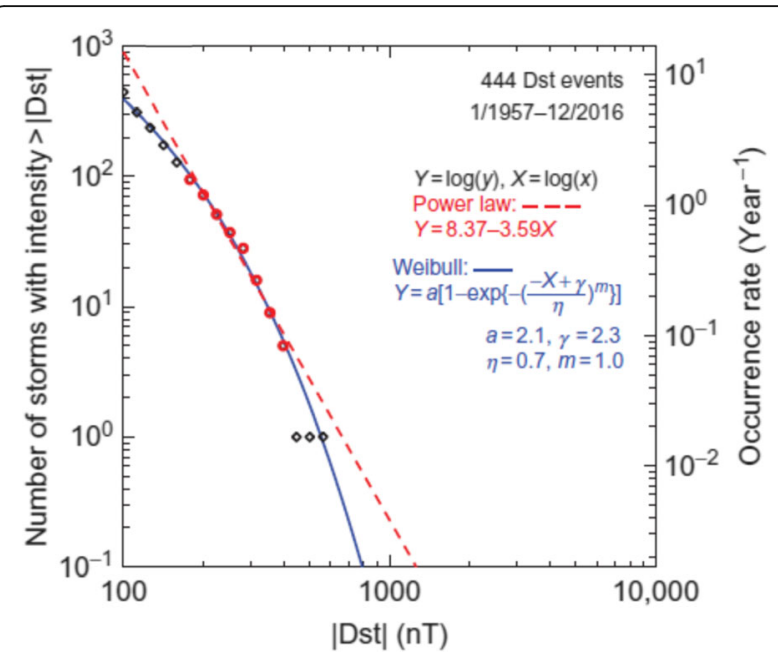

Fig. 8 Cumulative distribution of intense geomagnetic storms (Dst < $100 \mathrm{nT}$ ) and their yearly rates since 1957 (taken from Gopalswamy 2018)

events are sufficiently high in the period 1963-2015 and then extrapolated the distributions to the area of extreme magnetic storms where statistics are poor. They found that the most probable waiting times for extreme magnetic storms with Dst $\leq 500,-1000$, and $-1700 \mathrm{nT}$ are 24 years, 250 years, and 1500 years, respectively (with errors $10 \%, 40 \%$, and $100 \%$ ). If only the storms caused by magnetic clouds are considered, the waiting times reduce to 20,120 , and 500 years, respectively. A detailed review of the SEE results is given by Nandi et al. (2021).

\subsubsection{Highlights of contribution from young scientists to the SEE project}

As has been shown in the highlight of young scientists in VarSITI Newsletter, several active young scientists have contributed to the VarSITI/SEE project. Toriumi et al. (2014) studied solar flux emergence and formation of flare-productive active region on solar surface using both satellite observation and three-dimentional simulation. Jiang et al. $(2014,2015)$ studied effects on sunspot group tilt angles on large-scale magnetic field on the solar surface, and relation of the solar surface field evolution to the weak solar cycle 24. Pal et al. $(2017,2018)$ reported Sun-to-earth analysis of magnetic helicity of the 2013 March 17-18 interplanetary coronal mass ejection and the dependence of coronal mass ejection properties on their solar source active region characteristics and associated flare reconnection flux. Holappa et al. (2014a, b) showed a long-term relationship between solar wind structures and geomagnetic activities using new principal component analysis. For solar effect on the Earth's atmosphere, Maliniemi et al. $(2014,2016)$ reported spatial distribution of Northern Hemisphere winter temperatures during different phases of the solar 
cycle and the effect of geomagnetic activity on the Northern Annular Mode in the lower atmosphere.

\subsection{Project ISEST/MiniMax24: International Study of Earth- affecting Solar Transients}

The International Study for Earth-Affecting Solar Transients (ISEST) program started already within the framework of CAWSES II Task Group 3 ("Short-term Solar Variability and Geospace"). The summary of this activity is given by Gopalswamy et al. (2015a). The project continued during the VarSITI program, focused on the origin and propagation of solar transients, and their impact on the Earth.

Solar transients are short time-scale (from minutes to days) energetic and/or eruptive events occurring on the Sun that directly cause transient disturbances in the Earth's space environment and possibly impose adverse effects on advanced technological systems of human society.

Solar transient events can be divided in the following four categories: (1) solar flares, (2) coronal mass ejections (CMEs) including their interplanetary counterparts ICMEs, (3) solar energetic particle (SEP) events, and (4) stream interaction regions (SIRs) including corotating interaction regions (CIRs). These four types of Earth-affecting transient events differ in their physical origin or processes, observational appearances, and their geoeffectiveness.

The implementation of the ISEST project was centered around seven working groups, which are as follows:

(1) Data

(2) Theory

(3) Simulation

(4) Campaign study

(5) SEP

(6) Bs challenge

(7) MiniMax24 campaign.

This overview is a brief summary of the detailed description of the working group activities by Zhang et al. (2021).

\subsubsection{Data}

In the last decade, a large fleet of spacecraft provided continuous measurements of the Sun and the interplanetary space. Unprecedented multiple-angle observations were provided by the Solar Terrestrial Relations Observatory Ahead/Behind (STEREO A/B). Thanks to these observations, our knowledge on CME morphological and kinematics properties has improved significantly.

Several studies focused on Sun-to-Earth analysis of CMEs by linking the low coronal behaviour and properties of the eruption with its observed in situ signature (D'Huys et al. 2017; Temmer et al. 2017). A number of studies also compared magnetic flux rope properties, such as the magnetic flux, the chirality, and its helicity sign determined from post-eruptive arcades, flare ribbons, and coronal dimmings measured close to the Sun with magnetic cloud properties at $1 \mathrm{AU}$ (Qiu et al. 2007; Gopalswamy et al. 2017; Palmerio et al. 2017; James et al. 2017).

The weak solar cycle 24 was one of the main focuses of the VarSITI program. The properties of the transient events were extensively studied in the framework of ISEST/MiniMax. The overall rate of CMEs was found to have increased in solar cycle 24 relative to cycle 23 , although the rate of fast and wide CMEs decreased. Marked changes are observed in the number of intense (Dst $\leq 100 \mathrm{nT}$ ) geomagnetic storms (Gopalswamy et al., $2015 \mathrm{a}, \mathrm{b}, \mathrm{c})$ and high-energy ( $\geq 500 \mathrm{MeV}$ ) SEP events (Gopalswamy et al. 2014; Mewaldt et al. 2015). On the other hand, the number of halo CMEs in cycle 24 did not decrease significantly (Gopalswamy et al. 2015b). In fact, the number of halo CMEs as well as the total number of CMEs normalized to the sunspot number is larger in cycle 24 than in cycle 23.

\subsubsection{Theory}

Scolini et al. (2019) used proxies of magnetic flux estimates determined from post-flare arcades (Gopalswamy et al. 2017), flare ribbons (Kazachenko et al. 2017; Tschernitz et al. 2018), and coronal dimmings (Dissauer et al., 2018a, b) as initial input for the EUropean Heliospheric FORecasting Information Asset (EUHFORIA) model, to study the geoeffectiveness of the famous 2017 September events. Good agreement with the observed Dst profile was found for simulations using the optimized input and including CME-CME interactions.

Recently, there has been substantial development in the forward modelling of the magnetic structures using physics-based empirical models. The forward models typically assume a specific morphology of a magnetic structure, i.e., flux rope, and evolve it, assuming specific propagation and expansion (Wood et al. 2017). A step further is to include a specific flux rope magnetic field topology (e.g., Patsourakos et al. 2016; Isavnin 2016; Kay et al. 2017; Möstl et al. 2015).

\subsubsection{Simulation}

During the period of the VarSITI/ISEST, the main focus in the MHD space weather modeling was in the following areas: the background solar wind, CME initiation and propagation, interaction between CMEs and solar wind structures (CIR and HCS), and CME-CME interaction.

A detailed review of the recent progress in these areas is given in Zhang et al. (2021), and the main conclusions are as follows:

There has been a significant increase in the number of 3-D MHD codes that has been successfully used to simulate the Sun-to-Earth propagation of CMEs; this has been the case most notably in Europe with EUHFORIA, 
Japan, with SUSANOO and China with IN-TVD MHD. In addition, a number of existing MHD codes have been adapted to investigate the heliospheric propagation of CMEs, including LFM into LFM-Helio and MAS into MAS-Helio.

Heliospheric codes (starting typically at $0.1 \mathrm{AU}$ ) have been used with spheromak and/or flux rope CMEs, which bridges the gap between computationally intensive Sun-to-Earth simulations and heliospheric simulations with code models. These types of simulations may be used to investigate the magnetic field configuration inside CMEs as well as their arrival time, and are more physically consistent when investigating CME-CME interaction than simulations in which the CMEs do not have internal magnetic fields.

In parallel, there has been an effort to make the CME initialization quicker and easier to perform in coronal codes using out-of-equilibrium flux ropes. This paves the way for future real-time Sun-to-Earth simulations with magnetized CMEs initiated based on magnetograms, EUV images, and early coronagraphic images. It is well known that major changes in the CME properties, including its speed and orientation, may occur below $0.1 \mathrm{AU}$ where heliospheric models are initiated. At this time, it is however unclear whether simulations with magnetized CMEs initiated at $0.1 \mathrm{AU}$ using multi-viewpoints coronagraphic measurements will perform worse than simulations with magnetized CMEs initiated at the solar surface, in term of space weather forecasting capabilities. The number of Sun-to-Earth simulations of CMEs initiated at the solar surface with a realistic model is still relatively low, even though there has been effort in presenting the results near 1 AU of more complex initiation mechanisms.

There has been significant new physics included in the solar wind models, including more advanced thermodynamics treatment and the inclusion of Alfvén waves. There has not been significant work quantifying how these new additions affect the CME propagation and the resulting structure near $1 \mathrm{AU}$.

There has been progress towards coupling timedependent magnetic field models with coronal models and heliospheric models. Initiating CMEs by means of magnetofrictional or other self-consistent models based on solar observations or flux emergence may lead the way to a better physical understanding of CMEs and is also the only way space weather forecasting could provide information before the launch of a CME. Further improvements towards this coupling are expected in the next few years.

\subsubsection{Campaign study}

The task of ISEST Working Group 4 (campaign events) was to integrate theory, simulations, and observations for better understanding of the chain of activity from the Sun to the Earth for a few carefully selected events. One focus of WG 4 was on why forecasts fail and how we can improve our predictions. This included analyzing the complications in linking CMEs to ICMEs, usually observed only in situ at $1 \mathrm{AU}$.

After examination, WG 4 classified the studied events into three general categories (Webb and Nitta 2017) as follows:

1. "Textbook" cases in which the complete chain of well-observed events is relatively well understood from its solar source, through its heliospheric propagation, to its geo-effects. These cases involve forecasts that are successful in a general way.

2. Cases in which there were problems understanding the complete chain, but which we think we now understand it. Thus, something was missing in the chain of a well-observed event but, in retrospect after analysis, we now know why. These cases usually involve forecasts that failed because the events were not geoeffective or were underestimated.

3. Problem cases in which the chain is not complete, and we still do not understand why.

Fourteen campaign events were discussed and analyzed by WG 4 (Table 5-1 in Zhang et al. 2021). Figure 9 is an illustration of the first GLE event observed on September 10, 2017, on two planets: Earth and Mars. A detailed description of the event and the modeled geometry, kinematics, propagation, and interaction of the three CMEs launched around 2017-09-10 from their solar origin to their arrivals at Mars and Earth are given by Guo et al. (2018).

\subsubsection{SEP events}

3.2.5.1 SEP origin One of the more unusual solar phenomena is the long-duration gamma-ray flares (LDGR Fs). The prime characteristic of these events is delayed and prolonged $\gamma$-ray $(>100 \mathrm{MeV})$ emission after the impulsive phase. Recently, the Fermi Large Area Telescope (LAT) observed dozens of LDGRFs. Share et al. (2018) characterized and catalogued 30 solar eruptive events observed by Fermi/LAT from 2008 to 2016, referring to this emission as "late-phase gamma-ray emission" (LPGRE). In all the events studied, Share et al. (2018) found that the LPGRE is temporally and spectrally distinct from the impulsive phase emission and concluded that due to the broad range of the LPGRE characteristics it is unlikely that the mechanism of acceleration of particles by the CME-driven shock alone is able to account for the emission in all of the events under study.

3.2.5.2 SEP acceleration Some studies have provided new support for a significant contributory or dominant role for flare acceleration of high-energy protons in 


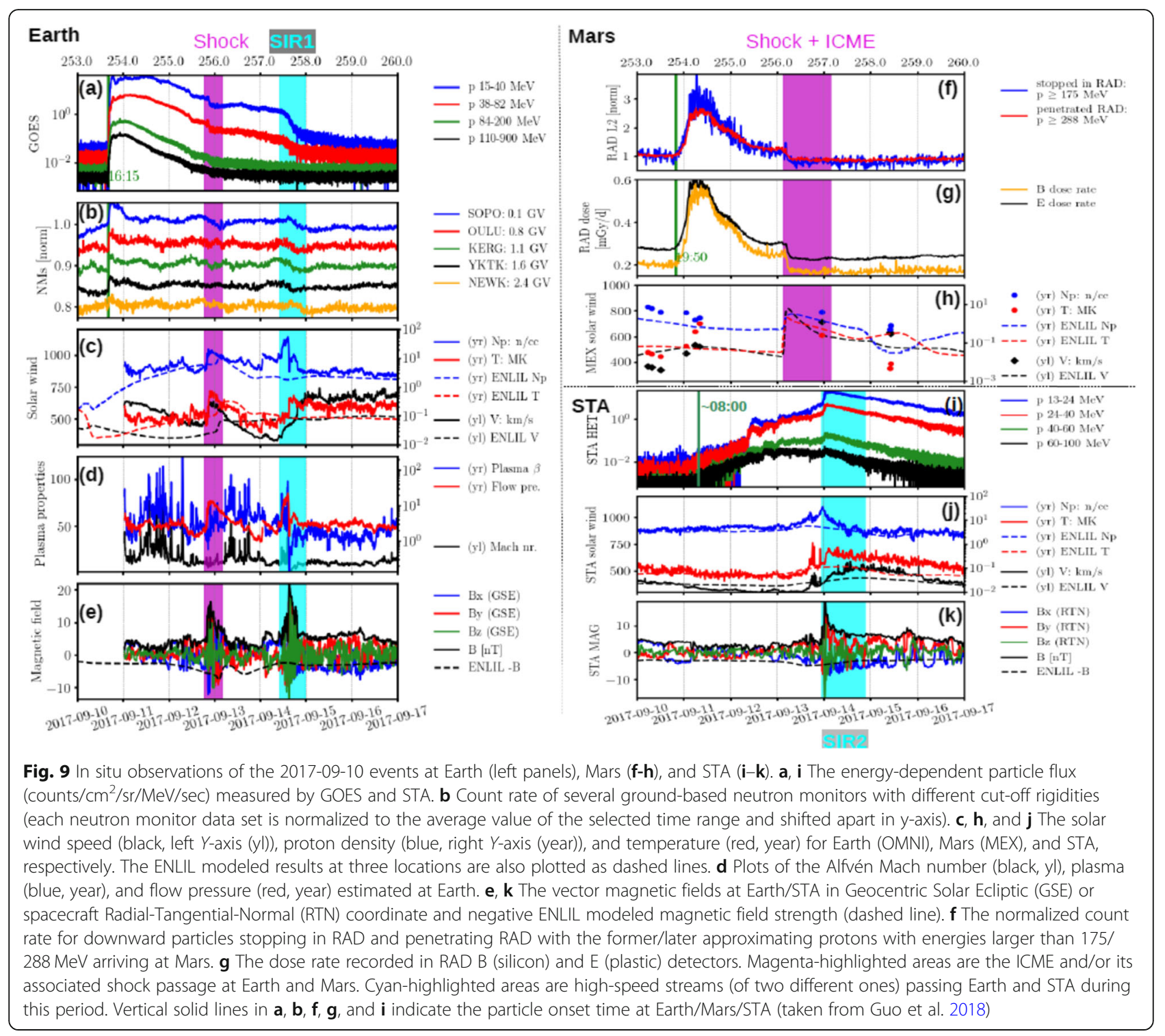

gradual SEP events, contrary to the generally accepted scenario favoring shock acceleration (e.g., Dierckxsens et al. 2015; Grechnev et al. 2015). Several other recent studies support the prevailing shock picture for gradual SEP events, such as the observation of a prompt SEP event at widespread locations in conjunction with the longitudinal propagation of a white-light shock (Lario et al. 2016), the SEP source temperatures (Reames 2015), and the hierarchical relationship between the fluence spectra of gradual SEP events and the kinematics of the CMEs.

3.2.5.3 SEP transport The unprecedented orbits of the two-spacecraft STEREO mission provided well-separated observations at $1 \mathrm{AU}$ and allowed to study the longitudinal distribution of SEPs and especially events with extraordinarily wide particle spreads in great detail. The STEREO mission has also enabled the identification and study of some extreme cases of widespread events with distributions up to $360^{\circ}$ around the Sun.

3.2.5.4 SEP compositional results Measurements of relative abundances of heavy elements and their isotopic and ionic charge state composition in SEP events have been used in a wide variety of ways to infer critical information about the origins of the seed populations and the physical conditions under which these populations are produced. These seed particles are accelerated by CME shocks or in solar jets and indicate the conditions of their transport through the solar corona, the interplanetary medium, and out into the heliosphere (e.g., see Reames 2015; Desai and Giacalone 2016).

3.2.5.5 Progress in SEP theory and modeling Valuable insight on particle acceleration at coronal shock waves 
has been recently obtained by studying the evolution of CME and shocks in the corona, as well as their interaction with underlying magnetic fields and coronal plasma, both through data-driven or analytical modelling, as well as MHD simulations and combinations of different approaches. New information has been gathered about the relevant parameters for efficient shock acceleration (such as the Mach number, compression ratios, and geometry of shock waves), the primary acceleration regions along the shock, the role of coronal magnetic field configuration, and how these factors are related to the particle spectra observed in space.

The effect of large-scale streamer-like magnetic configuration on particle acceleration at coronal shocks has been investigated by considering a CME-driven shock propagating through a streamer-like magnetic field (Kong et al. 2017) or from its flank (Kong et al. 2019), i.e., when the streamer is rotated with respect to the CME propagation direction. By numerically solving the Parker transport equation with both parallel and perpendicular diffusion in such configuration, Kong et al. (2019) found that the primary sources for particle acceleration are located at different regions and vary significantly as the shock propagates and expands, depending on the particle energy and time.

The well-separated SEP observations with the STER EO mission have also lent themselves to study the transport of SEPs in more detail. The comparison of multispacecraft observations with results of $2 \mathrm{D}$ or $3 \mathrm{D}$ models solving the focused transport equation allowed to study not only transport along the mean magnetic field but also perpendicular to it. It was found that the role of efficient transport perpendicular to the mean magnetic field can eventually be much stronger than expected (e.g., Dresing et al. 2012) and might play an important role, among extended injection and acceleration regions, in the longitudinal spreading of SEPs (e.g., Dröge et al. 2014), but also in creating asymmetries in their longitudinal distribution at $1 \mathrm{AU}$ (He and Wan 2015).

An important step taken in SEP transport modelling is the inclusion of a realistic solar wind background. Wijsen et al. (2019) used the data-driven EUHFORIA (Pomoell and Poedts 2018) to generate a background solar wind for their SEP transport code. This allows, on the one hand, the study of the effect of solar wind streams on the SEP propagation and also on adiabatic energy changes. On the other hand, case studies with a realistic background field will be possible accounting for the effects of transient structures leading to non-Parker field configurations.

\subsubsection{Stream Interaction Regions/Co-rotating Interaction Regions (SIRs/CIRs)}

The evolution of long-lived coronal holes, closely related to SIRs/CIRs, can be studied in detail using multiple views on the Sun from combined STEREO and Earth imagery. It was found that coronal holes undergo evolutionary patterns revealing a growing and declining phase where area increases and decreases again over several solar rotations (Heinemann et al. 2018, 2019). The coronal hole area is found to be well related to the solar wind speed measured in-situ at $1 \mathrm{AU}$ (e.g., Vršnak et al. 2007; Rotter et al. 2012). With this well-known areaspeed relation, empirical forecasting tools for the "pure" background solar wind on the basis of coronal hole area measurements are performed on a regular basis (Vršnak et al. 2007; Rotter et al. 2012). By understanding the photospheric and coronal evolutionary characteristics of coronal holes, one can aim to gain a better understanding and in turn improve the forecast of CIRs (Heinemann et al. 2018). The forecasts are found to be most successful for periods of low solar activity, as during increased solar activity transient events, such as CMEs, strongly disturb the rather stable solar wind outflow for several days (Temmer et al. 2017). As the high-speed solar wind streams emanate from coronal holes which are low dynamic structures, CIRs can be forecast with long lead times. Based on that, a variety of persistence models were developed. Under the assumption of persistence, in situ measurements of the solar wind plasma flow from L1 and varying STEREO vantage point provide a forecast for Earth position with lead times of up to 27 days (depending on the exact STEREO spacecraft position). Implementing the actual changes of coronal hole areas (from EUV data) into such simple forecasting tools can improve the forecast quality (Temmer et al. 2018). Lead times with about 4.5 days could be achieved when using data from an instrument permanently located at the Lagrangian point L5 $\left(60^{\circ}\right.$ behind Earth; ESA preparation for the future L5 mission "Lagrange").

Forecasting solar wind structures in interplanetary space serves also as important information for analytical CME propagation models and space weather models. Therefore, under the Space Situational Awareness Program of the European Space Agency, forecasting services using empirical, and numerical models for the solar wind are available (see http://swe.ssa.esa.int). As the forecasting/nowcasting quality is still not sufficient for producing reliable space weather alerts, we need to better understand and closely monitor SIRs/ CIRs. Main aims for the near future are to verify and evaluate background solar wind models, and with that improve the input for CME propagation models, to predict periodic and recurrent geomagnetic effects from CIRs more accurately. In general, single events are easier to forecast compared to multiple events covering CME-CME interactions or interactions of CMEs with CIRs. By better understanding the physics behind the coronal hole evolution, we may improve their forecasting capability. With that we will also 
gain more insight in the ejection and acceleration processes that define high-speed streams. For this we can exploit data from the NASA mission Parker Solar Probe (PSP) measuring the near-Sun space and with that regions where the solar wind actually gets accelerated.

Though harder to evaluate and forecast, interaction events between SIR/CIR and CMEs are of special interest. Interaction events can lead to significant increase in geomagnetic effects when compared to individual events of similar strength (e.g., He et al. 2018).

In a recent paper by Jian et al. (2019), physical properties of a large sample of slow-to-fast SIRs were investigated using STEREO-A and -B data. They identified 518 pristine SIRs, of which more than $50 \%$ are associated with crossings of the heliospheric current sheet (HCS) and are of slow speeds but higher densities, and of increased dynamic and total pressure compared to those without HCS. In that respect, HCS-related SIRs can be classified as more effective in terms of space weather.

The detection and extraction of reliable coronal hole areas from operational solar observations is extremely important, not only for solar wind forecasting using the area-speed relation, but also for investigating the magnetic open flux on the Sun. At present, most extraction methods focus on EUV observation taken by SDO/AIA, SOHO/EIT, GOES/SUVI, and/or STEREO/EUVI. A multi-wavelength approach was developed by Garton et al. (2018) in the form of the multi-thermal emission recognition algorithm CHIMERA. Recently, with the dawn of machine learning, new methods, utilizing the increased computational performance have also emerged to provide an additional tool to identify and extract coronal holes (e.g., Illarionov and Tlatov 2018).

Using various techniques, several coronal hole datasets were gathered (especially for coronal hole areas) that are freely available. Automatically created SPOCA boundaries of coronal holes are available via the Heliophysics Events Knowledgebase (HEK: https://www.lmsal.com/ hek/index.html), and the automated coronal hole detection and extraction using three SDO/AIA wavelengths (171, 193, $211 \AA$ ) CHIMERA is available via SolarMonitor (https://www.solarmonitor.org/) and an extensive, manually checked, coronal hole catalogue covering the SDO-era (2010-2019) created using CATCH is available via the VizieR catalog service (http://cdsarc.u-strasbg.fr/ viz-bin/cat/J/other/SoPh/294.144). VizieR, the CDS catalog service, provides the most complete library of published astronomical catalogs (currently, 20391)-tables and associated data-with verified and enriched data (DOI: $10.26093 / \mathrm{cds} /$ vizier).

To improve solar wind models and to ensure accurate space weather forecasting, the solar wind models have to be tested and validated. The validation of solar wind models is done by comparing the simulation results with in situ measurements.

The performance assessment of the EUHFORIA solarwind model was analyzed by Hinterreiter et al. (2019). The solar wind was modeled rather well for times of solar minimum but not during increased solar activity. In a study by Lee et al. (2009), the heliospheric models ENLIL/MAS and ENLIL/WSA were compared with in situ measurements from ACE and Wind (time range: 2003-2006). They found that the model results give lower densities for faster solar wind fully agreeing with the solar wind momentum flux constancy.

\subsubsection{Forecasting CMEs}

The lack of critical observations (e.g., no routine observations of the magnetic field in the corona) and limitations in theory and models (e.g., idealized initial and boundary conditions) is currently not allowed to predict when a CME would occur. However, thanks to advances in our observational knowledge (e.g., new observations from STEREO, Hinode, SDO, IRIS), and in modeling (e.g., increase of realism in models, data-constrained and data-driven models) and in analysis and forecasting techniques (e.g., use of advanced statistical tools and machine learning methods) significant progress in our understanding and eventual prediction of CMEs has been achieved over the last decade.

Tziotziou et al. (2012) found that helicity and magnetic free energy thresholds of $\sim 2 \times 10^{42} \mathrm{Mx}^{2}$ and $\sim 4 \times 10^{31}$ erg separate eruptive with non-eruptive ARs. Magnetic twist (Tw) (i.e., number of turns of field lines around a magnetic axis) of magnetic field lines is another parameter that is extensively used in CME onset studies. Magnetic twist is an integral part of magnetic helicity discussed above, and comparison of its properties/distribution in the pre-eruptive/eruptive configurations in the solar atmosphere and at $1 \mathrm{AU}$ supplies important physical clues about CMEs (Wang et al. 2016).

The problem of predicting major CMEs could be mitigated to predicting major flares. Recent reviews on flare forecasting, including machine-learning schemes, can be found in Leka et al. (2019) and Park et al. (2020). Major conclusions from their extensive benchmarking of a large number of methods currently used in flare forecasting are that numerous such methods do better than climatology, no method clearly outperforms the others, and consideration of prior flare history improves the corresponding skill scores.

Machine learning has been used directly in CME predictions. Bobra and Ilonidis (2016) applied a Support Vector Machine classification scheme to 18 parameters derived from HMI vector magnetograms for more than 3000 ARs and found that only 6 amongst these parameters are sufficient to separate erupting and non-erupting 
ARs within $24 \mathrm{~h}$ from the corresponding measurements. These parameters (e.g., mean gradient of the horizontal magnetic field, mean current helicity, mean twist parameter, etc) are intensive (i.e., do not depend on the AR size but are spatial averages) and not extensive (i.e., dependent on the AR size and corresponding to spatial sums). Guennou et al. (2017) by means of MHD analyzed a set of eruptive and non-eruptive MHD simulations and found, in agreement with Bobra and Ilonidis (2016), that intensive parameters are more relevant to eruptivity.

The availability of multi-viewpoint STEREO imaging observations allowed to monitor a number of modulations that CMEs experience in the corona and in the inner heliosphere in terms of deflections and rotations. CME rotations as well as deflections in the corona are simultaneously addressed by the ForeCAT model of Kay et al. (2015). The model has been applied to several CMEs, and it was able to reproduce the deflections and rotations that the CMEs undergone as derived from the analysis of the corresponding STEREO observations. The predicted deflections and rotations exhibit significant sensitivity on the input parameters and the employed background models.

Predicting the magnetic field distribution of CMEs/ ICMEs is of highest importance in heliophysics, as extended intervals of intense southward magnetic fields are a necessary condition for inducing geomagnetic storms. A thorough account of the state-of-the art in this important problem was recently given in Vourlidas et al. (2019).

\subsubsection{Minimax24 non-flare target}

The aim of the ISEST/MiniMax24 non-flare target service is to monitor potentially geoeffective phenomena which are not related to solar flares and to email alerts. This service, provided daily by the observer on duty, was first established in the scope of the SCOSTEP/CAWSES II "MiniMax24 Campaign" in 2013, which was declared as the year of "MiniMax24" to note that, even though the Sun is going through activity maximum conditions, the activity is rather low. The goal of the action was to understand and explain the current behavior of the Sun and its potential impact on human society and Earth's space environment through year-long scientific and outreach activities. The campaign team counted 37 institutions from 17 countries focused on the solar-terrestrial observations of solar eruptive events through the MaxMillenium program of solar flare research (http://solar. physics.montana.edu/max_millennium/) as well as coronal holes, filaments, and CIRs (i.e., non-flare related phenomena) through the newly established email alert service. By the end of the year of "MiniMax24," MiniMax24 email list reached more than 140 participants from more than 30 countries. After the end of CAWSES II program, the action transcended from its original 1year-campaign scheme and was included in the new SCOSTEP program VarSITI as one of the working groups of the ISEST project.

\subsubsection{Highlights of contribution from young scientists to the ISEST/Minimax24 project}

Many young scientists have been glowing to contribute to the ISEST/Minimax24 project. Thalmann et al. (2016) reported plasma and magnetic environment of a particular flare signature and coronal magnetic field based on combined SDO, RHESSI, and STEREO data. Cheng et al. (2014) made a tracking of magnetic flux rope from inner to outer corona. Sindhuja and Gopalswamy (2020) investigated properties of flux ropes in CME near the Sun. Shen et al. (2014) also investigate evolution of 12 July 2012 CME from Sun to Earth. Kay et al. (2015, 2016, 2017) studied global trends of CME deflections, evolution of CME, and predictability of the magnetic field of earth-impacting CMEs, respectively. Shen et al. $(2017,2018)$ investigated geoeffectiveness of interplanetary coronal mass ejection (ICME) statistically from 1995 to 2014 and for a particular ICME event on September 8, 2017. Dumbović et al. (2018) developed an analytical model of Forbush cosmic-ray decreases caused by flux ropes in the solar wind associated with interplanetary coronal mass ejection (ICME). Dissauer et al. (2018a, b, 2019) extensively investigated coronal dimmings associated with flares and CMEs.

\subsection{Project SPeCIMEN: Specification and Prediction of the Coupled Inner-Magnetospheric Environment}

The coupled inner-magnetospheric environment has been focused by the project "Specification and Prediction of the Coupled Inner-Magnetospheric Environment" (SPeCIMEN). The goal and objectives of this project were the quantitative prediction and specification of the Earth's inner magnetospheric environment based on Sun/solar wind driving inputs. Comprehensive review on the achievements of this project is provided by Kanekal and Miyoshi (2021). Here, we briefly review the highlights of the scientific results obtained on this topic.

Figure 10a shows basic configuration of energetic electrons and ions and the waves that interact with these particles in the inner magnetosphere around the earth. The energetic electrons and ions rotate around the Earth due to curvature and gradient of ambient magnetic field with a time scale of minutes to hours and interact with extremely low frequency (ELF) and very low frequency (VLF) waves (electron cyclotron waves) at frequencies of $\sim \mathrm{kHz}$, ultra-low frequency (ULF) (Pc1) waves (ion cyclotron waves) at frequencies of $\sim \mathrm{Hz}$, and ULF (Pc4-5) waves at frequencies of $\sim \mathrm{mHz}$. These energetic particles 


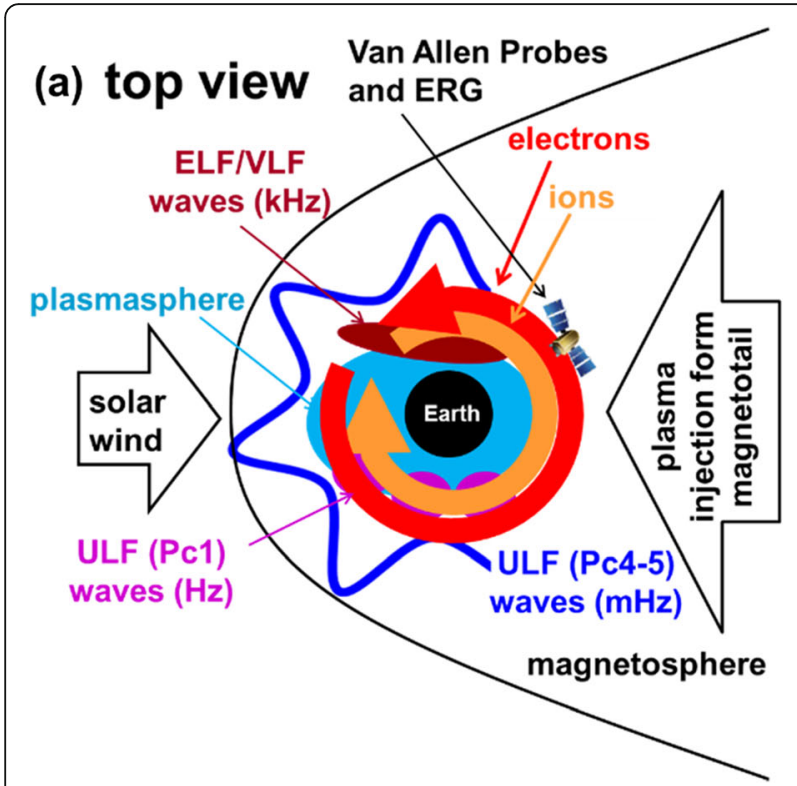

(b) side view

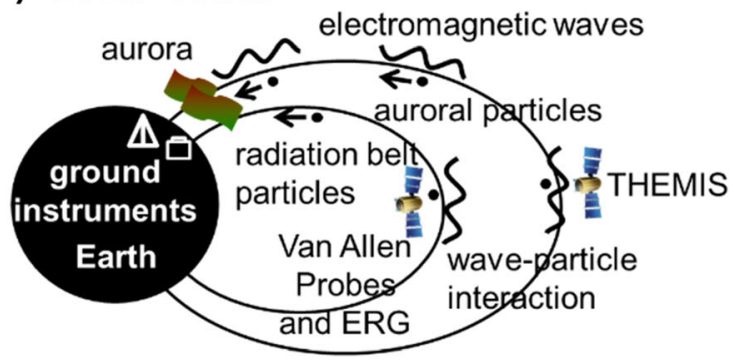

Fig. 10 Schematic picture of the energetic electron and ions and waves that interact with these particles in the inner magnetosphere around the earth. a Top view from above the north pole, and $\mathbf{b}$ side view from dusk to dawn

and waves propagate along the geomagnetic field line and cause aurora and ionization of the atmosphere, as shown in Fig. 10b.

During the VarSITI program, two major satellite projects had been in actively operated to investigate the inner magnetosphere, i.e., Van Allen Probes (also called as Radiation Belt Storm Probes) (2012-2019, Kirby et al. 2013) and Energization and Radiation in Geospace (ERG, also called as Arase) (2016-, Miyoshi et al. 2018). The Time History of Events and Macroscale Interactions during Substorms (THEMIS) satellites (2007-, Angelopoulos 2008) have also been in operation throughout the VarSITI Program, and Magnetospheric Multiscale (MMS) satellites (2015-, Burch et al. 2016) was newly launched. The THEM IS and MMS can provide information of the outer magnetosphere, which is the boundary condition of the energization of plasma in the inner magnetosphere. Recently, Cubesat measurements also contribute to the understanding of radiation belt precipitation at low-Earth orbit (e.g., Li et al. 2015; Kanekal et al. 2019).

Ground network instruments have been deployed extensively at subauroral latitudes by the PWING project since 2016 (Shiokawa et al. 2017). PWING stands for study of dynamical variation of Particles and Waves in the INner magnetosphere using Ground-based network observations. Modeling efforts to cover the inner magnetosphere has also been made, such as Block-AdaptiveTree-Solar-wind-Roe-Upwind-Scheme with Comprehensive Ring Current Model (BATSRUS/CRCM, Glocer et al. 2013) and Ring current-Atmosphere interaction Model (RAM, Jordanova et al. 2010). These extensive observation networks and advanced modeling efforts make a golden era of research for the inner magnetosphere during the VarSITI program.

Figure 11 shows an example of 1-year electron flux variation in 2013 at energies from $46 \mathrm{keV}$ to $1.553 \mathrm{MeV}$ in the inner magnetosphere observed by the Van Allen Probes (Reeves et al. 2016). The vertical axis is the $L$ value, which is the radial distance from the Earth with a unit of Earth's radius. We can see dynamic variation of electron fluxes in the inner magnetosphere. The amplitude of the variation reaches a few orders of magnitudes. The enhancements of electron fluxes clearly correlated with solar wind speed enhancements and decreases of Dst index (geomagnetic storms). The high-flux regions are separated into two regions around $L \sim 4-6$ and $L<$ 2 , forming outer and inner radiation belts, respectively. Clear differences can be also seen in the electron behavior at different energies and from event to event. Basically, no significant electron fluxes are seen at energies above $1 \mathrm{MeV}$ in the inner belt at $L$ value less than 3 , as newly found by Fennel et al. (2015), while the inner belt clearly appears at energies below $459 \mathrm{keV}$. At further high energies, Van Allen Probes also discovered sharp inner boundary for the ultrarelativistic (energies higher than $5 \mathrm{MeV}$ ) electrons in the Earth's radiation belts (Baker et al. 2014). A comprehensive review of the results obtained by the Van Allen Probes mission has been provided by Baker et al. (2018).

The ERG satellite was launched in December 2016 and has provided several interesting observations particularly related to the wave-particle interactions in the 


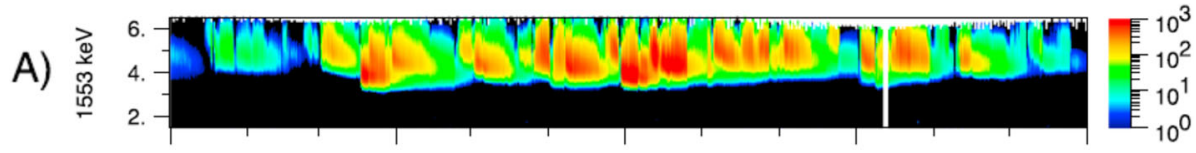
B) 弯

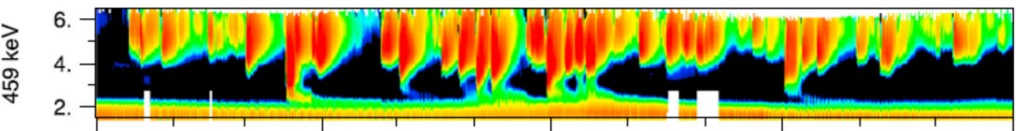
$=10^{3}$

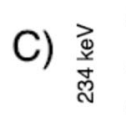

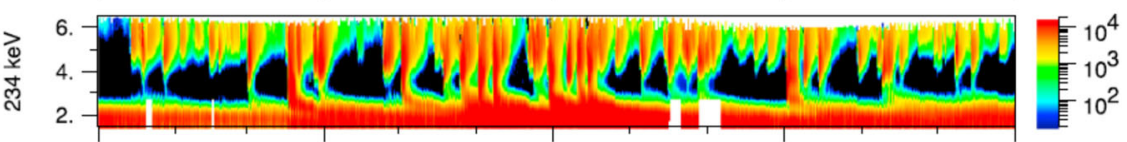

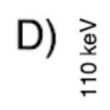

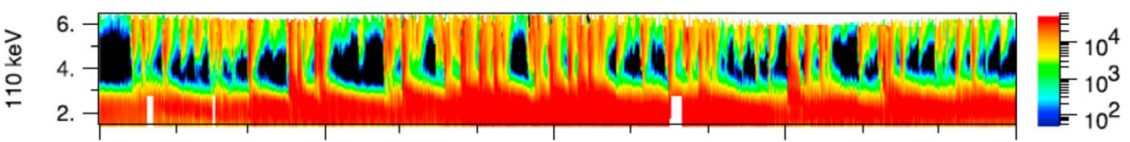

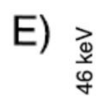

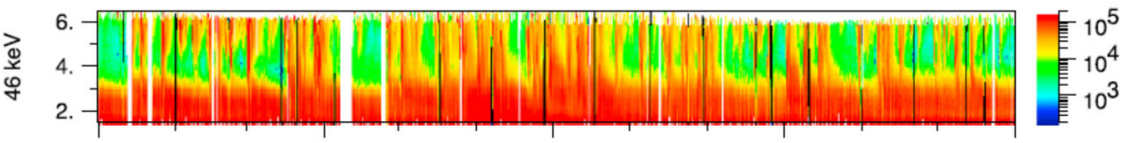

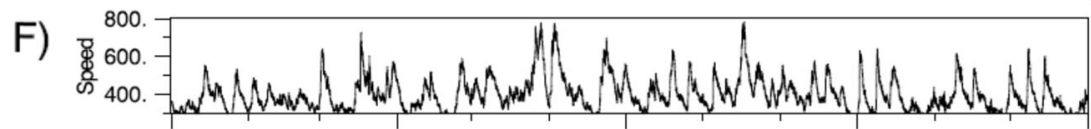

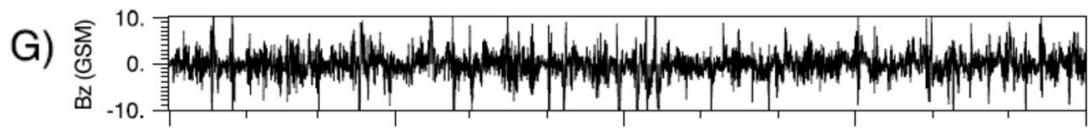

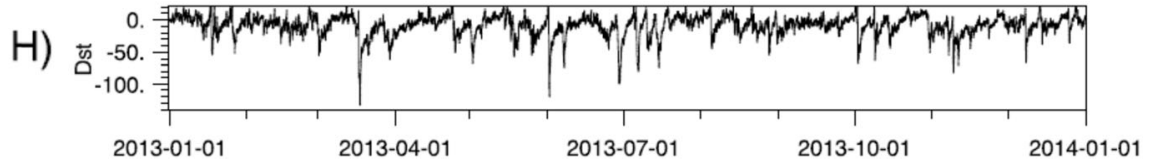

Fig. 11 A multi-energy view of flux as a function of $L$ shell (distance from the Earth in unit of Earth radius) and time from the Van Allen Probes mission for 2013. a-d Background-corrected electron fluxes measured by MagEIS, e electron fluxes measured by HOPE, f solar wind speed, $\mathbf{g}$ IMF $\mathrm{Bz}$, and $\mathbf{g}$ Dst index. Clear differences can be seen in radiation belt electron behavior at different energies and from event to event (taken from Reeves et al. 2016)

inner magnetosphere. Figure 12 shows one-to-one correspondence between ELF/VLF chorus wave elements (panel c) that have a time scale of less than $1 \mathrm{~s}$ observed by ERG with electrons at energies of kilo-electronvolts that causes visible flush aurora observed by ground an all-sky camera (panels b and f) (Ozaki et al. 2019). ERG and the ground all-sky camera were nearly on the same geomagnetic field line. Clear one-to-one correspondence can be seen at four ELF/VLF chorus wave elements in panel (c) with the four auroral flashes in panel (f) at 13:01:28 UT and $\sim$ 13:01:32 UT. This correspondence indicates that the observed ELF/VLF chorus waves scatter electrons along the magnetic field line to cause precipitation of the electrons and the flash aurora. Kasahara et al. (2018) did show one-to-one correspondence between ELF/VLF chorus waves and electron fluxes in the loss cone, which is the direct evidence of pitch-angle scattering of keV-energy electrons by ELF/VLF chorus waves. On the other hand, Teramoto et al. (2019) provided evidence of wave-particle interaction between ULF (Pc4-5) waves at frequencies of $\mathrm{mHz}$ with energetic electrons through drift resonance based on multisatellite coordinated observation by the Van Allen Probes and ERG satellites. More comprehensive results obtained from the ERG mission have been provided by two special issues in Earth Planets and Space in 2017 and in Geophysical Research Letters in 2018.

In the objectives of SPeCIMEN (specification and prediction), the modeling takes the part of quantitative prediction of the Earth's inner magnetospheric environment. BATSRUS/CRCM model (Glocer et al. 2013) provides global response of the outer and inner magnetosphere to the solar wind. RAM simulation (Jordanova et al. 2010, 2012) provides distribution of whistler-mode chorus waves that contribute acceleration and loss of the radiation belt electrons. Geomagnetic Environment Modeling System for Integrated Studies (GEMSIS)-Ring Current and Radiation 

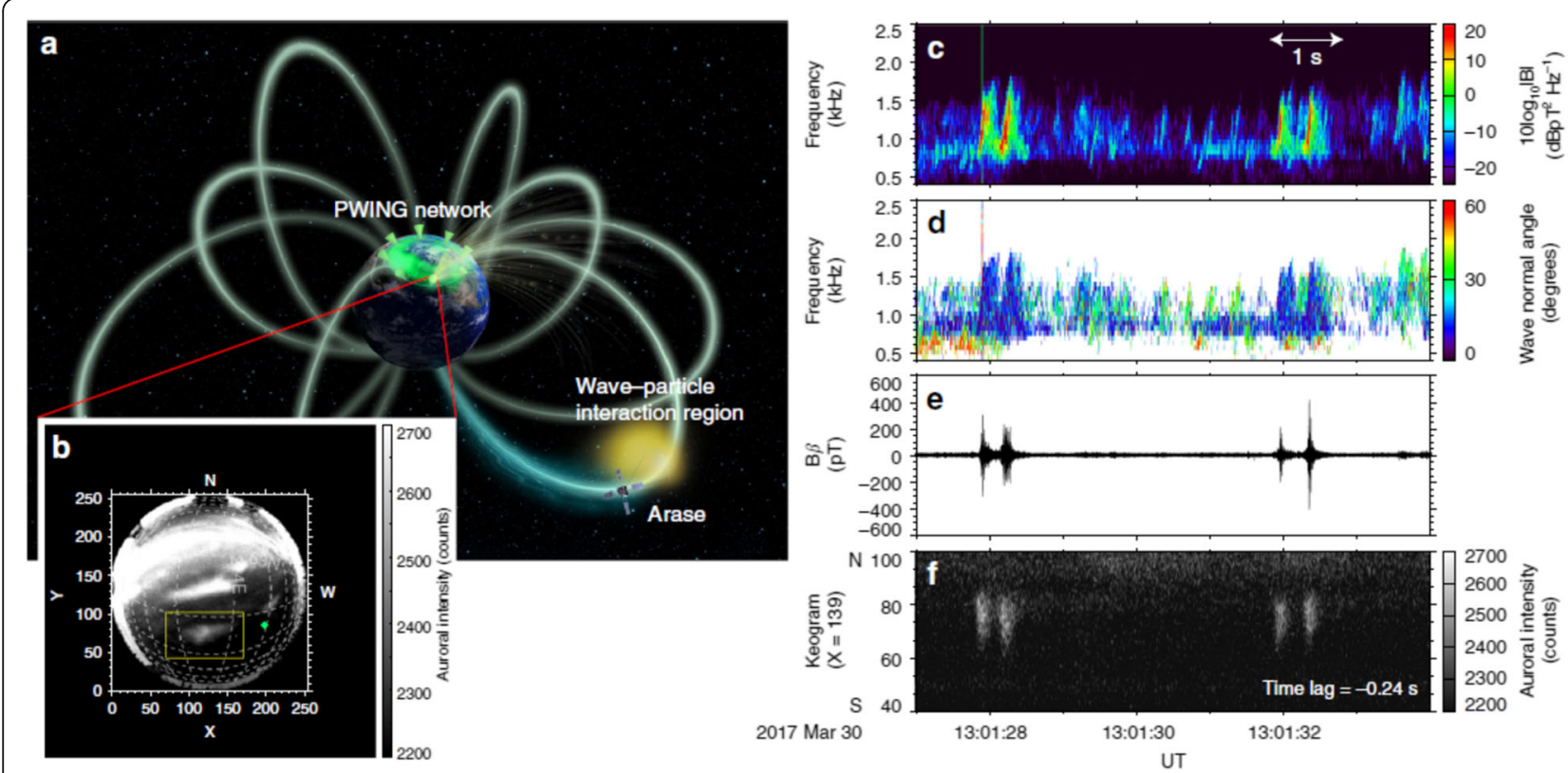

Fig. 12 Coordinated ground and ERG (Arase) observations. a Illustration of conjugate observations from the ground network of the PWING project and the ERG satellite. Earth in panel $\mathbf{a}$ is mapped using NASA image. All rights reserved. $\mathbf{b}$ All-sky EMCCD snapshot observed at Gakona in Alaska at 13:01:28 UT, 30 March 2017. Dotted lines indicate the spacing of geographical latitudes and longitudes at $1^{\circ}$ and $2^{\circ}$ intervals. The yellow frame indicates the auroral region that is focused on in this study. The green diamond symbol indicates ERG's footprint at the time of observation. c, e The dynamic spectrum, wave-normal angle with respect to the geomagnetic field line, and the waveform of large-amplitude chorus elements observed by ERG near the magnetic equator. $\mathbf{f}$ North to South cross-section (keogram) of auroral emissions with a time shift of -0.24 s (taken from Ozaki et al. 2019)

Belt models reproduce interaction of Pc5 magnetic pulsations with relativistic electrons (Kamiya et al. 2018). Not only by these physical models, artificial intelligence has been introduced for reconstruction of the inner magnetosphere dynamics. Figure 13 shows neural network reconstruction of the global plasma density as a function of L and MLT by Bortnik et al. (2016), using measurements by three THEMIS satellites between 2008 and 2014.

\subsubsection{Highlights of contribution from young scientists to the SPeCIMEN project}

More than ten active young scientists contributed to the researches of the SPeCIMEN project and wrote articles for highlight of young scientists in the VarSITI newsletter. For studies of whistler mode waves which possibly accelerate relativistic electrons, Li et al. (2014) have shown acceleration of radiation belt electrons by chorus waves during the March 17, 2013, storm based on observations by the Van Allen Probes satellites. Nishimura et al. (2015) reported chorus intensity modulation driven by time-varying field-aligned low-energy plasma observed by the Time History of Events and Macroscale Interactions during Substorms (THEMIS) satellites. Gabrielse et al. (2014) reported statistical characteristics of particle injections, which can be a source of the waves, in the equatorial plane of the magnetotail using THEM IS satellites. Martinez-Calderon et al. (2015a, b, 2016, 2019) reported ground and conjugate satellite observations of VLF chorus waves to find their propagation characteristics from the inner magnetosphere to the ground. Douma et al. (2018) showed comparison of relativistic electron microburst activity seen by SAMPEX with ground-based wave measurements at Halley, Antarctica, and concluded that whistler mode chorus waves are, most likely, the primary drivers of relativistic electron microbursts. Jones et al. (2017) and Greeley et al. (2019) reported secular drift of South Atlantic anomaly during solar cycle 22-24 and quantify the contribution of relativistic electron microbursts to the global electron loss in the radiation belts, based on long-term data from the SAMPEX satellite. Shirokov et al. (2017) and Shirokov (2018) investigated receiving antenna characteristics to measure quasi-static whistler-mode waves including chorus emissions. An et al. (2019) investigated three seemingly different nonlinear wave structures originated from the same nonlinear electron trapping process by whistler-mode chorus waves and pointed out that the ratio of the Landau resonant velocity to the electron thermal velocity controls the 


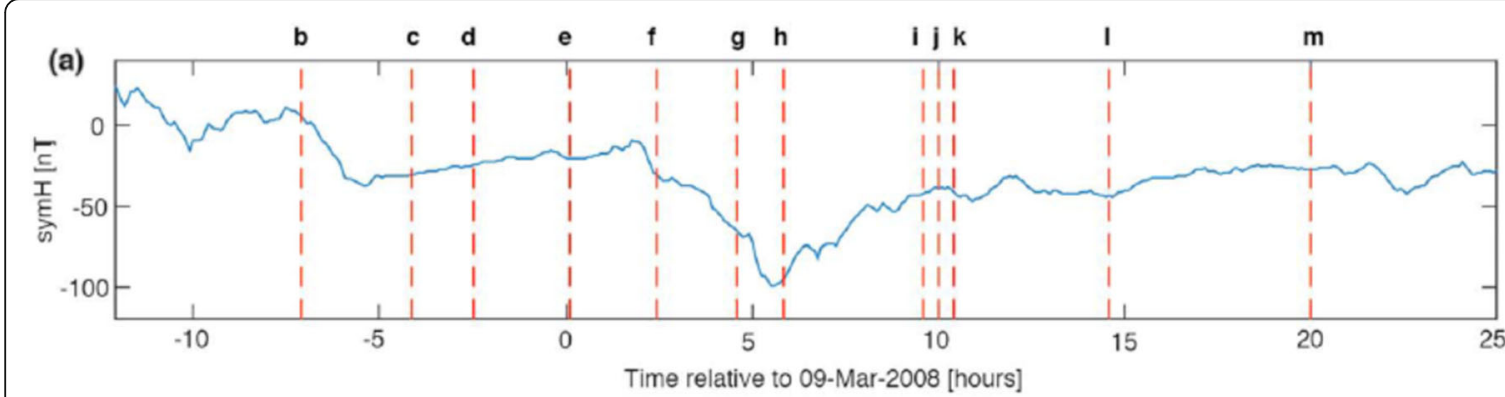

(b) 08-Mar-2008 16:55:00

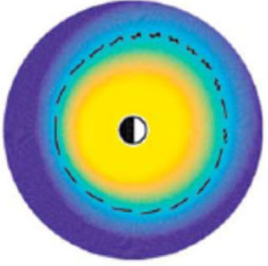

(f) 09-Mar-2008 02:25:00

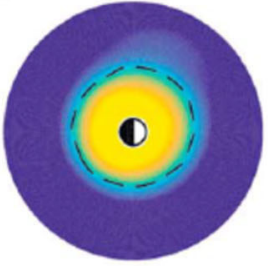

(j) 09-Mar-2008 10:00:00

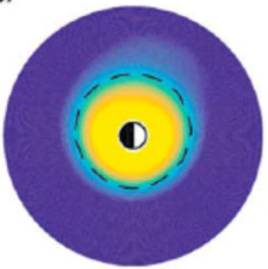

(c) 08-Mar-2008 19:50:00

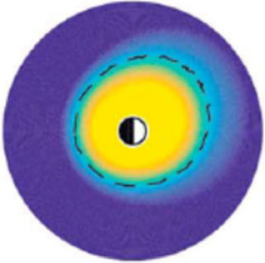

(g)

g) 09-Mar-2008 04:35:00

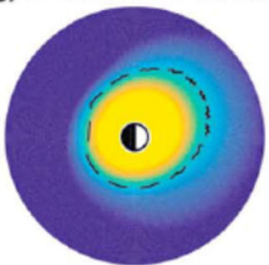

(k) 09-Mar-2008 10:25:00

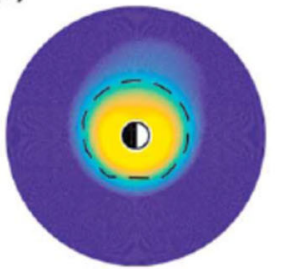

(d)

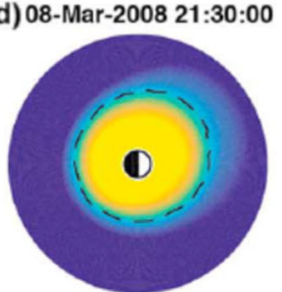

(h)

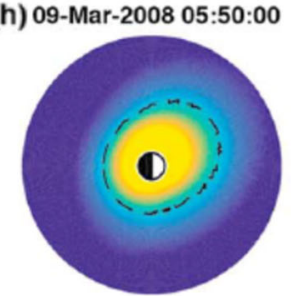

(I) 09-Mar-2008 14:35:00

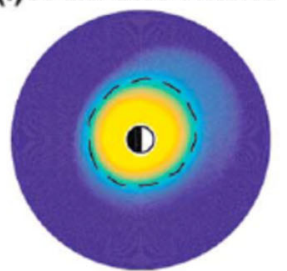

(e) 09-Mar-2008 00:05:00

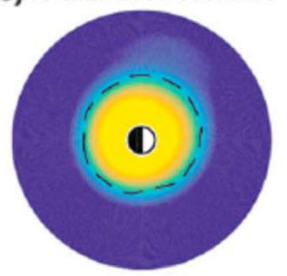

(i) 09-Mar-2008 09:35:00

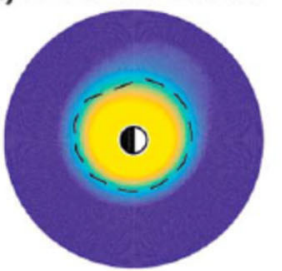

(m) 09-Mar-2008 20:00:00

10

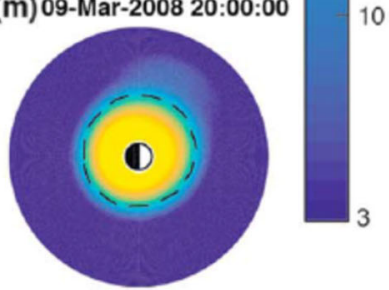

Fig. 13 Neural network reconstruction of the global plasma density as a function of $L$ and MLT. a The SYM-H index relative to 9 March 2008 00:00 UT. The red vertical dashed lines correspond to the times of the snapshots shown in the 12 panels beneath. The common color scale indicating electron density in electrons per cubic centimeter is shown on the right, and the dashed line in $\mathbf{b}-\mathbf{m}$ represents the $50 \mathrm{el} / \mathrm{cm}^{3}$ contour. The entire simulation period is outside the training interval (i.e., out of sample) (taken from Bortnik et al. 2016)

generated type of nonlinear wave structures. Píša et al. $(2015,2016)$ investigated Langmuir waves observed upstream of Saturn's foreshock and bow shock observed by Cassini, which also has some implications on highenergy plasma acceleration in the inner magnetosphere.

For the magnetosphere-ionosphere coupling in the inner magnetosphere and ionospheric processes, Thomas et al. $(2015,2016,2019)$ investigated magnetic field variations associated with $\mathrm{Pi}^{2}$ and ionospheric current observed by the CHAMP and Swarm satellites just above the ionosphere and on the ground to show their characteristic in and near the ionosphere.
McGranaghan et al. (2015a, b, 2016a, b) extensively investigated high-latitude ionospheric conductivities based on satellite observations and developed a model of the high-latitude ionosphere to reconstruct its electrodynamic variations. Gokani et al. (2015) reported lightning-associated whistlers at very low latitudes $(L=$ $1.08)$, suggesting ducted mode of propagation of these waves near the equator. McCormick et al. (2018) proposed spatial and temporal monitoring of the D-region ionosphere using lightning-induced broadband sferic measurements. These ionospheric topics also have strong relation with the ROSMIC project. 


\subsection{Project ROSMIC: Role Of the Sun and the Middle atmosphere/thermosphere/ionosphere In Climate}

The goals and objectives of the Project "Role of the Sun and the middle atmosphere/thermosphere/ionosphere in Climate (ROSMIC)" was to understand the impact of the Sun on the terrestrial middle atmosphere, lower thermosphere, and ionosphere and Earth's climate and its importance relative to anthropogenic forcing over various time scales from minutes to centuries. A comprehensive review on the achievements of this project is provided by Ward et al. (2021). Here, we briefly review the highlights of the scientific results obtained on this topic during the VarSITI program.

The topic of ROSMIC can be divided to (1) coupling from above, (2) coupling from below, and (3) observation of long-term trends. The coupling from above comes from (1a) solar radiation in various wavelengths from X-ray, ultraviolet, and visible wavelengths, (1b) solar energetic particles (SEP) or solar proton events (SPE) and (1c) magnetospheric energetic particles (MEP). The effects of (1a) are often divided into total solar irradiance (TSI) and spectral solar irradiance (SSI). SEP and MEP are called as energetic particle precipitation (EPP).

\subsubsection{Coupling from above}

Figure 14 shows an example of the EPP effect on the middle atmosphere observed by the three different satellites for three different magnetic storms and in superposed epoch analysis based on satellite-based measurements by GOMOS, SABER, and MLS (Andersson et al. 2014). Both the particular storm events in Fig. 14a-c as well as superposed epoch analysis in Fig. 14d-i, there are significant ozone depletions at the middle atmosphere with the maximum loss of ozone from 10 to $30 \%$ at altitudes between 70 and $78 \mathrm{~km}$ after the storms. This indicates a significant effect of ozone loss by EPP in the middle atmosphere. Funke et al. (2014) have shown intrusions of EPP-caused nitric oxide (NOy) into the stratosphere with a time scale of several months, based on measurements by Michelson Interferometer for Passive Atmospheric Sounding (MIPA S) on board the Envisat satellite. This gradual descent of NOy from the mesosphere to the middle and lower stratosphere contributes to the catalytic destruction of ozone. Efforts to quantify the total forcing of EPP to the atmosphere have also been made during the VarSITI interval. Isono et al (2014) reported NO column density enhancement 1-5 days after the commencement of geomagnetic storms based on ground-based millimeter-wave

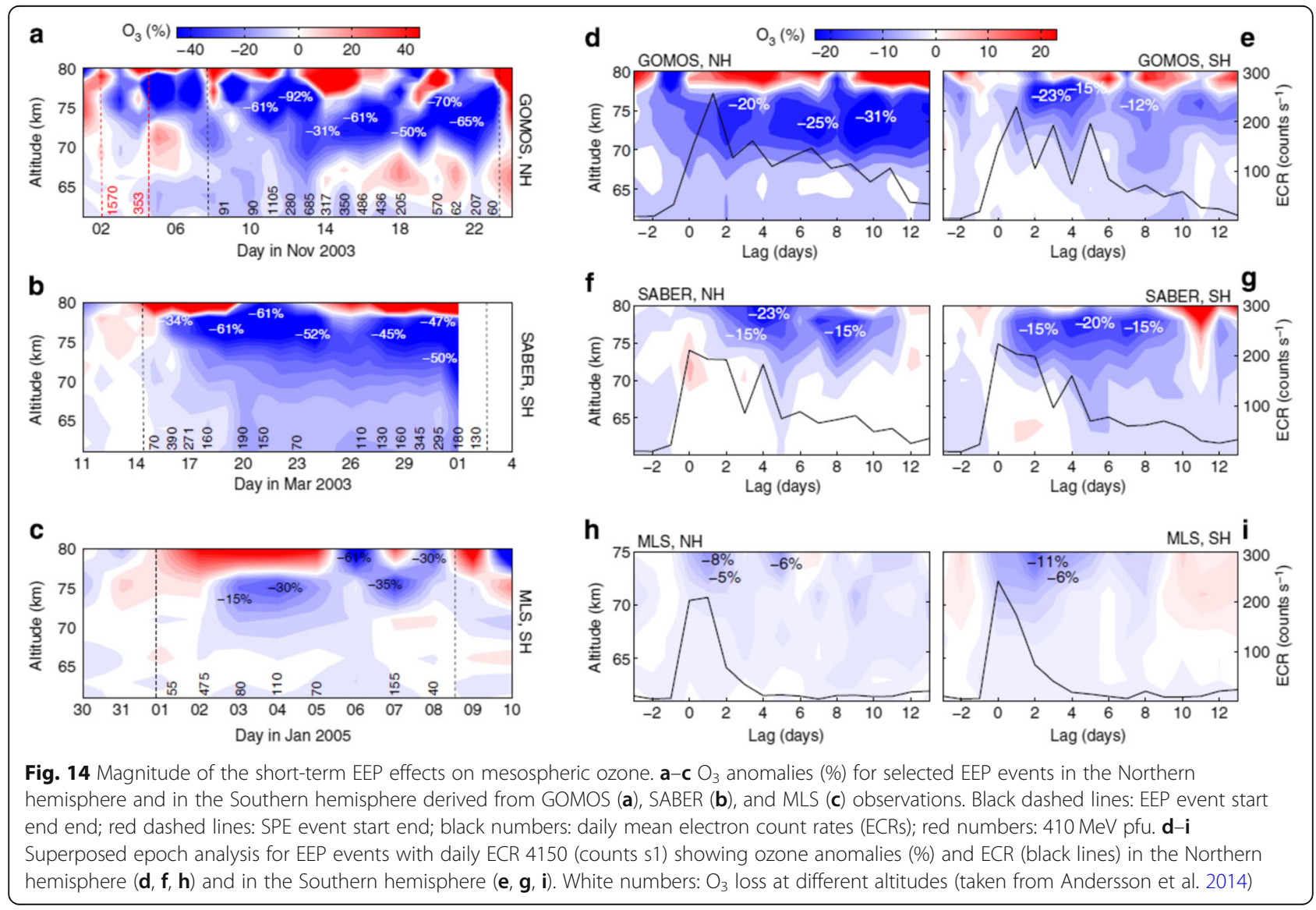


spectroscopic radiometer at Syowa Station in Antarctica.

Together with these new measurements of EPP effects on the atmosphere, efforts to model the global effects have also been made. Andersson et al. (2018) combined the Whole Atmosphere Community Climate Model (WACCM) together with the EPP forcing model developed by van de Kamp et al. (2016) for the 6th phase of the Coupled Model Intercomparison Project (CMIP6) (Matthes et al. 2017). They concluded that mediumenergy (30 keV-1 MeV) electrons (MEE) can enhance the stratospheric ozone response to solar activity by a factor of 2. Thus, the EPP forcing can be significant for the long-term stratospheric ozone variation, implying their effects on the thermal structure of the middle and lower atmosphere.
Not only the EPP effect but also understanding of the effects of irradiance variation of the Sun (total solar irradiance (TSI) and spectral solar irradiance (SSI)) on the atmosphere has also been progressed during the VarSITI interval. This part will be visited in the Section 3.3.3 below.

\subsubsection{Coupling from below}

During the CAWSES and CAWAES-II interval, penetration of sound waves, gravity waves, tides, and planetary waves beyond the mesopause region into the thermosphere and their interaction with the ionospheric plasma had been newly recognized (e.g., Vadas and Crowley 2010; Goncharenko and Zhang 2008; Oberheide et al. 2015). During VarSITI interval, further studies on the role of these waves in the thermosphere and ionosphere

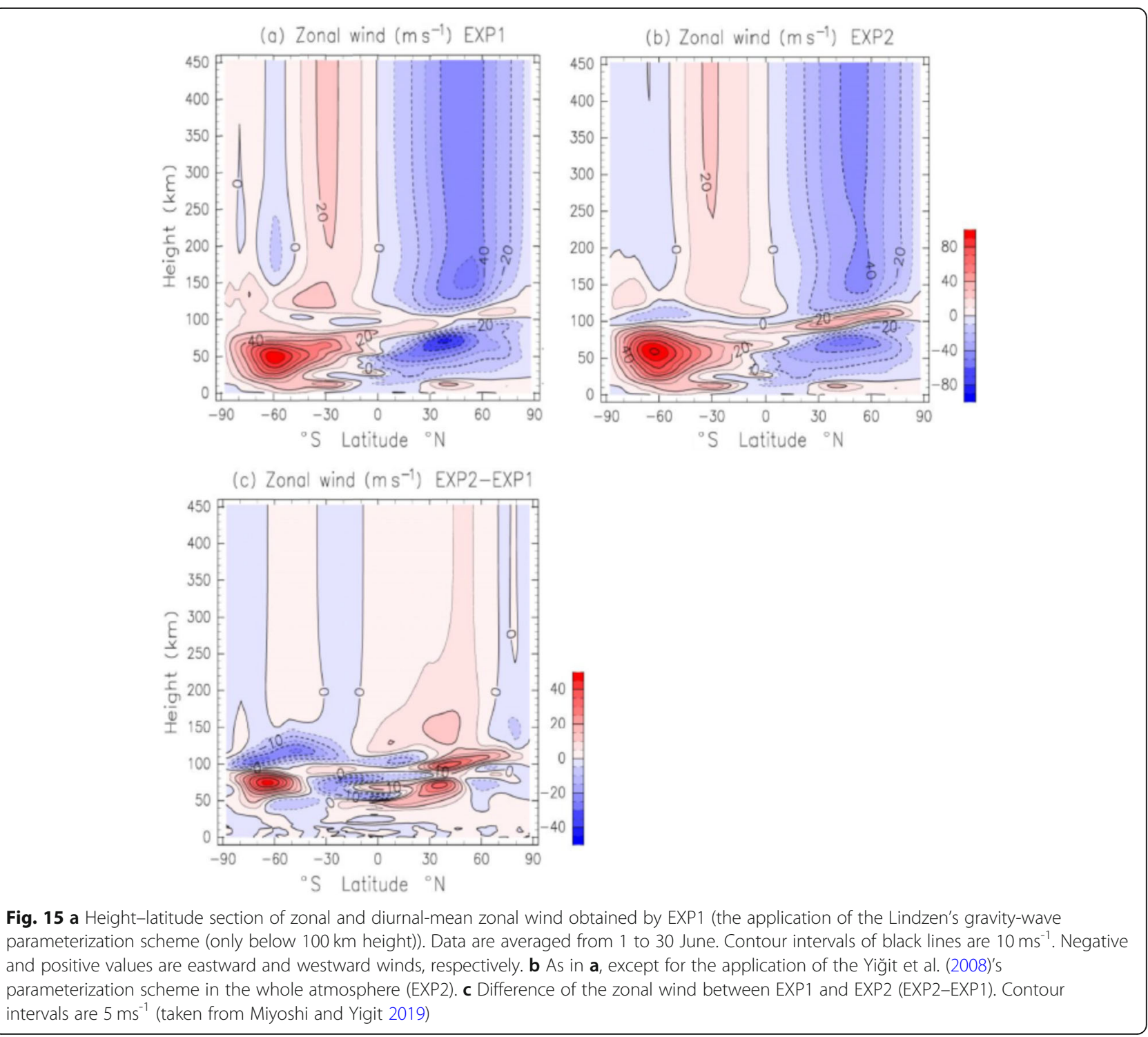


have been made. Yiğit et al. (2016) reviewed the effects of these waves on the structure of atmosphere, motivated by the IAGA/ICMA/SCOSTEP Workshop on Vertical Coupling in the Atmosphere-Ionosphere System. Figure 15 shows the height-latitude profiles of zonal winds without gravity wave forcing above $100 \mathrm{~km}$ (Fig. 15a) and with the forcing modeled by Yiğit et al. (2008) (Fig. 15b) and their differences (Fig. 15c). The gravity wave dissipation and their forcing to the mean zonal wind can affect the magnitude of the zonal-mean zonal wind and provide a deceleration mechanism in the mesopause region and lower thermosphere.

New observations have been developed regarding connection from lower to upper atmosphere during the VarSITI program. Gravity wave generation, propagation, and dissipation impact to the atmospheric dynamics have been reported in the special issue of "ACP (2017) sources, propagation, dissipation and impact of gravity waves" in the Atmospheric Chemistory and Phycis (https://acp. copernicus.org/articles/special_issue899.html) in relation to the German Role Of the Middle atmosphere In Climate (ROMIC) project (2013-2017). For example, Baumgarten et al. (2018) reported a 10-day continuous lidar sounding of temporal variability of tidal and gravity waves, indicating the importance of such continuous high-resolution measurements to detect interaction phenomena between waves for improving parametrization schemes of gravity waves in general circulation models. The ROMIC project has extended in 2018 for additional 3-4 years in Germany. New Program of the Antarctic Syowa MST/IS radar (PANSY) has been operational (Sato et al. 2014), and Interhemispheric Coupling Study by Observations and Modeling (ICSOM) campaigns (http://pansy.eps.s.u-tokyo.ac. $\mathrm{jp} / \mathrm{icsom} /$ ) have been carried out in association with VarSITI to understand dynamical variation of the whole atmosphere during stratospheric sudden warming (SSW). Liu (2016) have shown possible influences of ENSO and QBO in the neutral density variations in the thermosphere using a 46-year-long dataset of the thermospheric density during 1967-2012.

Efforts of model extension to the thermosphere and ionosphere have also been done. Liu et al. (2018) have developed the NCAR Whole Atmosphere Community Climate Model with thermosphere and ionosphere extension (WACCM-X). This new model reproduces thermospheric composition, density, and temperature and ionospheric plasma density and ExB drifts including prereversal enhancement in the equatorial region. Pedatella and Liu (2018) noted using the WACCM-X simulations that the effects of lower atmosphere variability should be included to accurately capture smaller-scale features of the upper atmosphere response to geomagnetic storms. Shinagawa et al. $(2017,2018)$ successfully reproduced global distribution of sporadic E layers and daily and seasonal variation of equatorial spread F, respectively, based on the Ground-to-topside model of Atmosphere and Ionosphere for Aeronomy (GAIA) model (Jin et al. 2011).

\subsubsection{Long-term trend}

The long-term trend has been extensively studied under the working group 3 of the ROSMIC project. Laštovička (2017) provided a review of recent progress in trends in the upper atmosphere, together with the special issue of the long-term changes and trends in the upper atmosphere (https://www.sciencedirect.com/journal/journalof-atmospheric-and-solar-terrestrial-physics/vol/163/ suppl/C). Figure 16 shows linear temperature trends from the 25-year data set measured by a sodium lidar at Fort Collins $\left(41^{\circ} \mathrm{N}, 105^{\circ} \mathrm{W}\right)$ in the USA reported by She et al. (2015). By removing strong warming effect by Mt. Pinatubo eruption in 1991, they concluded a cooling trend starting from an insignificant value of $0.64 \pm 0.99$ $\mathrm{K} /$ decade at a $85-\mathrm{km}$ altitude, increasing to a maximum of $2.8 \pm 0.58 \mathrm{~K} /$ decade between 91 and $93 \mathrm{~km}$, and then decreasing to a warming trend above $103 \mathrm{~km}$. Berger and Lübken (2015) reported trends in the polar mesospheric clouds (PMCs) which respond to long-term changes in mesospheric temperatures at northern high latitudes for the summer in 1961-2013. They suggested that the thermal conditions near $83 \mathrm{~km}$ height, with a cooling of $-0.58 \pm 0.32 \mathrm{~K} /$ decade, mainly determine trends in the PMCs, whereas cooling at lower heights, induced by stratospheric ozone, controls to a large extent the long-term behavior of PMC altitudes. Lübken et al. (2018) used model simulations over 138 years to

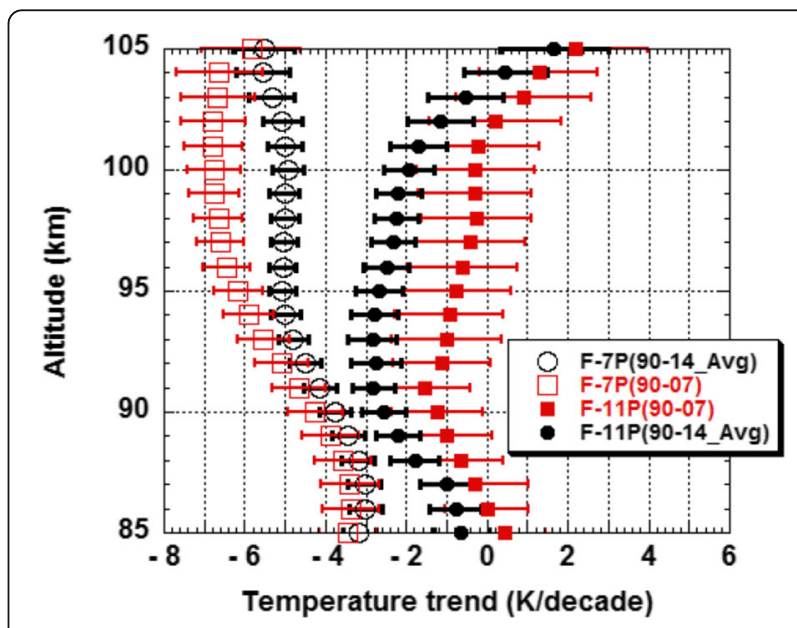

Fig. 16 Linear temperature trend from the quarter century data set with 11- and 7-parameter analyses, respectively, denoted as F11P(90-14_Avg) in black solid circles and F-7P(90-14_Avg) in black open circles. Shown for comparison are those data published based on an 18-year data set denoted as F-11P(90-07) in red solid squares and F-7P(90-07) in open red squares (taken from She et al. 2015) 
study the impact of increasing $\mathrm{CO}_{2}$ and $\mathrm{H}_{2} \mathrm{O}$ on the development of noctilucent clouds (NLCs) on centennial time scales. They concluded that NLC presumably existed centuries earlier, but the chance to observe them by the naked eye was extremely small before the twentieth century, whereas it is likely to see several NLC per season in the modern era.

The above studies of long-term trends are motivated to identify the anthropogenic effects, i.e., the effect of increasing greenhouse gases, on the mesosphere and thermosphere. On the other hand, solar cycle effects on the upper atmosphere have also been evaluated during the VarSITI interval. Yeo et al. (2017) developed a new empirical reconstruction model of total and spectral solar irradiance (TSI and SSI) variability based on the linear combination of solar activity indices. Mitchell et al. (2015) used historical simulations of the CMIP-5 model to evaluate tropospheric signatures of solar cycle variations through the stratosphere. Thiéblemont et al. (2015) reported synchronization of solar forcing with decadal variability in North Atlantic climate, based on two 145-year experiments of the fully coupled oceanatmosphere model CESM-WACCM3.5 (Marsh et al. 2013) up to a $140-\mathrm{km}$ altitude with interactive chemistry. Cullens et al. (2016) reported the influence of the 11year solar cycle on gravity waves and the wave-driven circulation, using the Whole Atmospheric Community Climate Model (WACCM). The changes in gravity wave dragged during the solar maximum modify the waveinduced residual circulation and contribute to the warming of $\sim 1-4 \mathrm{~K}$ in the mesosphere and lower thermosphere. Amorim et al. (2011), Takeo et al. (2017) and Tsuchiya et al. (2019a, 2019b) reported clear anticorrelation between 11-year solar activity and nighttime medium-scale traveling ionospheric disturbances (MSTI Ds) at middle and subauroral latitudes. This anticorrelation can be explained by the linear growth rate of ionospheric Perkins instability, responding to the solarcycle variation of neutral-plasma collision frequency in the bottom-side ionosphere. This negative correlation of nighttime MSTIDs at middle latitudes to solar cycle is a clear contrast to the positive correlation of post-sunset plasma bubbles in the equatorial ionosphere (e.g., Nishioka et al. 2008).

\subsubsection{Highlights of contribution from young scientists to the ROSMIC project}

Many young scientists have been newly joined in the field of the upper atmosphere during the VarSITI interval and contributed to the ROSMIC project. From space to the atmosphere, Misios et al. (2015) investigate the troposphere response to the 11-year solar cycle based on the ensemble simulations of the twentieth century climate performed in the fifth phase of the Coupled Model
Inter-Comparison Project (CMIP5). Wenzel et al. (2016) reported development of global ionospheric flare detection system (GIFDS) using very low frequency (VLF) radio transmissions in the northern hemisphere. Yadav et al. (2016) reported the impact of the St. Patrick's Day storm on March 15, 2017, on the evolutionary pattern of equatorial ionization anomaly over the Indian longitudes using high-resolution TEC maps. Karan et al. (2016), Karan and Pallamraju (2017) reported electrodynamic influence on the diurnal behavior of oxygen dayglow and longitudinal variations of equatorial thermospheric waves seen in the dayglow observed from the ground.

rom low to upper atmosphere, Laskar et al. (2014) and Laskar and Pallamraju (2014) investigated responses of equatorial electrojet (EEJ) strength, total electron content (TEC), and oxygen dayglow in the Indian sector to the sudden stratospheric warming and solar activity. Trinh et al. $(2015,2016,2018)$ reported a comprehensive global observation of gravity waves in the middle atmosphere and thermosphere using several low-altitude satellites, providing evidences of strong vertical coupling from lower to middle and upper atmosphere through gravity waves on global scale. Gao et al. (2015) reported double-layer structure in hydroxyl $(\mathrm{OH})$ dayglow measured by the Thermosphere-Ionosphere-Mesosphere Energetics and Dynamics (TIMED) satellite. Stober et al. (2014, 2018), Stober and Chau (2015) investigated neutral density variation using meteor radar echoes in the mesosphere and developed novel technique to improve wind measurements in the mesosphere and lower thermosphere using a multi-static multi-frequency meteor radar.

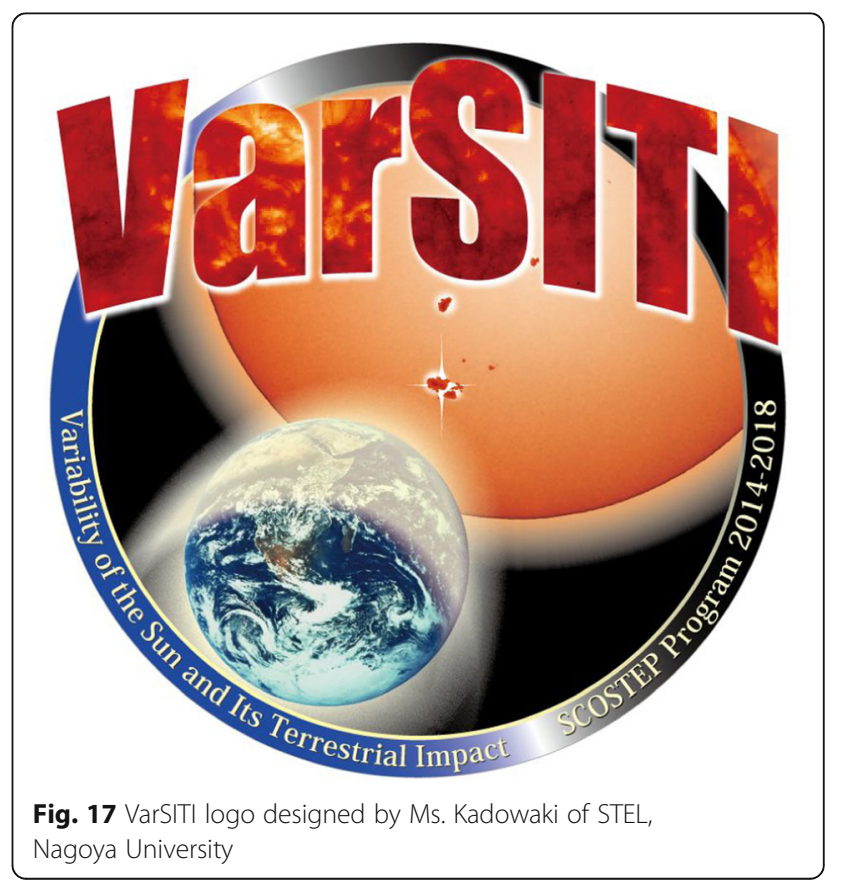


For the use of GNSS positioning, Macalalad et al. (2014) evaluated performance of different ionospheric models in single-frequency code-based differential GPS positioning. Seif et al. $(2015,2017,2018)$ investigated daytime ionospheric scintillations at equatorial latitudes and their relationship with the sporadic $E$ layer and the gradient-drift instability.

\section{Implementation of the VarSITI program}

The VarSITI program officially started on January 13, 2014. It was announced in a press release by the SCOSTEP's Bureau and in information for media in various countries provided by members of the SCOSTEP community. A video was prepared highlighting the scientific objectives of VarSITI (https://www.youtube.com/ watch?v=couR4MyxNPY).

A competition was announced for the VarSITI program's logo. The logo, selected by the voting during the
Panel 3 of CAWSES-II Symposium in Nagoya, Japan (November 18-22, 2013), was made by Ms. Kadowaki of STEL, Nagoya University (Fig. 17).

In the following subsections, we describe various implementation activities of VarSITI. Table 1 summarizes some representative numbers of these activities.

\subsection{Website}

The program's website (http://varsiti.org/) contains information about VarSITI's projects and members, VarSITI-related meetings with lots of freely available presentations, journal articles and books, and links to numerous resources including real time data, data bases of space-borne and ground-based measurements, models, visualization, and forecasting tools. After the end of the VarSITI program, the website remains operational. It is maintained by Dimitar Danov from the

Table 1 Some representative numbers of the VarSITI implementation activities

\begin{tabular}{|c|c|c|}
\hline \multicolumn{3}{|l|}{ VarSITI website (http://varsiti.org/) } \\
\hline number of website visits in 2014-2018 & \multicolumn{2}{|l|}{$\sim 180,000$} \\
\hline \multicolumn{3}{|l|}{ VarSITI mailing list } \\
\hline category & number of regsitered addresses & number of countries \\
\hline VarSITI_all & 1116 & 72 \\
\hline SEE & 635 & 63 \\
\hline ISEST/Minimax24 & 744 & 67 \\
\hline SPeCIMEN & 620 & 60 \\
\hline ROSMIC & 824 & 67 \\
\hline \multicolumn{3}{|l|}{ VarSITI Newsletter (total 21 issues) } \\
\hline category & number of articles & number of countries \\
\hline articles & 60 & 41 \\
\hline highlight of young scientists & 49 & \\
\hline meeting reports & 85 & \\
\hline short news & 24 & \\
\hline \multicolumn{3}{|l|}{ VarSITI finantial support } \\
\hline meetings & 64 & \\
\hline database construction & 16 & \\
\hline campaign & 1 & \\
\hline intedisciplinary project & 1 & \\
\hline \multicolumn{3}{|l|}{ VarSITI-related special issues in journals } \\
\hline \multicolumn{3}{|c|}{$\begin{array}{l}\text { more than } 8 \text { special issues in Journal of Geophysical Research, Earth Planets and Space, Journal of Atmospheric and Solar-Terrestrial Physics, Solar } \\
\text { Physics, and Progress in Earth and Planetary Science }\end{array}$} \\
\hline \multicolumn{3}{|c|}{ VarSITI-related databases (http://varsiti.org/ $\rightarrow$ Resources $\rightarrow$ Databases) } \\
\hline databases & \multicolumn{2}{|l|}{124} \\
\hline data analysis \& visualization tools & \multicolumn{2}{|l|}{10} \\
\hline \multicolumn{3}{|c|}{ Capacity Building Schools during the VarSITI interval } \\
\hline Schools organized by the VarSITI co-chairs & \multicolumn{2}{|c|}{5 schools at Nigeria (x2), Indonesia (x2), and Russia } \\
\hline schools organized by SCOSTEP & \multicolumn{2}{|c|}{3 schools at Peru, India, and Azerbaijan } \\
\hline
\end{tabular}




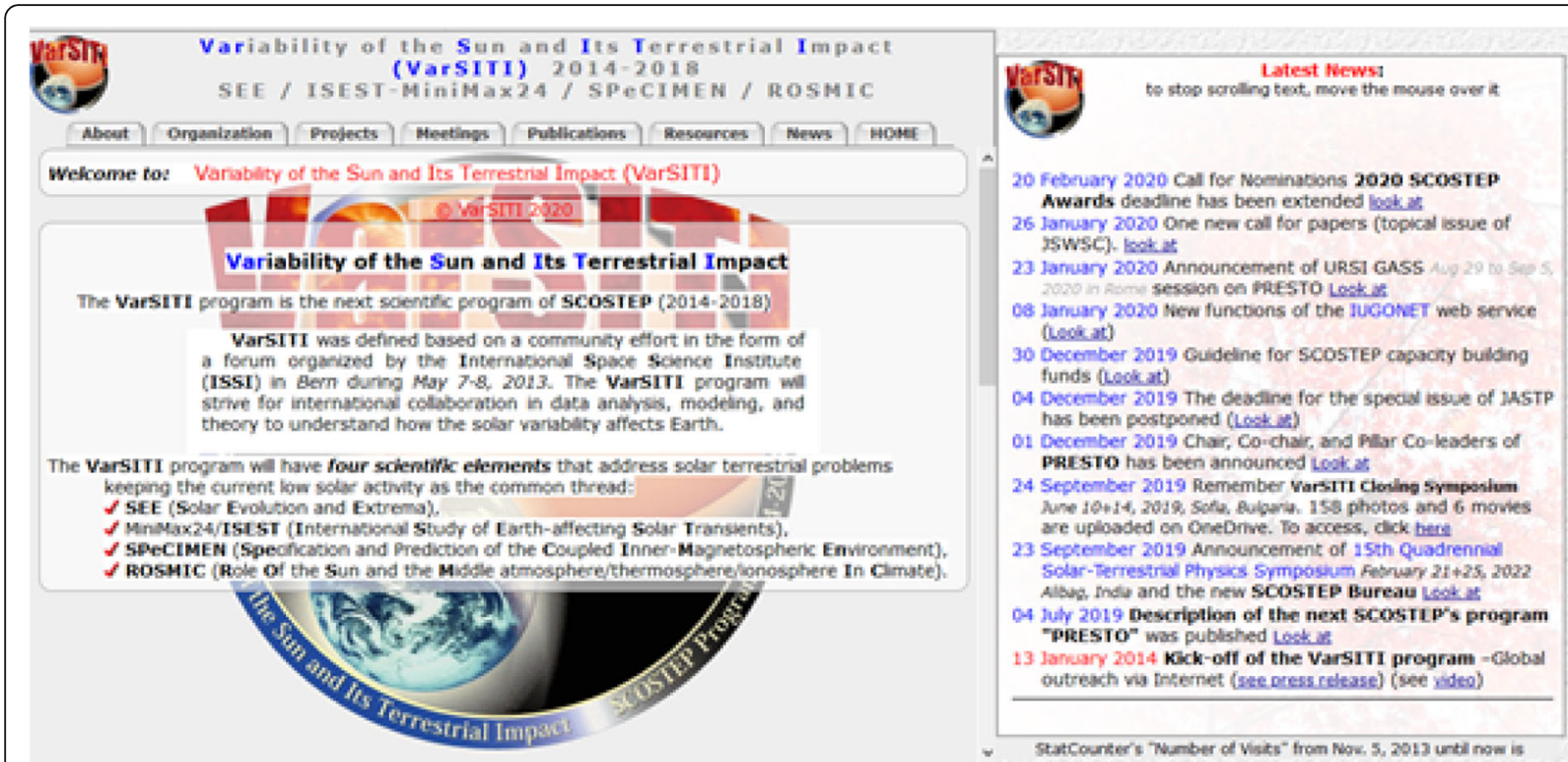

Fig. 18 Home page of the VarSITI website

Space Research and Technology Institute at the Bulgarian Academy of Sciences (Fig. 18).

For the duration of the program, the website had been visited more than 180 thousand times, as shown in Fig. 19.

\subsection{Mailing lists}

Five mailing lists were compiled and regularly updated: for each of the four projects and an integrated list for all projects. They contained the names and e-mail addresses of the scientists who have expressed their interest to participate in the program and to whom announcements were sent related to activities of VarSITI and its projects. The statistics by the end of the program is as follows:
1. SEE: 635 members from 63 countries

2. ISEST MiniMax24: 744 members from 67 countries

3. SPeCIMEN: 620 members from 60 countries

4. ROSMIC: 824 members from 67 countries

5. The whole VarSITI program: 1116 members from 72 countries.

\subsection{VarSITI newsletter}

VarSITI newsletter (Fig. 20) had been published with 4 issues per year: a total of 21 issues until May 2019. The newsletter had four categories of the articles:

1. Articles on new projects, campaigns, ground observations, satellite observations, modeling, workshop/conference/symposium reports, etc.;

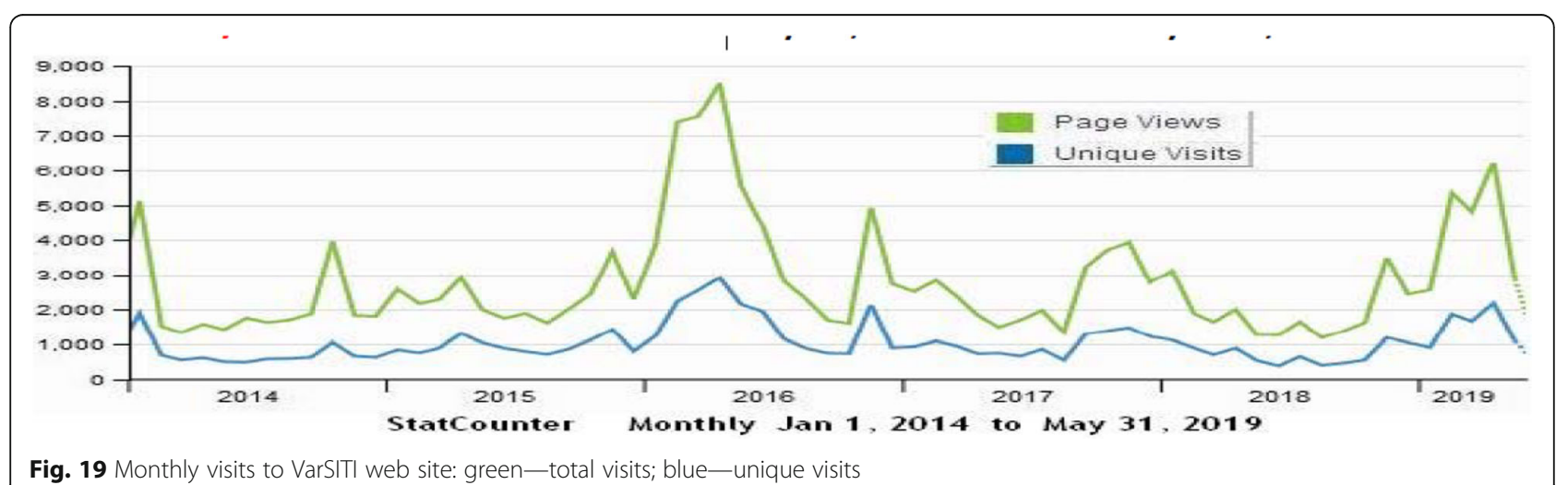

Fig. 19 Monthly visits to VarSITI web site: green —-total visits; blue—unique visits 


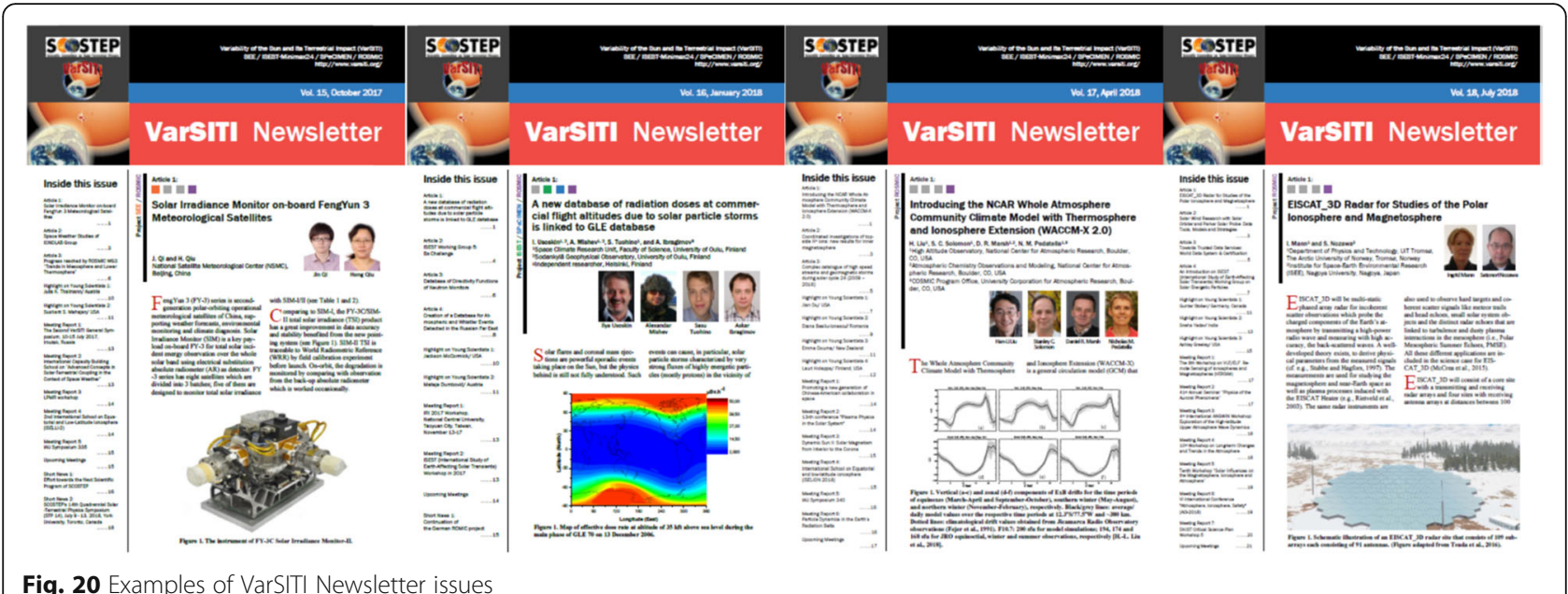

Fig. 20 Examples of VarSITI Newsletter issues

2. Highlights on young scientists based on the young scientist's own work related to VarSITI;

3. Short news: announcements of campaigns, workshops, etc.;

4. Meeting schedules.

Since the start of the VarSITI program in January 2014, 60 articles, 49 highlights of young scientists, 85 meeting reports, and 24 short news from 41 countries were published in these 21 newsletter volumes.

The newsletter was distributed online and in printed form at international meetings. The full archive is available on VarSITI web site (http://varsiti.org/).

\subsection{Financial support}

An important tool for implementing VarSITI program was the SCOSTEP's financial support provided annually for the organization of meetings, creation of databases, and campaigns. The grants were distributed by the VarSITI co-chair following recommendations and endorsements by the VarSITI projects' co-leaders. The grants were associated with the condition links to materials to be added to the VarSITI website and to be then freely available to all in the VarSITI community (e.g., presentations, virtual observatories, press releases, publications, etc.).

For the 5-year duration of the VarSITI program, we have organized or supported the following:

1. 64 meetings or sessions, including the three VarSITI General Symposia: VarSITI2016,

VarSITI2017, and VarSITI2019

2. 16 databases

3. 1 campaign

4. 1 interdisciplinary project

\subsection{VarSITI-related special issues in journals}

Related to the above meetings organized for VarSITI and its projects, several topical/special issues have been published in international journals. The representative issues are listed as follows.

(1) Special section on "Variability of the Sun and Its Terrestrial Impact-VarSITI" in Journal of Geophysical Research-Space Physics (preface: Hu 2015): https://agupubs.onlinelibrary.wiley.com/doi/ toc/10.1002/(ISSN)2169-9402.VarSITI1

(2) Special issue on "Global Data Systems for the Study of Solar-Terrestrial Variability (from SCOSTEPWDS workshop)" in Earth Planets and Space (preface: Watanabe et al. 2017): https://www. springeropen.com/collections/gdsys

(3) Special issue on "Long-term changes and trends in the upper atmosphere" in Journal of Atmospheric and Solar-Terrestrial Physics (preface: Laštovička and Lübken 2017): https://www.sciencedirect.com/ journal/journal-of-atmospheric-and-solarterrestrial-physics/vol/163/suppl/C

(4) Special issue on "Expected Evolution of Solar Activity in the Following Decades" in Journal of Atmospheric and Solar-Terrestrial Physics (introductory paper: Obridko and Georgieva 2018): https://www.sciencedirect.com/ journal/journal-of-atmospheric-and-solar-terrestrialphysics/vol/176/suppl/C

(5) Special collection and book on "Earth-affecting solar transients in Solar Physics" (editorial: Zhang et al. 2018): Journal:https://link.springer.com/ journal/11207/topicalCollection/AC_74be62d9d035 e23ca163bf5434bd2877

Book: https://www.springer.com/gp/book/9789402415698 
(6) Special issue of the "VarSITI-2017 symposium" in Journal of Atmospheric and Solar-Terrestrial Physics (preface: Georgieva and Shiokawa 2018): https:// www.sciencedirect.com/journal/journal-ofatmospheric-and-solar-terrestrial-physics/vol/180/ suppl/C

(7) Special issue of the "VarSITI closing symposium 2019" in Journal of Atmospheric and SolarTerrestrial Physics (under preparation)

(8) Special issue of the "VarSITI summarizing workshop" in Progress in Earth and Planetary Science (this issue)

\subsection{Database collection}

The effort to collect VarSITI-related database was initiated after the SCOSTEP - World Data System (WDS) workshop "Global Data Activities for the Study of SolarTerrestrial Variability" held during 28-30 September 2015 in Tokyo, Japan. VarSITI strives for the international collaboration in data analysis, modelling, and theory to understand how solar variability affects the Earth's environment. The provision and long-term preservation of quality-assessed data are common objectives for SCOSTEP and the WDS. The development of advanced data systems to enable scientists to perform multidisciplinary data-analysis are another common target. This workshop marked the beginning of collaborations between SCOSTEP and WDS, and a Letter of Agreement was signed by both organizations

The principal objective of the workshop was to stimulate interaction among data providers (WDS members, data centers, data networks, etc.), data scientists, and data-oriented researchers of the SCOSTEP community. Data analysis of selected solar-terrestrial events was an important component of the workshop also, not only to develop the study of solar-terrestrial variability but also to establish a mutual feedback loop between "data users" and data providers.

As an outcome of the discussions during the workshop, it was recommended to have a unified metadata system that enables users to search for VarSITI data holdings from a single entry point, for example, a "VarSITI Data Portal." After the VarSITI co-chairs asked via the VarSITI mailing list the members to provide links to their resources, a prototype of such a system has been realized in the VarSITI webpage under the title of "VarSITI-related Database Resources" (http://varsiti.org/ $\rightarrow$ Resources $\rightarrow$ Databases). It comprises 124 different databases plus 10 data analysis and visualization tools. This database list can be used for students and young scientists for their easy access to the solar-terrestrial physics data, allowing interdisciplinary data analysis over the wide area from the Sun to the earth.

\section{Capacity building of SCOSTEP/VarSITI}

One of the major tasks of SCOSTEP is the capacity building of solar-terrestrial physics for students and young scientists. During the VarSITI interval in 20142018, SCOSTEP has made three large schools in collaboration with International Space Weather Initiative (ISWI) at Lima, Peru, on September 15-24, 2014, at Sangli Maharashtra, India, on November 7-17, 2016, and at Baku, Azerbaijan, in October 8-12, 2018.

In addition to these SCOSTEP/ISWI schools, the VarSITI co-chairs organized five schools in Indonesia, Nigeria, and Russia. The two schools in Nigeria were named as the International School on Equatorial and Low-Latitude Ionosphere (ISELLI) and ISELLI-2. ISELLI was held at Abuja, Nigeria, on September 14-18, 2015, and 65 students joined from 7 African countries. ISEL LI-2 was held at Ota, Nigeria, on September 11-15, 2017, and 38 students joined from 7 African countries. The two schools in Indonesia were named as the International School on Equatorial and Low-Latitude Ionosphere (ISELION) and ISELION2018. ISELION was held at Bandung, Indonesia, on March 16-20, 2015, and 39 students joined from 9 Asian countries. ISELION2018 was also held at Bandung, Indonesia, on March 5-9, 2018, and 40 students joined from 7 Asian countries. The school in Russia was held on July 9-12, 2017, in Irkutsk, Russia, in association with the VarSITI 2017 General Symposium (July 10-15, 2017) at the same venue. Thirty-five students joined in this school from 5 countries. The database list developed by VarSITI was introduced in these schools to make it available to access novel data from latest missions for young scientists and students in developing countries (Fig. 21).

\section{Future topic for predictability of solar-terrestrial coupling}

As addressed above, there has been great progress during the 5-year VarSITI program on 2014-2018. These progresses of understanding solar-terrestrial coupling mechanisms make it possible to consider predictability of the variable coupling processes more quantitatively. The expansion of space use for better human life, such as GNSS positioning and broadcast satellites, requires more accurate prediction of space weather and hazardous events in space. In addition, threats to Earth's climate change also requests study of predictability on the effect of solar variability on Earth's climate. Under these circumstances the SCOSTEP decided to have the next program as PRESTO-Predictability of variable solarterrestrial coupling for 2020-2024 (http://www.issibj.ac. cn/Publications/Forum_Reports/201404/W0201906205 92906717714.pdf). The mission of PRESTO is to identify predictability of the variable solar-terrestrial coupling performance metrics through modeling, measurements, 


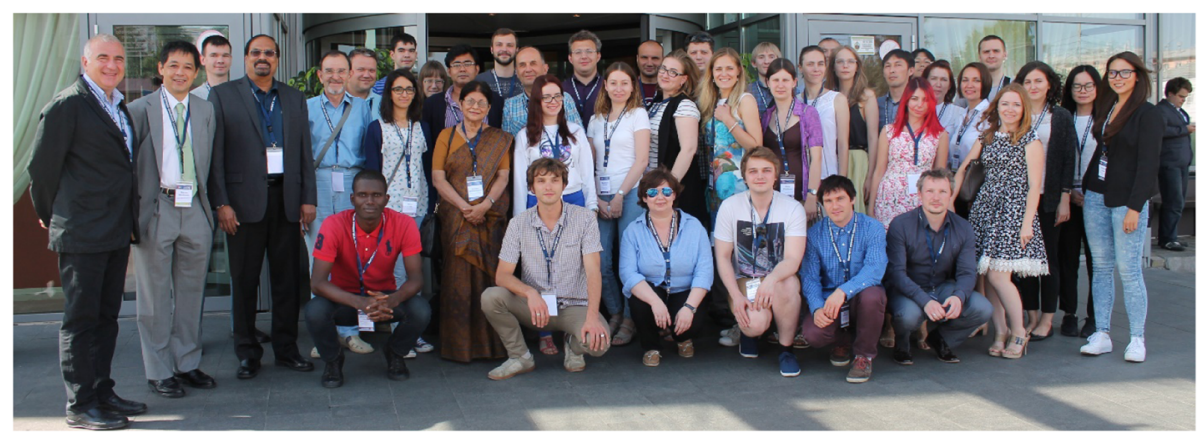

Fig. 21 Photo of a VarSITI School on July 2017 at Irkutsk, Russia, with 35 students from 5 countries

and data analysis and to strengthen the communication between scientists and users. The details of the PRESTO definition are provided by Daglis et al. (2020).

Figure 22 summarizes challenging scientific topics in the solar-terrestrial coupling processes that have been investigated during the VarSITI program, but still need further investigation during the PRESTO program. For short-term variabilities, which are shown in the leftside of Fig. 22, the following topics will stand even after the VarSITI interval.

\subsection{Short-term variability from Sun to earth 6.1.1 Evolution of sunspot from solar interior to solar surface}

The sunspot evolution in the solar active region is one of the key processes to understand and predict the solar flare eruption (e.g., Toriumi and Takasao 2017 and references therein). It is still a difficult part to realistically model this procedure from the solar interior to solar surface and to use it for prediction of sunspot evolution.

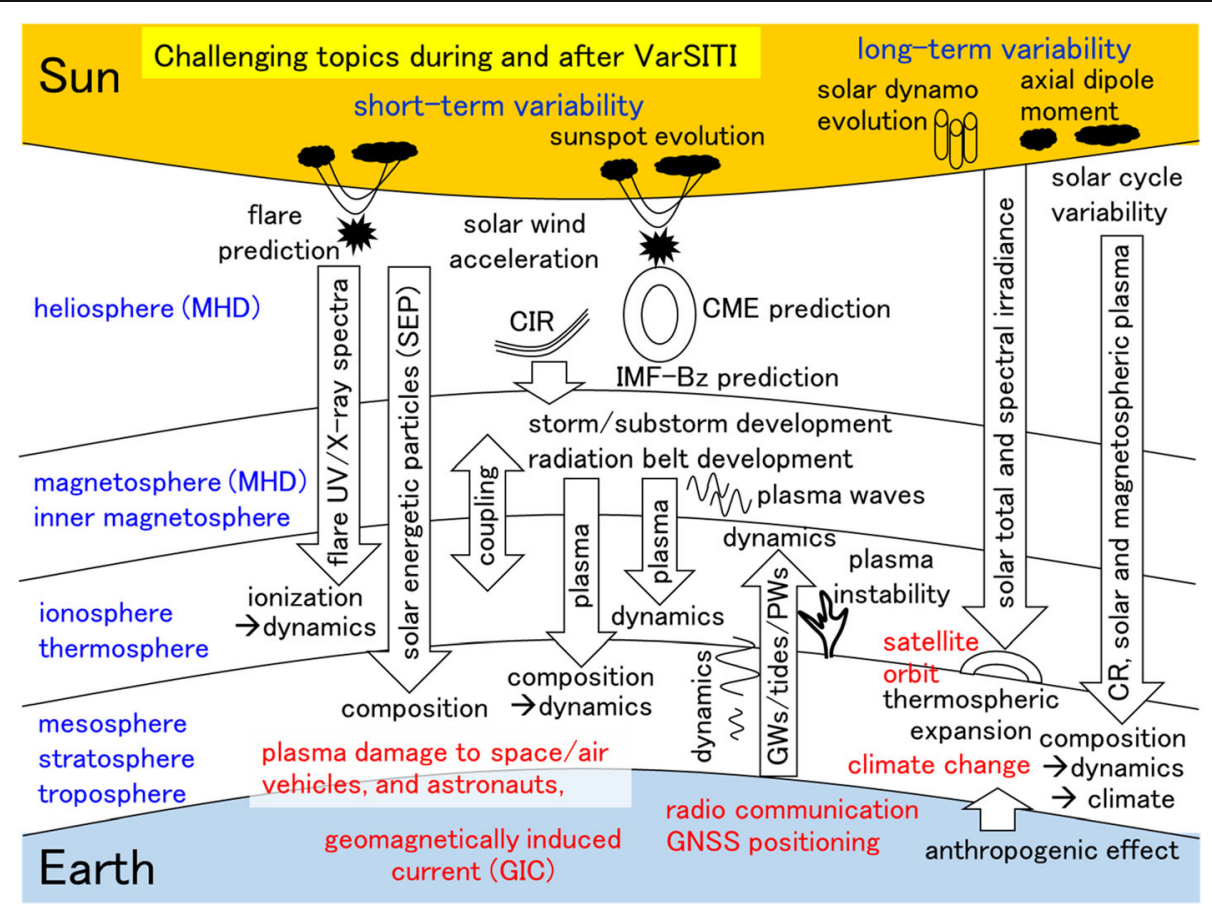

Fig. 22 Black: challenging scientific topics in the solar-terrestrial coupling during and after the VarSITI program. Red: their consequences on human life. Short and long-term variabilities are shown in the left and right side of the figure, respectively. CIR corotating interaction region, CME coronal mass ejection, CR cosmic ray, IMF interplanetary magnetic field, GNSS global navigation satellite system, GW gravity wave, MHD magnetohydrodynamics, PW planetary wave, UV ultraviolet 


\subsubsection{Flare/CME prediction at the solar surface}

Many progresses and proposals of new models have been made for the flare and CME prediction during the VarSITI program, as summarized by Zhang et al. (2021) and as shown by e.g., Bamba and Kusano (2018) and Kusano et al. (2020). However, this topic is still a challenging key topic during the PRESTO interval.

\subsubsection{Accurate measurements and prediction of flare UV} and $X$-ray spectra to understand ionospheric consequences In order to understand the effect of solar flares on the ionosphere, the spectral information of the solar flare is essential, because the UV and X-ray spectral distribution provides height distribution of ionization in the ionosphere. In other words, UV and X-ray emissions at shorter (longer) wavelengths cause ionization at lower (higher) altitudes in the ionosphere. The flare spectra can be different for different flares, even if the flare class defined by the X-ray intensity is comparable. Recently, Flare Irradiance Spectral Model (FISM) (Chamberlin et al. 2008) has been widely used to model the flare effects on the ionosphere. The model provides flare UV spectra from 0.1 to $190 \mathrm{~nm}$ with $1 \mathrm{~nm}$ resolution with a time resolution of $60 \mathrm{~s}$, based on the satellite measurements. However, this model does not provide real time data. Efforts to measure these spectra have been made during the VarSITI program (e.g., Woods et al. 2017). Prediction of the spectra is a further challenging issue.

\subsubsection{Measurement and prediction of spectra of Solar Energetic Particles (SEP)}

Similarly to the flare UV/X-ray spectra, the energy distribution of SEP determines the height variation of the ionization in the middle atmosphere (e.g., Turunen et al. 2009). Thus, measurement and prediction of the spectral information of SEP are an essential part to understand SEP effect on the atmosphere.

\subsubsection{Accurate IMF-Bz modeling and prediction in the CME} During the VarSITI program, IMF-Bz modeling and prediction in the CME were the topic in a working group of ISEST/Minimax24 (see Zhang et al. 2021 in details). But it is still a challenging issue to make accurate prediction of IMF-Bz direction and intensity in the CME, which essentially controls intensity of geomagnetic disturbances in the Earth's magnetosphere. For example, Cho et al. (2017) inspected two abnormal CME-Storm events and suggested the importance of 3D magnetic field geometry of interplanetary Flux Ropes.

\subsubsection{Modeling and prediction of IMF-Bz, speed, and dy- namic pressure in the CIR}

Another solar wind structure that causes strong geomagnetic disturbances is the CIR, which comes mainly from solar coronal holes during solar quiet time (e.g., Zhang et al. 2007). Similarly to the CME, modeling and prediction of IMF-Bz, speed, and dynamic pressure in the CIR is necessary to predict geomagnetic disturbances in the Earth's magnetosphere and ionosphere.

\subsubsection{Connection between the outer magnetosphere and the inner magnetosphere}

During the VarSITI program, the plasma dynamics in the inner magnetosphere and acceleration and dissipation of plasma through wave-particle interaction have been extensively studied by the SPeCIMEN project (Kanekal and Miyoshi 2021). The connection between the outer magnetosphere and the inner magnetosphere during storms and substorms provides boundary condition of global energy inputs from dayside magnetopause and nightside magnetotail to the inner magnetosphere. One issue is that the modeling using MHD approximation is applicable in the outer magnetosphere, while it is not in the inner magnetosphere due to significant magnetic gradient and curvature and strong coupling with the non-MHD ionosphere. This situation causes a gap of simulation codes used to describe the outer magnetosphere (MHD simulation) and inner magnetosphere (test particles and magnetosphere-ionosphere-thermosphere coupling codes). Several attempts have been made to connect these different models smoothly and self-consistently (e.g., Fok et al. 2014; Seki et al. 2018). However, the connection of these different models is still a challenging issue in the PRESTO program.

\subsubsection{Connection between the magnetosphere and the ionosphere/thermosphere}

Another challenging issue of MHD-non-MHD modeling connection is the magnetosphere-ionosphere coupling, which is a key process for the energy input from geospace to the Earth's atmosphere (e.g., Wiltberger et al. 2017; Ebihara and Tanaka 2017). The self-consistent connection of the magnetosphere and ionosphere including neutral atmosphere is still a challenging issue in the PRESTO program.

\subsubsection{Connection from the high-latitude energy input to the thermospheric dynamics and to the plasma bubble generation}

The plasma convection driven by MHD processes in the magnetosphere can cause associated neutral wind in the thermosphere through ion-neutral collision (e.g., Conde et al. 2001; Xu et al. 2019). The auroral particles and associated Joule heating also cause disturbances in the high-latitude thermosphere (e.g., Lu et al. 2016). The resultant neutral wind in the thermosphere further propagates to lower latitudes (e.g., Shiokawa et al. 2007) and 
causes westward neutral wind by the disturbance dynamo (Blanc and Richmond 1980), which may suppress ionospheric instabilities (plasma bubbles) in the equatorial evening terminator (e.g., Carter et al. 2014; Shinagawa et al. 2018). The prompt penetrating electric field (PPEF) from the magnetosphere to the equatorial ionosphere is another major force to control equatorial plasma bubbles during magnetic disturbances (storms and substorms) (e.g., Tulasi Ram et al. 2015). During the VarSITI program, these global processes have been extensively studied. However, further modeling and observation efforts should be made for accurate prediction of plasma bubbles, particularly for their day-to-day variability. The equatorial plasma bubbles are one of the most intense ionospheric disturbances on the Earth that significantly affect GNSS positioning and radiocommunication with satellites.

\subsubsection{Connection from the high-latitude energy input to the composition and dynamics of the atmosphere}

During the VarSITI program, growing interest and significant studies have been made on the solar energetic particles (SEP) and magnetospheric energetic particles (MEP) (Ward et al. 2021 and references therein). These high-energy ( $\mathrm{keV}-\mathrm{MeV})$ electrons and protons can cause significant ozone depletion in the middle atmosphere (e.g., Andersson et al. 2018) which propagates downward with a seasonal time scale. The challenging part is how these ozone depletion and associate temperature change in the middle atmosphere can change the dynamical coupling between the middle atmosphere and troposphere.

\subsection{Short-term variability from the earth to geospace}

From the Earth's lower atmosphere to the thermosphere and ionosphere, significant dynamical effect can be caused by penetration of acoustic sound waves (periods: less than minutes), gravity waves (several minutes to hours), tides (6 h to 1 day), and planetary waves (days). Below are some outstanding topics that will stand even after the VarSITI program.

\subsubsection{Gravity wave penetration to the thermosphere and its consequences to the thermospheric dynamics and circulation}

During the CAWSES-II and the VarSITI program, a great progress has been made on the penetration of gravity waves into the thermosphere (e.g., Oberheide et al. 2015; Yiğit 2018). It has been well known that the gravity waves control global circulation of the middle atmosphere through their dissipation in the mesopause region. However, the role of the primary and secondary gravity waves that penetrate into the thermosphere on global circulation is still not fully understood. Several papers during the VarSITI program have suggested that the role can be significant (e.g., Miyoshi and Yigit 2019; Vadas and Becker 2019). However, more comparison with global observation of the thermosphere and ionosphere will be needed to fully understand the gravity wave role in the thermospheric dynamics and circulation.

\subsubsection{Gravity wave penetration to the thermosphere and its consequences to the ionospheric disturbances}

Not only the global dynamics, the gravity waves penetrated into the thermosphere can also generate ionospheric disturbances both directly and by seeding ionospheric plasma instabilities (e.g., Otsuka 2018; Moral et al. 2019; Vadas et al. 2019). Thus, the gravity wave in the thermosphere is one of the key parameters to understand and predict the ionospheric disturbances that can cause degradation of GNSS positioning accuracy (e.g., Tsugawa et al. 2018). Further investigation of both modeling and ground and satellite measurements should be done.

\subsubsection{Variability of pre-reversal enhancement and gener- ation of equatorial plasma bubbles}

Pre-reversal enhancement in the evening solar terminator of the ionosphere is another key process that controls the generation of equatorial plasma bubbles. The equatorial plasma bubble is the strongest disturbance in the Earth's ionosphere and significantly affects the GNSS positioning. Recent global modeling such as by TIEGCM and GAIA successfully reproduces seasonal variability of pre-reversal enhancement, and thus, plasma bubbles (e.g., Carter et al. 2014; Shinagawa et al. 2018). However, prediction of day-to-day variability of plasma bubbles is still a challenging issue. The day-to-day variability of pre-reversal enhancement can be one of the causes of this plasma bubble variability (e.g., Ghosh et al. 2020).

\subsubsection{GW/Tide/Planetary wave penetration to the thermosphere and ionosphere and its consequences in the plasmasphere}

As cited above, the penetration of these waves with different periods can cause significant effects on the thermosphere (neutral atmosphere) and the ionosphere (plasma). However, their effect to the magnetosphere has not well been understood. For example, storm enhanced density (SED) in the highlatitude ionosphere corresponds to a plume structure in the plasmasphere around the Earth (Foster et al. 2005). The clear conjugacy of nighttime traveling ionospheric disturbances between the northern and southern hemispheres (e.g., Otsuka et al. 2004; Narayanan et al. 2018) indicates that these ionospheric disturbances are mapped between the hemispheres along geomagnetic field line, including the equatorial 
plane of the near-Earth magnetosphere. The mapped density structures in the plasmasphere can contribute ducting and cross-field localization of ULF/ELF/ VLF waves in the magnetosphere that are responsible for acceleration and dissipation of high-energy (radiation belt) plasma particles. Conjugate measurements with satellites in the inner magnetosphere and ground instruments will be necessary to see these possible connections between the ionosphere and the magnetosphere.

\subsection{Long-term variability}

\subsubsection{Solar dynamo evolution and axial dipole moment to predict variability of the 11-year solar cycle}

As cited in the above section on Solar Evolution and Extrema, the solar dynamo evolution to predict variability of the 11-year solar cycle is still a challenging issue even after the great efforts during the VarSITI program. The solar axial dipole moment during the solar cycle minimum can be an indicator of the activity of next solar cycle (e.g., Iijima et al. 2017; Jiang et al. 2018). The prediction of the 11-year solar cycle intensity is important for long-term prediction of the space weather condition that directly affects spacecraft operation in geospace (Bhowmik and Nandy 2018; Gopalswamy et al. 2018).

\subsubsection{Long-term variation of solar total and spectral irradiance for atmospheric consequences}

The long-term variation of solar total and spectral irradiance (TSI and SSI) can be a key parameter to affect the Earth's climate change. Various modeling efforts have been made during the VarSITI program (e.g., Matthes et al. 2017). However, quantitative assessment of TSI and SSI effects on the atmosphere and long-term climate change is not fully obtained yet. These irradiances also cause significant variation in atmospheric density in the thermosphere where most of the low-earth orbiting satellites are flying (e.g., Liu et al. 2018). The thermospheric density variation controls the lifetime of these satellites through atmospheric drag.

\subsubsection{High-energy plasma effect on the atmospheric variability, i.e., composition change and its dynamical effect} via ozone concentration

The energetic particle precipitation (EPP) on the atmosphere and subsequent ozone depletion have been observed and modeled in a seasonal time scale during the VarSITI program (e.g., Funke et al. 2014; Turunen et al. 2016; Andersson et al. 2018). However, their consequences on climate change are the difficult part to approach. As cited before, the key issue is the effect of the ozone depletion on the temperature variation in the middle atmosphere and their connection to the troposphere through various types of atmospheric waves.
Long-term data analysis and modeling efforts should be done further during the PRESTO program.

\subsubsection{Solar dependence of tropospheric parameters and their connecting mechanisms}

It is well known that the atmospheric density and temperature in the thermosphere significantly vary during the 11-year solar cycle. This is clearly due to the variation of the solar UV emission. We also see solar variation in the tropospheric parameters, such as a 27day solar rotation in lightning activity (Miyahara et al. 2018) and 11-year solar cycle in Pacific Walker Circulation (Misios et al. 2019). The physical mechanisms that create these solar variations in the troposphere have not been quantitatively explained. The variation of solar irradiance in the visible wavelength that reaches the troposphere seems to be too small $(\sim 0.1 \%)$ to explain the observed variations. However, the amplitude of variation in solar UV emission is much larger than that in visible wavelength, though the UV emission cannot reach the troposphere due to absorption in the thermosphere and in the ozone layer in the middle atmosphere. This reads the idea of atmospheric wave coupling to cause global circulation and tropospheric climate change (e.g., Kodera and Kuroda 2002) as below.

\subsubsection{Atmospheric wave coupling to cause global circulation and tropospheric climate change}

The atmospheric waves, i.e., gravity waves, tides, and planetary waves, can connect the middle atmosphere and the troposphere through dynamical coupling with global circulation, resulting in climate change in the troposphere driven by middle atmosphere variation (e.g., Kodera and Kuroda 2002; Lu et al. 2017). This process is one of the key issues to understand possible connection between the solar variabilities and the Earth's climate, because the solar UV emission and energetic particles can cause significant ozone depletion and associated temperature variation in the middle atmosphere.

\subsubsection{Separation of anthropogenic effect and solar variability effect}

The global warming of the troposphere due to anthropogenic effect, such as $\mathrm{CO}_{2}$ and methane, is more quantitatively understood than that of the solar forcing effect. However, the actual observation of climate change contains both effects in several different time scales. Modeling efforts have been made to separate these two mechanisms (e.g., Egorova et al. 2018; Solomon et al. 2019). Comparison of these modeling efforts with longterm observation becomes increasingly important to identify the mechanisms on solar forcing to climate change. 


\subsection{Consequences on human life}

The red characters in Fig. 22 indicate the consequences on human life, which are (a) plasma damage to space/air vehicles and astronauts by energetic particles from the Sun and the magnetosphere; (b) degradation of radio communication and GNSS positioning by equatorial plasma instabilities (plasma bubbles), auroras, and traveling ionospheric disturbances; (c) geomagnetically induced currents (GIC) caused by auroral electrojet currents and flowing through electric supply network and pipelines; (d) satellite orbital change due to atmospheric drag that is controlled by solar UV emission and auroral plasma; and (e) climate change possibly caused by energetic particles and solar UV radiation that changes dynamics of the middle atmosphere through ozone depletion. When we consider these consequences, the parameters used in scientific research, such as the sunspot number and the Kp and Dst indices, may not be useful, and more appropriate parameters, such as temporal and spatial scales and amplitudes of ionospheric plasma variation, radiation dose and its temporal variation, and atmospheric temperature variation, will be necessary for space users and climate scientists. Close communication with space users and climate scientists will be necessary for solar-terrestrial physics for space weather and space climate applications.

\section{Summary}

To understand variability of the Sun and its consequence on Earth, communication of different fields and interdisciplinary researches are essential. During the 5-year program of VarSITI, major efforts have been made to encourage more communication between solar and interplanetary scientists and magnetosphere, ionosphere, and atmosphere scientists. The efforts were made by developing mailing lists and websites; by distributing VarSITI newsletters; by supporting interdisciplinary meetings, databases, and campaigns; and by creating database list. More than 1000 scientists in solarterrestrial physics have joined in this program.

Although it is still challenging to predict the intensity of the next solar maximum, several key procedures of solar dynamo have been understood during the VarSTII interval under the SEE project. The interplanetary connection from the solar surface to the Earth's magnetopause has been investigated in detail by combining several in situ and remote-sensing satellites and ground instruments under the ISEST/Minimax 24 project. Study of the inner magnetosphere was in the golden era by the THEMIS, Van Allen Probes, and ERG satellites as well as multi-point ground measurements and the global modeling efforts that connect outer and inner magnetosphere and ionosphere. Coordination efforts have been done for these inner-magnetosphere data under the SPeCIMEN project. The high-energy plasma input to the atmosphere and its connection to the climate change in the middle and lower atmosphere have been extensively studied, as well as short-term effects from the lower atmosphere to the thermosphere and the ionosphere, under the ROSMIC project. All these scientific achievements obtained during the VarSITI program allow direction to the quantitative assessment of predictability of short- and long-term variation of solar-terrestrial coupling system. However, there are still many challenging issues in all regions from the solar interior to the Earth's atmosphere to make prediction of their variability. Increasing the use of space by human beings, such as GNSS positioning and broadcast satellites, and increasing threat to the Earth's climate change, are resulting in increasing requirements for reliable prediction of the variability of the Sun-Earth system. Under these circumstances, it is quite natural to have the next SCOSTEP program, PRESTO, to focus on the predictability of variable solar-terrestrial coupling.

\section{Abbreviations}

ACE: Advanced Composition Explorer; ACRIM: Active Cavity Radiometer Irradiance Monitor; AGU: American Geophysical Union; BATSRUS/ CRCM: Block-Adaptive-Tree-Solar-wind-Roe-Upwind-Scheme with Comprehensive Ring Current Model; CATCH: Collection of Analysis Tools for Coronal Holes; CAWSES: Climate and Weather of the Sun-Earth System; CDS: Centre de Données astronomiques de Strasbourg (Strasbourg astronomical Data Cente); CESM: Coupled Ocean-Atmosphere Model; CHAMP: Challenging Minisatellite Payload; CHIMERA: Coronal Hole Identification via Multi-thermal Emission Recognition Algorithm; CIR: Corotating interaction region; CME: Coronal mass ejection; CMIP5: Fifth Phase of the Coupled Model Inter-Comparison Project; CR: Cosmic ray; ECR: Electron count rate; EEJ: Equatorial electrojet; EEP: Energetic electron precipitation; ELF: Extremely low frequency; EMCCD: Electron-multiplying charge-coupled device; EPIC: Equatorial Processes Including Coupling; EPP: Energetic particle precipitation; ERG: Energization and radiation in geospacer; EUHFORIA: EUropean Heliospheric FORecasting Information Asset; GAIA: Ground-to-topside model of atmosphere and ionosphere for aeronomy; GEMSIS: Geomagnetic Environment Modeling System for Integrated Studies; GHG: Greenhouse gases; GIC: Geomagnetically induced current; GNSS: Global navigation satellite system; GOMOS: Global Ozone Monitoring by Occultation of Stars; GPS: Global Positioning System; GW: Gravity wave; HCS: Heliospheric current sheet; HOPE: Helium Oxygen Proton Electron; ICME: Interplanetary coronal mass ejection;

ICSU: International Council of Scientific Union; IMF: Interplanetary magnetic field; IMS: International Magnetospheric Study; IPCC AR5: Intergovernmental Panel on Climate Change Fifth Assessment Report; IRMB: Integrated Runoff Model-F. Bultot; ISC: International Science Council; ISCS: International Solar Cycle Study; ISELION: International School on Equatorial and Low-Latitude Ionosphere; ISELLI: International School on Equatorial and Low-Latitude Ionosphere; ISEST: International Study of Earth-affecting Solar Transients;

ISWI: International Space Weather Initiative; IUCSTP: Inter-Union Commission on Solar-Terrestrial Physics; keV: Kilo electronvolt; LDGRF: Long-duration gamma-ray flare; LPGRE: Late-phase gamma-ray emission; MagEIS: Magnetic electron-ion spectrometer; MAP: Middle Atmosphere Program;

MEP: Magnetospheric energetic particles; MeV: Mega electronvolt; MHD: Magnetohydrodynamics; MLS: Microwave limb sounder; MLT: Magnetic local time; MMS: Magnetospheric multiscale; PMOD: Physical Meteorological Observatory in Davos; PPEF: Prompt penetrating electric field; PRES

TO: Predictability of variable solar-terrestrial coupling; PSMOS: Planetary Scale Mesopause Observing System; PW: Planetary wave; PWING: Study of dynamical variation of particles and waves in the inner magnetosphere using ground-based network; RAM: Ring current-atmosphere interactions model; RGO: Royal Greenwich Observatory; ROSMIC: Role Of the Sun and the Middle atmosphere/thermosphere/ionosphere In Climate; SABER: Sounding of the 
Atmosphere using Broadband Emission Radiometry; SAMPEX: Solar Anomalous and Magnetospheric Particle Explorer; SCOSTEP: Scientific Committee on Solar-Terrestrial Physics; SDO: Solar Dynamics Observatory; SED: Storm enhanced density; SEE: Solar Evolution and Extrema; SEP: Solar energetic particles; SOHO: Solar and Heliospheric Observatory; SPE: Solar proton events; SPeCIMEN: Specification and Prediction of the Coupled InnerMagnetospheric Environment; SPOCA: Spatial POssibilistic Clustering Algorithm; S-RAMP: STEP_Results, Application and Modeling Phase; SSI: Spectral solar irradiance; SSW: Stratospheric sudden warming; STA: Solar Terrestrial Relations Observatory Ahead; STEL: Solar-Terrestrial Environment Laboratory; STEP: Solar-Terrestrial Energy Program; STEREO: Solar Terrestrial Relations Observatory; SUSANOO: Space-Weather-forecast-Usable System Anchored by Numerical Operations and Observations; TEC: Total electron content; TG1: Task group 1; TG2: Task group 2; TG3: Task group 3; TG4: Task group 4; THEMIS: Time History of Events and Macroscale Interactions during Substorms; TIEGCM: Thermosphere ionosphere electrodynamics general circulation model; TIMED: Thermosphere-lonosphere-Mesosphere Energetics and Dynamics; TSI: Total solar irradiance; ULF: Ultra low frequency; UV: Ultraviolet; VarSITI: Variability of the Sun and its Terrestrial Environment: VLF: Very low frequency; WACCM: Whole Atmosphere Community Climate Model; WDS: World Data System

\section{Acknowledgements}

We are grateful to Dimitar (Mitko) Danov of the Space Research and Technology Institute, Bulgarian Academy of Sciences, Bulgaria, for his skillful support for construction and maintenance of the VarSITI website. We are also grateful to the four secretaries, Mai Asakura, Miwa Fukuichi, Megumi Nakamura, and Ayumi Asai of the Institute for Space-Earth Environmental Research, Nagoya University, for their skillful support to bring out the VarSITI newsletters.

\section{Authors' contributions}

KS and KG are the two co-chairs of the VarSITI program. Both authors contributed to the writing this article. The authors read and approved the final manuscript.

\section{Authors' information}

KS and KG are the two co-chairs of the VarSITI program.

\section{Funding}

Because VarSITI is the 5-year program of SCOSTEP, the funding of VarSITI has been provided by SCOSTEP. KS was supported by JSPS KAKENHI Grant Number $15 \mathrm{H} 05815$ and $16 \mathrm{H} 06286$ and the JSPS Core-to-Core Program, B. AsiaAfrica Science Platforms. The VarSITI Newsletter production has been supported by the Institute for Space-Earth Environmental Research, Nagoya University, Japan. The VarSITI website construction has been supported by the Space Research and Technology Institute, Bulgarian Academy of Sciences, Bulgaria.

\section{Availability of data and materials}

The dataset in this article is provided by www.varsiti.org except for the figures taken from other references.

\section{Competing interests}

The authors declare that they have no competing interests.

\section{Author details}

${ }^{1}$ Institute for Space-Earth Environmental Research (ISEE), Nagoya University, Furo-cho, Chikusa-ku, Nagoya, Aichi 464-8601, Japan. ${ }^{2}$ Space Research and Technology Institute (SRTI), Bulgarian Academy of Sciences, Sofia, Bulgaria. ${ }^{3}$ Climate, Atmosphere and Water Research Institute (CAWRI), Bulgarian Academy of Sciences, Sofia, Bulgaria.

Received: 30 August 2020 Accepted: 25 January 2021 Published online: 09 March 2021

\section{References}

Amorim DCM, Pimenta AA, Bittencourt JA, Fagundes PR (2011) Long0 before addin medium. https://doi.org/10.1029/2010JA016090
An X, Li J, Bortnik J, Decyk V, Kletzing C, Hospodarsky G (2019) Unified view of nonlinear wave structures associated with whistler-mode chorus. Phys Rev Lett 122:045101. https://doi.org/10.1103/PhysRevLett.122.045101

Andersson ME, Verronen PT, Marsh DR, Seppälä A, Päivärinta SM, Rodger CJ, Clilverd MA, Kalakoski N, van de Kamp M (2018) Polar ozone response to energetic particle precipitation over decadal time scales: the role of mediumenergy electrons. J Geophys Res-Atmos 123:607-622. https://doi.org/10.1002/ 2017JD027605

Andersson ME, Verronen PT, Rodger CJ, Clilverd MA, Seppälä A (2014) Missing driver in the Sun-Earth connection from energetic electron precipitation impacts mesospheric ozone. Nat Commun 5(1):5197. https://doi.org/10.1038/ ncomms6197

Angelopoulos V (2008) The THEMIS Mission. Space Sci Rev 141(1-4):5-34. https://doi.org/10.1007/s11214-008-9336-1

Aulanier G, Démoulin P, Schrijver CJ, Janvier M, Paria E, Schmieder B (2013) The standard flare model in three dimensions. II. Upper limit on solar are energy. Astrophys J 549:A66. https://doi.org/10.1051/0004-6361/201220406

Aulanier G, Torok T, Demoulin P, DeLuca EE (2010) Formation of torus-unstable flux ropes and electric currents in erupting sigmoids. Astrophys J 708:314333. https://doi.org/10.1088/0004-637X/708/1/314

Baker DN, Jaynes AN, Hoxie VC, Thorne RM, Foster JC, Li X, Fennell JF, Wygant JR, Kanekal SG, Erickson PJ, Kurth W, Li W, Ma Q, Schiller Q, Blum L, Malaspina DM, Gerrard A, Lanzerotti LJ (2014) An impenetrable barrier to ultrarelativistic electrons in the Van Allen radiation belts. Nature 515(7528):531-534. https://doi.org/10.1038/nature13956

Baker DN, Erickson PJ, Fennell JF, Foster JC, Jaynes AN, Verronen PT (2018) Space weather effects in the earth's radiation belts. Space Sci Rev 214:17. https:// doi.org/10.1007/s11214-017-0452-7

Bamba Y, Kusano K (2018) Evaluation of applicability of a flare trigger model based on a comparison of geometric structures. Astrophys J 856(1):43. https://doi.org/10.3847/1538-4357/aaacd1

Baumgarten K, Gerding M, Baumgarten G, Lübken F-J (2018) Temporal variability of tidal and gravity waves during a record long 10-day continuous lidar sounding. Atmos Chem Phys 18:371-384. https://doi.org/10.5194/acp-18-371-2018

Beer J, McCracken K (2009) Evidence for solar forcing: Some selected aspects. In: Tsuda T, Fujii R, Shibata K, Geller MA (eds) Climate and Weather of the SunEarth System(CAWSES): Selected Papers from the2007 Kyoto Symposium. TERRAPUB, Tokyo, pp 201-216

Benz AO (2017) Flare observations. Living Rev Sol Phys 14:1. https://doi.org/10. 1007/s41116-016-0004-3

Berger U, Lübken F-J (2015) Trends in mesospheric ice layers in the Northern Hemisphere during 1961-2013. J Geophys Res Atmos 120:11,277-11,298. https://doi.org/10.1002/2015JD023355

Bhowmik P, Nandy D (2018) Prediction of the strength and timing of sunspot cycle 25 reveal decadal-scale space environmental conditions. Nat Commun 9:5209. https://doi.org/10.1038/s41467-018-07690-0

Blanc M, Richmond AD (1980) The ionospheric disturbance dynamo. J Geophys Res 85(16):925

Bobra MG, llonidis S (2016) Predicting coronal mass ejections using machine learning methods. ApJ 798:135. https://doi.org/10.1088/0004-637X/798/2/135.

Bortnik J, Li W, Thorne RM, Angelopoulos V (2016) A unified approach to inner magnetospheric state prediction. J Geophys Res Space Physics 121:24232430. https://doi.org/10.1002/2015JA021733

Brodrick D, Tingay S, Wieringa M (2005) X-ray magnitude of the 4 November 2003 solar flare inferred from the ionospheric attenuation of the galactic radio background. J Geophys Res 110:A09S36. https://doi.org/10.1029/ 2004JA010960

Burch JL, Moore TE, Torbert RB, Giles BL (2016) Magnetospheric multiscale overview and science objectives. Space Sci Rev 199(1-4):5-21. https://doi. org/10.1007/s11214-015-0164-9

Burton RK, McPherron RL, Russell CT (1975) An empirical relationship between interplanetary conditions and Dst. J Geophys Res 80:4204-4214. https://doi. org/10.1029/JA080i031 p04204

Cameron RH, Jiang J, Schüssler M (2016) Solar cycle 25: another moderate cycle? Astrophys J Lett 823:L22. https://doi.org/10.3847/2041-8205/823/2/L22

Carter BA, Retterer JM, Yizengaw E, Groves K, Caton R, McNamara L, Bridgwood C, Francis M, Terkildsen M, Norman R, Zhang K (2014) Geomagnetic control of equatorial plasma bubble activity modeled by the TIEGCM with Kp. Geophys Res Lett 41:5331-5339. https://doi.org/10.1002/2014GL060953 
Chae J, Kim YH (2017) Performance of the autoregressive method in long-term prediction of sunspot number. J Korean Astron Soc 50:21-27. https://doi.org/ 10.5303/JKAS.2017.50.2.21

Chamberlin PC, Woods TN, Eparvier FG (2008) Flare Irradiance Spectral Model (FISM): flare component algorithms and results. Space Weather 6:S05001. https://doi.org/10.1029/2007SW000372

Charbonneau P (2020) Dynamo models of the solar cycle. Living Rev Sol Phys 17: 4. https://doi.org/10.1007/s41116-020-00025-6

Cheng X, Ding MD, Guo Y, Zhang J, Vourlidas A, Liu YD, Olmedo O, Sun JQ, Li C (2014) Tracking the evolution of a coherent magnetic flux rope continuously from the inner to the outer corona. ApJ 780(1):28. https://doi.org/10.1088/ 0004-637X/780/1/28

Cho K-S, Marubashi K, Kim R-S, Park S-H, Lim E-K, Kim S-J, Kumar P, Yurchyshyn V, Moon Y-J, Lee J-O (2017) Impact of the ICME-Earth geometry of the strength of the associated geomagnetic storm: the September 2014 and March 2015 events. J Korean Astronomical Socy 50:29-39. https://doi.org/10.5303/JKAS. 2017.50.2.29

Clette F, Berghmans D, Vanlommel P, Van der Linden RAM, Koeckelenbergh A, Wauters $L$ (2007) From the Wolf number to the International Sunspot Index: 25 years of SIDC. Adv Space Res 40:919-928. https://doi.org/10.1016/j.asr. 2006.12.045.

Clette F, Svalgaard L, Vaquero JM, Cliver EW (2014) Revisiting the sunspot number. A 400-year perspective on the solar cycle. Space Sci Rev 186:35-103. https://doi.org/10.1007/s11214-014-0074-2

Cliver EW, Clette F, Svalgaard L (2013) Recalibrating the Sunspot Number (SSN): the SSN Workshops. Central Europ Astrophys Bull 37:401-416

Cnossen I, Richmond AD (2013) Changes in the Earth's magnetic field over the past century: effects on the ionosphere-thermosphere system and solar quiet (Sq) magnetic variation. J Geophys Res Space Physics 118:849-858. https:// doi.org/10.1029/2012JA018447

Conde M, Craven JD, Immel T, Hoch E, Stenbaek-Nielsen H, Hallinan T, Smith RW, Olson J, Sun W (2001) Assimilated observations of thermospheric winds, the aurora, and ionospheric currents over Alaska. J Geophys Res 106(A6):1049310508. https://doi.org/10.1029/2000JA000135

Covas E, Peixinho N, Fernandes J (2019) Neural network forecast of the sunspot butterfly diagram. Sol Phys 294:24. https://doi.org/10.1007/s11207-019-1412-z

Cullens CY, England SL, Garcia RR (2016) The 11 year solar cycle signature on wave-drivendynamics in WACCM. J Geophys Res Space Physics 121:34843496. https://doi.org/10.1002/2016JA022455

D'Huys E, Seaton DB, De Groof A, Berghmans D, Poedts S (2017) Solar signatures and eruption mechanism of the August 14, 2010 Coronal Mass Ejection (CME). J Space Weather Space Climate 7(March):A7. https://doi.org/10.1051/ swsc/2017006

Daglis IA, Chang L, Dasso S, Gopalswamy N, Khabarova OV, Kilpua E, Lopez R, Marsh D, Matthes K, Nandi D, Seppälä A, Shiokawa K, Thiéblemont R, Zong Q (2020) Predictability of the variable solar-terrestrial coupling, submitted to Annales Geophysicae

Danilov AD (2012) Long-term trends in the upper atmosphere and ionosphere (a review). Geomagn Aeron 52:271-291. https://doi.org/10.1134/ S0016793212030036

Desai M, Giacalone J (2016) Large gradual solar energetic particle events. Living Rev Solar Phys 13(1):3. https://doi.org/10.1007/s41116-016-0002-5

Dierckxsens M, Tziotziou K, Dalla S, Patsou I, Marsh MS, Crosby NB, Malandraki O, Tsiropoula G (2015) Relationship between solar energetic particles and properties of flares and CMEs: statistical analysis of solar cycle 23 events. Sol Phys 290:841-874. https://doi.org/10.1007/s11207-014-0641-4

Dissauer K, Veronig AM, Temmer M, Podladchikova T (2019) Statistics of coronal dimmings associated with coronal mass ejections. II. Relationship between coronal dimmings and their associated CMEs. Astrophys J 874(April):123. https://doi.org/10.3847/1538-4357/ab0962

Dissauer K, Veronig AM, Temmer M, Podladchikova T, Vanninathan K (2018a) Statistics of coronal dimmings associated with coronal mass ejections. I. Characteristic dimming properties and flare association. Astrophys J 863(August):169. https://doi.org/10.3847/1538-4357/aad3c6.

Dissauer K, Veronig AM, Temmer M, Podladchikova T, Vanninathan K (2018b) On the detection of coronal dimmings and the extraction of their characteristic properties. Astrophys J 855:137

Douma E, Rodger CJ, Clilverd MA, Hendry AT, Engebretson MJ, Lessard MR (2018) Comparison of relativistic microburst activity seen by sampex with groundbased wave measurements at Halley, Antarctica. J Geophys Res Space Physics. https://doi.org/10.1002/2017JA024754
Dresing N, Gómez-Herrero R, Klassen A, Heber B, Kartavykh Y, Dröge W (2012) The large longitudinal spread of solar energetic particles during the 17 January 2010 solar event

Dröge W, Kartavykh YY, Dresing N, Heber B, Klassen A (2014) Wide longitudinal distribution of interplanetary electrons following the 7 February 2010 solar event: observations and transport modeling. J Geophys Res Space Physics 119:6074-6094. https://doi.org/10.1002/2014JA019933

Dumbović M, Heber B, Vršnak B, Temmer M, Kirin A (2018) An analytical diffusion-expansion model for forbush decreases caused by flux ropes. Astrophys J 860(1):71. https://doi.org/10.3847/1538-4357/aac2de

Ebihara Y, Tanaka T (2017) Energy flow exciting field-aligned current at substorm expansion onset. J Geophys Res Space Physics 122:12,288-12,309. https://doi. org/10.1002/2017JA024294

Echer E, Gonzalez WD, Tsurutani BT (2008) Interplanetary conditions leading to super intense geomagnetic storms (Dst $\leq-250 \mathrm{nT}$ ) during solar cycle 23 . Geophys Res Lett 35:03-06. https://doi.org/10.1029/2007GL031755

Egorova T, Rozanov E, Arsenovic P, Peter T, Schmutz W (2018) Contributions of natural and anthropogenic forcing agents to the early 20th century warming. Front Earth Sci 6:UNSP 206. https://doi.org/10.3389/feart.2018. 00206

England SL (2012) Review of the effects of non-migrating atmospheric tides on Earth's low-latitude ionosphere. Space Sci Rev 168(1-4):211-236. https://doi. org/10.1007/s11214-011-9842-4

Fennell JF, Claudepierre SG, Blake JB, O'Brien TP, Clemmons JH, Baker DN, Reeves Spence HE., G D, (2015) Van Allen Probes show that the inner radiation zone contains no MeV electrons: ECT/MagEIS data. Geophys Res Lett 42(5):12831289. https://doi.org/10.1002/2014GL062874

Fok MC, Buzulukova NY, Chen SY, Glocer A, Nagai T, Valek P, Perez JD (2014) The comprehensive inner magnetosphere-ionosphere model. J Geophys Res Space Physics 119:7522-7540. https://doi.org/10.1002/2014JA020239

Foster JC, Coster AJ, Erickson PJ et al (2005) Redistribution of the stormtime ionosphere and the formation of the plasmaspheric bulge. In: Burch J, Schultz M (eds) New perspectives from imaging. AGU Press, Washington DC, pp 277-289

Fröhlich C (2009) Total solar irradiance variability: What have we learned about its variability from the record of the last three solar cycles? In: Tsuda T, Fujii R, Shibata K, Geller MA (eds) Climate and Weather of the Sun-Earth System (CAWSES): selected papers from the 2007 Kyoto Symposium. (C) TERRAPUB, Tokyo, pp 217-230

Funke B, López-Puertas M, Stiller GP, von Clarmann T (2014) Mesospheric and stratospheric NOy produced by energetic particle precipitation during 20022012. J Geophys Res Atmos 119:4429-4446. https://doi.org/10.1002/ 2013JD021404

Gabrielse C, Angelopoulos V, Runov A, Turner DL (2014) Statistical characteristics of particle injections throughout the equatorial magnetotail. J Geophys Res Space Physics 119:2512-2535. https://doi.org/10.1002/2013JA019638.

Gao H, Xu J, Ward W, Smith AK, Chen G-M (2015) Double-layer structure of OH dayglow in the mesosphere. J Geophys Res 120(7):5778-5787. https://doi. org/10.1002/2015JA021208

Garton TM, Gallagher PT, Murray SA (2018) Automated coronal hole identification via multi-thermal intensity segmentation. J Space Weather Space Climate 8: A02. https://doi.org/10.1051/swsc/2017039

Georgieva K, Shiokawa K (2018) Variability of the sun and its terrestrial impacts. J Atmos Solar-Terrestrial Phys 180:1-2. https://doi.org/10.1016/j.jastp.2018.09.008

Ghosh P, Otsuka Y, Mani S, Shinagawa H (2020) Day-to-day variation of pre-reversal enhancement in the equatorial ionosphere based on GAIA model simulations. Earth Planets Space 72:93. https://doi.org/10.1186/s40623-020-01228-9

Glocer A, Fok M, Meng X, Toth G, Buzulukova N, Chen S, Lin K (2013) CRCM + BATS-R-US two-way coupling: CRCM+BATS-R-US 2-WAY COUPLING. J Geophys Res Space Physics 118(4):1635-1650. https://doi.org/10.1002/jgra. 50221

Gokani SA, Singh R, Cohen MB, Kumar S, Venkatesham K, Maurya AK, Selvakumaran R, Lichtenberger J (2015) Very low latitude $(I=1.08)$ whistlers and correlation with lightning activity. J Geophys Res Space Physics 120(8): 6694-6706

Goncharenko L, Zhang SR (2008) lonospheric signatures of sudden stratospheric warming: Ion temperature at middle latitude. Geophys Res Lett 35:L21103. https://doi.org/10.1029/2008GL035684

Gonzalez WD, de Gonzalez ALC, Dal Lago A, Tsurutani BT, Arballo JK, Lakhina GS, Buti B, Ho CM, Wu S-T (1998) Magnetic cloud field intensities and solar wind velocities. Geophys Res Lett 25:963-966. https://doi.org/10.1029/98GL00703 
Gopalswamy N (2013) Editorial - message from the president. SCOSTEP Newslett 6 https://www.bc.edu/content/dam/bc1/offices/ISR/SCOSTEP/Multimedia/ newsletterarchive/SCOSTEP_Newsletter_6_Dec2013.pdf

Gopalswamy N (2016) History and development of coronal mass ejections as a key player in solar terrestrial relationship. Geosci Lett 3:8-26. https://doi.org/ 10.1186/s40562-016-0039-2

Gopalswamy N (2018) Part 2: solar origins and statistics of extremes. In: Buzulukova N (ed) Extreme events in geospace. Origins, predictability, and consequences. Elsevier, Amsterdam

Gopalswamy N, Mäkelä P, Yashiro S, Akiyama S (2018) Long-term solar activity studies using microwave imaging observations and prediction for cycle 25. J Atmos Solar-Terrestrial Phys 176:26-33. https://doi.org/10.1016/j.jastp.2018.04.005

Gopalswamy N, Tsurutani B, Yan Y (2015a) Short-term variability of the sun-earth system: an overview of progress made during the CAWSES-II period. Prog Earth Planet Sci 2(December):13. https://doi.org/10.1186/s40645-015-0043-8

Gopalswamy N, Xie H, Akiyama S, Mäkelä P, Yashiro S, Michalek G (2015b) The peculiar behavior of halo coronal mass ejections in solar cycle 24. Astrophys J Lett 804(May):L23. https://doi.org/10.1088/2041-8205/804/1/L23

Gopalswamy N, Xie H, Akiyama S, Mäkelä PA, Yashiro S (2014) Major solar eruptions and high-energy particle events during solar cycle 24. Earth Planets Space 66(December):104. https://doi.org/10.1186/1880-5981-66-104

Gopalswamy N, Yashiro S, Akiyama S, Xie H (2017) Estimation of reconnection flux using post-eruption arcades and its relevance to magnetic clouds at 1 AU. Sol Phys 292(April):65. https://doi.org/10.1007/s11207-017-1080-9.

Gopalswamy N, Yashiro S, Xie H, Akiyama S, Mäkelä P (2015c) Properties and geoeffectiveness of magnetic clouds during solar cycles 23 and 24. J Geophys Res Space Physics 120(November):9221-9245. https:/doi.org/10.1002/2015JA021446

Gray LJ, Beer J, Geller M, Haigh JD, Lockwood M, Matthes K, Cubasch U, Fleitmann D, Harrison G, Hood L, Luterbacher J, Meehl GA, Shindell D, van Geel B, White W (2010) Solar influences on climate, Rev Geophys 48:RG4001. https://doi.org/10.1029/2009RG000282

Grechnev W, Kiselev VI, Meshalkina NS, Chertok IM (2015) Relations between microwave bursts and near-earth high-energy proton enhancements and their origin. Solar Phys 290(10):2827-2855. https://doi.org/10.1007/s11207-015-0797-6

Guennou C, Pariat E, Leake JE, le Vilmer N (2017) Testing predictors of eruptivity using parametric flux emergence simulations. J Space Weather Space Climate 7:A17. https://doi.org/10.1051/swsc/2017015

Guo J, Dumbović M, Wimmer-Schweingruber RF, Temmer M, Lohf H, Wang Y, Veronig A, Hassler DM, Mays LM, Zeitlin C, Ehresmann B, Witasse O, Freiherr von Forstner JL, Heber B, Holmström M, Posne A (2018) Modeling the evolution and propagation of 10 September 2017 CMEs and SEPS arriving at mars constrained by remote sensing and in situ measurement. Space Weather 16:1156-1169. https://doi.org/10.1029/2018SW001973

Haigh JD (2009) Mechanisms for solar influence on the Earth's climate. In: Tsuda T, Fujii R, Shibata K, Geller MA (eds) Climate and Weather of the Sun-Earth System (CAWSES): selected papers from the 2007 Kyoto Symposium. (C) TERR APUB, Tokyo, pp 231-256

Hathaway D, Upton L (2016) Predicting the amplitude and hemispheric asymmetry of solar cycle 25 with surface flux transport. J Geophys Res Space Physics 121:10,744-10,753. https://doi.org/10.1002/2016JA023190

He H-Q, Wan W (2015) Numerical study of the longitudinally asymmetric distribution of solar energetic particles in the heliosphere. Astrophys J Suppl Ser 218(2):17. https://doi.org/10.1088/0067-0049/218/2/17

He W, Liu YD, Hu H, Wang R, Zhao X (2018) A stealth CME bracketed between slow and fast wind producing unexpected geoeffectiveness. Astrophys J 860: 78. https://doi.org/10.3847/1538-4357/aac381

Heinemann SG, Temmer M, Farrugia CJ, Dissauer K, Kay C, Wiegelmann T, Dumbović M et al (2019) CME-HSS interaction and characteristics tracked from Sun to Earth. Sol Phys 294:121. https://doi.org/10.1007/s11207-0191515-6

Heinemann SG, Temmer M, Hofmeister SJ, Veronig AM, Susanne Vennerstrøm S (2018) Three-phase evolution of a coronal hole. I. 360 remote sensing and in situ observations. ApJ 861:151. https://doi.org/10.3847/1538-4357/aac897

Helal HR, Galal AA (2013) An early prediction of the maximum amplitude of the solar cycle 25. J Adv Res 4:275-278. https://doi.org/10.1016/j.jare.2012.10.002

Hinterreiter J, Magdalenic J, Temmer M, Verbeke C, Jebaraj IC, Samara E, Asvestari E et al (2019) Assessing the performance of EUHFORIA modeling the background solar wind. Sol Phys 294:170. https://doi.org/10.1007/s11207-019-1558-8

Holappa L, Mursula K, Asikainen T (2014a) A new method to estimate annual solar wind parameters and contributions of different solar wind structures to geomagnetic activity. J Geophys Res 119:9407-9418
Holappa L, Mursula K, Asikainen T, Richardson IG (2014b) Annual fractions of high-speed streams from principal component analysis of local geomagnetic activity. J Geophys Res 119:4544-4555

Houtgast J, van Sluiters A (1948) Statistical investigations concerning the magnetic fields of sunspots I. Bull Astron Inst Netherlands 10:325-333

Hoyt DV, Schatten KH (1998) Group sunspot numbers: a new solar activity reconstruction. Sol Phys 179:189-219

Hu Q (2015) Preface to VarSITI special section: Preface: VARSITI SPECIAL COLLECTION. J Geophys Res Space Physics 120(12):10,137-10,138. https://doi. org/10.1002/2015JA021882

lijima H, Hotta H, Imada S, Kusano K, Shiota D (2017) Improvement of solar-cycle prediction: plateau of solar axial dipole moment. Astron Astrophys 607:L2. https://doi.org/10.1051/0004-6361/201731813

Illarionov EA, Tlatov AG (2018) Segmentation of coronal holes in solar disc images with a convolutional neural network. MNRAS 481:5014-5021. https:// doi.org/10.1093/mnras/sty2628

Immel TJ, Sagawa E, England SL, Henderson SB, Hagan ME, Mende SB et al (2006) Control of equatorial ionospheric morphology by atmospheric tides. Geophys Res Lett 33:L15108. https://doi.org/10.1029/2006GL026161

Isavnin A (2016) FRiED: a novel three-dimensional model of coronal mass ejections. Astrophys J 833(2):267. https://doi.org/10.3847/1538-4357/833/2/267

Isono Y, Mizuno A, Nagahama T, Miyoshi Y, Nakamura T, Kataoka R, Tsutsumi M, Ejiri MK, Fujiwara H, Maezawa H, Uemura M (2014) Ground-based observations of nitric oxide in the mesosphere and lower thermosphere over Antarctica in 2012-2013. J Geophys Res Space Physics 119:7745-7761. https://doi.org/10.1002/2014JA0198812014JA019881

James AW, Green LM, Palmerio E, Valori G, Reid HAS, Baker D, Brooks DH, van Driel-Gesztelyi L, and Kilpua EKJ (2017) On-disc observations of flux rope formation prior to its eruption. Sol Phys 292 (May): 71. https://doi.org/10. 1007/s11207-017-1093-4.

Jian LK, Luhmann JG, Russell CT, Galvin AB (2019) Solar terrestrial relations observatory (STEREO) observations of stream interaction regions in 20072016: relationship with heliospheric current sheets, solar cycle variations, and dual observations. Sol Phys 294:31. https://doi.org/10.1007/s11207-019-1416-8

Jiang J, Cameron RH, Schüssler M (2014) Effects of the scatter in sunspot group tilt angles on the large-scale magnetic field at the solar surface. Astrophys J 791(1):5. https://doi.org/10.1088/0004-637X/791/1/5

Jiang J, Cameron RH, Schüssler M (2015) The cause of the weak solar CYCLE 24. Astrophys J 808(1):L28. https://doi.org/10.1088/2041-8205/808/1/L28

Jiang J, Wang JX, Jiao QR, Cao JB (2018) Predictability of the solar cycle over one cycle. Astrophys J 863:159. https://doi.org/10.3847/1538-4357/aad197

Jin H, Miyoshi Y, Fujiwara H, Shinagawa H, Terada K, Terada N, Ishii M, Otsuka Y, Saito A (2011) Vertical connection from the tropospheric activities to the ionospheric longitudinal structure simulated by a new Earth's whole atmosphere-ionosphere coupled model. J Geophys Res 116:A01316. https:// doi.org/10.1029/2010JA015925

Jones AD, Kanekal SG, Baker DN, Klecker B, Looper MD, Mazur JE, Schiller Q (2017) SAMPEX observations of the South Atlantic anomaly secular drift during solar cycles 22-24. Space Weather 15:44-52. https:/doi.org/10.1002/2016SW001525

Greeley AD, Kanekal SG, Baker DN, Klecker B, Schiller Q (2019) Quantifying the contribution of microbursts to global electron loss in the radiation belts. J Geophys Res Space Physics 124:1111-1124. https://doi.org/10.1029/ 2018JA026368

Jordanova VK, Thorne RM, Li W, Miyoshi Y (2010) Excitation of whistler mode chorus from global ring current simulations: global simulations of chorus waves. J Geophys Res Space Physics 115(A5):n/a-n/a. https://doi.org/10.1029/ 2009JA014810

Jordanova VK, Welling DT, Zaharia SG, Chen L, Thorne RM (2012) Modeling ring current ion and electron dynamics and plasma instabilities during a highspeed stream driven storm: ring current dynamics during hss storms. J Geophys Res Space Physics 117(A9). https://doi.org/10.1029/2011JA017433

Kamiya K, Seki K, Saito S, Amano T, Miyoshi Y (2018) Formation of butterfly pitch angle distributions of relativistic electrons in the outer radiation belt with a monochromatic Pc5 wave. J Geophys Res Space Physics 123(6):4679-4691. https://doi.org/10.1002/2017JA024764

Kanekal SG, Miyoshi Y (2021) Dynamics of the the terrestrial radiation belts: a review of recent results during the VarSITI (Variability of the Sun and Its Terrestrial Impact) era, 2014-2018. Progress in Earth and Planetary Science (this special issue, the paper has no bibliographic information yet)

Kanekal SG, Blum L, Christian ER, Crum G, Desai M, Dumonthier J, Evans A, Greeley AD, Guerro S, Livi S, LLera K, Lucas J, MacKinnon J, Mukherjee J, 
Ogasawara K, Paschalidis N, Patel D, Pollack E, Riall S et al (2019) The MERiT onboard the CeREs: a novel instrument to study energetic particles in the Earth's radiation belts. J Geophys Res Space Physics 124(7):5734-5760. https://doi.org/10.1029/2018JA026304

Karan DK, Pallamraju D (2017) Small-scale longitudinal variations in the daytime equatorial thermospheric wave dynamics as inferred from oxygen dayglow emissions. J Geophys Res Space Physics 122:6528-6542. https://doi.org/10. 1002/2017JA023891

Karan DK, Pallamraju D, Phadke KA, Vijayalakshmi T, Pant TK, Mukherjee S (2016) Electrodynamic influence on the diurnal behavior of neutral daytime airglow emissions. Ann Geophys 34:1019-1030. https://doi.org/10.5194/angeo-341019-2016

Karoff C, Knudsen MF, De Cat P, Bonanno A, Fogtmann-Schulz A, Fu, Jianning Frasca A, Inceoglu F, Olsen J, Zhang Y, Hou Y, Wang Y, Shi J, Zhang W (2016) Observational evidence for enhanced magnetic activity of superflare stars. Nat Commun 7:11058. https://doi.org/10.1038/ncomms1 1058

Kasahara S, Miyoshi Y, Yokota S, etal, (2018) Pulsating aurora from electron scattering by chorus waves. Nature 554(7692):337-340. https://doi.org/10. 1038/nature25505

Kay C, Evans RM, Opher M (2015) Global trends of CME deflections based on CME and solar parameters. ApJ 805:168. https://doi.org/10.1088/0004-637X/805/2/168

Kay C, Gopalswamy N, Reinard A, Opher M (2017) Predicting the magnetic field of Earth-impacting CMEs. Astrophys J 835(2):117. https://doi.org/10.3847/ 1538-4357/835/2/117

Kay C, Opher M, Colannino RC, Voulidas A (2016) Using ForeCAT deflections and rotations to constrain the early evolution of CMEs. ApJ 827:70. https://doi. org/10.3847/0004-637X/827/1/70

Kazachenko MD, Lynch BJ, Welsch BT, Sun X (2017) A database of flare ribbon properties from the solar dynamics observatory. I. Reconnection Flux. Astrophys I 845(August):49. https://doi.org/10.3847/1538-4357/aa7ed6

Kirby K, Artis D, Bushman S, Butler M, Conde R, Cooper S, Fretz K, Herrmann C, Hill A, Kelley J, Maurer R, Nichols R, Ottman G, Reid M, Rogers G, Srinivasan D, Troll J, Williams B (2013) Radiation belt storm probes-observatory and environments. Space Sci Rev 179(1-4):59-125. https://doi.org/10.1007/s11214-012-9949-2

Kirov B, Asenovski S, Georgieva K, Obridko VN, Maris-Muntean G (2018) Forecasting the sunspot maximum through an analysis of geomagnetic activity. J Atmos Solar-Terrestrial Phys 176:42-50. https://doi.org/10.1016/j. jastp.2017.12.016

Kodera K, Kuroda Y (2002) Dynamical response to the solar cycle. J Geophys ResAtmos 107:4749. https://doi.org/10.1029/2002JD002224

Kong F-J, Qin G, Wu S-S, Zhang L-H, Wang H-N, Chen T, Sun P (2019) Study of time evolution of the bend-over energy in the energetic particle spectrum at a parallel shock. ApJ 877. https://doi.org/10.3847/1538-4357/ab1b33

Kong F-J, Qin G, Zhang L-H (2017) Numerical simulations of particle acceleration at interplanetary quasi-perpendicular shocks. ApJ 845:43. https://doi.org/10. 3847/1538-4357/aa7745

Kopp G, Lean JL (2011) A new, lower value of total solar irradiance: evidence and climate significance. Geophys Res Lett 38:L01706. https://doi.org/10.1029/ 2010GL045777

Kusano K, Iju T, Bamba Y, Inoue S (2020) A physics-based method that can predict imminent large solar flares. Science 369(6503):587-591. https://doi. org/10.1126/science.aaz2511

Lakhina GS, Tsurutani BT (2018) Supergeomagnetic storms: past, present, and future. In: Buzulukova N (ed) Extreme events in geospace. Origins, predictability, and consequences. Elsevier, Amsterdam

Lario D, Kwon R-Y, Vourlidas A, Raouafi NE, Haggerty DK, Ho GC, Anderson BJ, Papaioannou A, Gómez-Herrero R, Dresing N, Riley P (2016) Longitudinal properties of a widespread solar energetic particle event on 2014 February 25: evolution of the associated CME shock. ApJ 819(72):23. https://doi.org/10. 3847/0004-637X/819/1/72

Laskar Fl, Pallamraju D (2014) Does sudden stratospheric warming induce meridional circulation in the mesosphere thermosphere system? I Geophys Res Space Physics 119(12):10,133-10,143. https://doi.org/10.1002/2014JA020086

Laskar Fl, Pallamraju D, Veenadhari B (2014) Vertical coupling of atmospheres: dependence on strength of sudden stratospheric warming and solar activity. Earth Planets Space 66(1):94. https://doi.org/10.1186/1880-5981-66-94

Laštovička J (2013) Trends in the upper atmosphere and ionosphere: recent progress. J Geophys Res 118:3924-3935. https://doi.org/10.1002/jgra.50341

Laštovička J (2017) A review of recent progress in trends in the upper atmosphere. J Atmos Solar-Terrestrial Phys 163:2-13. https://doi.org/10.1016/j. jastp.2017.03.009
Laštovička J, Lübken F-J (2017) Preface to long-term trends in the upper atmosphere and ionosphere. J Atmos Solar-Terrestrial Phys 163:1. https://doi. org/10.1016/j.jastp.2017.09.020

Laštovička J, Akmaev RA, Beig G, Bremer J, Emmert JT (2006) Global change in the upper atmosphere. Science 314:1253-1254. https://doi.org/10.1126/ science.1135134

Laštovička J, Akmaev RA, Emmert JT (2009) Long-term changes and trends in the upper atmosphere - an introduction. J Atmos Solar-Terr Phys 71(14-15): 1511-1513. https://doi.org/10.1016/j.jastp.2009.06.007

Laštovička J, Solomon SC, Qian L (2012) Trends in the neutral and ionized upper atmosphere. Space Sci Rev 168:113-145. https://doi.org/10.1007/s11214-011-9799-3

Laštovička J, Beig G, Marsh DR (2014) Response of the mesospherethermosphere-ionosphere system to global change - CAWSES-II contribution. Prog Earth Planet Sci 1:21. https://doi.org/10.1186/s40645-014-0021-6

Lee CO, Luhmann JG, Odstrcil D, MacNeice PJ, de Pater I, Riley P, Arge CN (2009) The Solar Wind at $1 \mathrm{AU}$ during the declining phase of solar cycle 23: comparison of 3D numerical model results with observations. Sol Phys 254: 155-183. https://doi.org/10.1007/s11207-008-9280-y

Leka KD, Park S-H, Kusano K, Andries J, Barnes G, Bingham S, Bloomfield DS et al (2019) A comparison of flare forecasting methods. Il. Benchmarks, metrics, and performance results for operational solar flare forecasting systems. ApJ Supplement Series 243:36. https://doi.org/10.3847/1538-4365/ab2e12

Li W, Thorne RM, Ma Q, Ni B, Bortnik J, Baker DN, Spence HE, Reeves GD, Kanekal SG, Green JC, Kletzing CA, Kurth WS, Hospodarsky GB, Blake JB, Fennell JF, Claudepierre SG (2014) Radiation belt electron acceleration by chorus waves during the 17 March 2013 storm. J Geophys Res Space Physics 119(6):46814693. https://doi.org/10.1002/2014JA019945

Li X, Selesnick RS, Baker DN, Jaynes AN, Kanekal SG, Schiller Q, Blum L, Fennell J, Blake JB (2015) Upper limit on the inner radiation belt MeV electron intensity. J Geophys Res Space Physics 120(2):1215-1228. https://doi.org/10. 1002/2014JA020777

Liu H (2016) Thermospheric inter-annual variability and its potential connection to ENSO and stratospheric QBO. Earth Planet Sp 68:77. https://doi.org/10. 1186/s40623-016-0455-8

Liu HL, Bardeen CG, Foster BT, Lauritzen PH, Liu J, Lu G, Marsh DR, Maute A, Mclnerney JM, Pedatella NM, Qian L, Richmond AD, Roble RG, Solomon SC, Vitt FM, Wang W (2018) Development and validation of the Whole Atmosphere Community Climate Model With Thermosphere and Ionosphere Extension (WACCM-X 2.0). J Adv Model Earth Syst 10:381-402. https://doi. org/10.1002/2017MS001232

Lu G, Richmond AD, Lühr H, Paxton L (2016) High-latitude energy input and its impact on the thermosphere. J Geophys Res Space Phys 121:7108-7124. https://doi.org/10.1002/2015JA022294

Lu H, Scaife AA, Marshall GJ, Turner J, Gray L (2017) Downward wave reflection as a mechanism for the stratosphere-troposphere response to the 11-Yr solar cycle. J Clim 30:2395-2414. https://doi.org/10.1175/JCLI-D-16-0400.1

Lübken F-J, Berger U, Baumgarten G (2018) On the anthro-pogenic impact on long-term evolu-tion of noctilucent clouds. Geophys Res Lett 45:6681-6689 https://doi-org.ejgw.nul.nagoya-u.ac.jp/10.1029/2018GL077719

Macalalad EP, Tsai LC, Wu J (2014) Performance evaluation of different ionospheric models in single-frequency code-based differential gps positioning. GPS Solutions. https://doi.org/10.1007/s10291-014-0422-4

Maehara H, Shibayama T, Notsu S, Notsu Y, Nagao T, Kusaba S, Honda S, Nogami D, Shibata K (2012) Superflares on solar-type stars. Nature 485(7399):478-481. https://doi.org/10.1038/nature11063

Maliniemi V, Asikainen T, Mursula K (2014) Spatial distribution of Northern Hemisphere winter temperatures during different phases of the solar cycle. $J$ Geophys Res Atmos 119. https://doi.org/10.1002/2013JD021343

Maliniemi V, Asikainen T, Mursula K (2016) Effect of geomagnetic activity on the northern annular mode: QBO dependence and the holton-tan relationship. J Geophys Res Atmos 121. https://doi.org/10.1002/2015JD024460

Marsh DR, Mills MJ, Kinnison DE, Lamarque J-F, Calvo N, Polvani LM (2013) Climate change from 1850 to 2005 simulated in CESM1(WACCM). J Climate 26(19):7372-7391. https://doi.org/10.1175/JCLI-D-12-00558.1

Martinez-Calderon C, Katoh Y, Manninen J, Kasahara Y, Matsuda S, Kumamoto A, Tsuchiya F, Matsuoka A, Shoji M, Teramoto M, Shinohara I, Shiokawa K, Miyoshi Y (2019) Conjugate observations of dayside and nightside VLF chorus and QP emissions between Arase (ERG) and Kannuslehto, Finland. J Geophys Res 124. https://doi.org/10.1029/2019JA026663

Martinez-Calderon C, Shiokawa K, Miyoshi Y, Ozaki M, Schofield I, Connors M (2015a) Polarization analysis of VLF/ELF waves observed at subauroral 
latitudes during the VLF-CHAIN campaign. Earth Planets Space 67:21. https:// doi.org/10.1186/s40623-014-0178-7

Martinez-Calderon C, Shiokawa K, Miyoshi Y, Ozaki M, Schofield I, Connors M (2015b) Statistical study of ELF/NLF emissions at subauroral latitudes in Athabasca, Canada. J Geophys Res Space Phys 120:8455-8469. https://doi. org/10.1002/2015JA021347

Martinez-Calderon C et al (2016) ELFNLF wave propagation at subauroral latitudes: conjugate observation between the ground and Van Allen Probes A. J Geophys Res Space Phys 121:5384-5393. https://doi.org/10.1002/2015JA022264

Matthes K, Funke B, Andersson ME, Barnard L, Beer J, Charbonneau P, Clilverd MA, de Wit TD, Haberreiter M, Hendry A, Jackman CH, Kretzschmar M, Kruschke T, Kunze M, Langematz U, Marsh DR, Maycock AC, Misios S, Rodger CJ, Scaife AA, Seppala A, Shangguan M, Sinnhuber M, Tourpali K, Usoskin I, De Kamp MV, Verronen PT, Versick S (2017) Solar forcing for CMIP6 (v3.2). Geosci Model Dev 10:2247-2302. https://doi.org/10.5194/gmd-10-2247-2017

McCormick JC, Cohen MB, Gross NC, Said RK (2018) Spatial and temporal ionospheric monitoring using broadband sferic measurements. J Geophys Res Space Physics 123:3111-3130. https://doi.org/10.1002/2017JA024291

McGranaghan R et al (2015a) A fast, parameterized model of upper atmospheric ionization rates, chemistry, and conductivity. J Geophys Res Space Physics. https://doi.org/10.1002/2015JA021146,2015JA021146.

McGranaghan R et al (2015b) Modes of high-latitude auroral conductance variability derived from DMSP energetic electron precipitation observations: empirical orthogonal function analysis. J Geophys Res Space Physics. https:// doi.org/10.1002/2015JA021828,2015JA021828

McGranaghan R et al (2016a) High-latitude ionospheric conductivity variability in three dimensions. Geophys Res Lett 43:7867-7877. https://doi.org/10.1002/ 2016GL070253

McGranaghan R et al (2016b) Optimal interpolation analysis of high-latitude ionospheric Hall and Pedersen conductivities: application to assimilative ionospheric electrodynamics reconstruction. J Geophys Res Space Physics 121:4898-4923. https://doi.org/10.1002/2016JA022486

Meehl GA, Arblaster JM, Branstator G, van Loon H (2008) A coupled air-sea response mechanism to solar forcing in the pacific region. J Clim 21:28832897. https://doi.org/10.1175/2007JCLI1776.1

Mewaldt R, Cohen C, Mason G, von Rosenvinge T, Li G, Smith CW, Vourlidas A (2015) An investigation of the causes of solar-cycle variations in SEP fluences and composition. 34(July):30 Available at http.//adsabs.harvard.edw/abs/2015ICRC..34...30M

Misios S, Mitchell DM, Gray L, Tourpali K, Matthes K, Hood L, Schmidt H, Chiodo G, Thieblemont R, Rozanov E, Shindell D, Krivolutsky A (2015) Solar signals in CMIP-5 simulations: effects of atmosphere-ocean coupling. Q J R Meteorol Soc. https://doi.org/10.1002/qj.2695

Misios S, Gray L, Knudsen MD, Karoff C, Schmidt H, Haigh JD (2019) Slowdown of the Walker circulation at solar cycle maximum. Proc Natl Acad Sci 116(15): 7186-7191. https://doi.org/10.1073/pnas.1815060116

Mitchell DM, Misios S, Gray L, Tourpali K, Matthes K, Hood L, Schmidt H, Chiodo G, Thiéblemont R, Rozanov E, Shindell D, Krivolutsky A (2015) Solar signals in CMIP-5 simulations: the stratospheric pathway: solar signals in CMIP-5. Q J R Meteorol Soc 141:2390-2403. https://doi.org/10.1002/qj.2530

Miyahara H, Kataoka R, Mikami T, Zaiki M, Hirano J, Yoshimura M, Aono Y, Iwahashi K (2018) Solar rotational cycle in lightning activity in Japan during the 18-19th centuries. Ann Geophys 36:633-640. https://doi.org/10.5194/angeo-36-633-2018

Miyoshi Y, Shinohara I, Takashima T, Asamura K, Higashio N, Mitani T, Kasahara S, Yokota S, Kazama Y, Wang S-Y, Tam SWY, Ho PTP, Kasahara Y, Kasaba Y, Yagitani S, Matsuoka A, Kojima H, Katoh Y, Shiokawa K, Seki K (2018) Geospace exploration project ERG. Earth Planets Space 70(1):101. https://doi. org/10.1186/s40623-018-0862-0

Miyoshi Y, Yigit E (2019) Impact of gravity wave drag on the thermospheric circulation: implementation of a nonlinear gravity wave parameterization in a whole-atmosphere model. Ann Geophys 37:955-969. https://doi.org/10.5194/ angeo-37-955-2019

Moral AC, Shiokawa K, Suzuki S, Liu H, Otsuka Y, Yatini CY (2019) Observations of low-latitude traveling ionospheric disturbances by a 630.0-nm airglow imager and the CHAMP satellite over Indonesia. J Geophys Res Space Physics 124. https://doi.org/10.1029/2018JA025634

Möstl C, Rollett T, Frahm RA, Liu YD, Long DM, Colaninno RC, Reiss MA et al (2015) Strong coronal channelling and interplanetary evolution of a solar storm up to Earth and Mars. Nat Commun 6(May):7135. https://doi.org/10.1038/ncomms8135

Nandy D, Martens PCH, Obridko V, Dash S, Georgieva K (2021) Solar evolution and extrema: current state of understanding. Progress in Earth and Planetary Science (this issue)
Narayanan VL, Shiokawa K, Otsuka Y, Neudegg D (2018) On the role of thermospheric winds and sporadic $\mathrm{E}$ layers in the formation and evolution of electrified MSTIDs in geomagnetic conjugate regions. I Geophys Res-Space Phys 123:6957-6980. https://doi.org/10.1029/2018JA025261

Nelson NJ (2013) Magnetic cycles and buoyant loops in convective dynamos. AAS Meeting \#221, id.415.01

Nelson NJ, Brown BP, Brun AS, Miesch MS, Toomre J (2011) Buoyant Magnetic Loops in a global dynamo simulation of a young sun. Astrophys J Lett 739: L38. https://doi.org/10.1088/2041-8205/739/2/L38

Nelson NJ, Brown BP, Brun AS, Miesch MS, Toomre J (2013) Magnetic wreaths and cycles in convective dynamos. Astrophys J 762:73. https://doi.org/10. 1088/0004-637X/762/2/73

Nishimura Y, Bortnik J, Li W, Liang J, Thorne RM, Angelopoulos V, Le Contel O, Auster U, Bonnell JW (2015) Chorus intensity modulation driven by timevarying field-aligned low-energy plasma. J Geophys Res 120:7433-7446

Nishioka M, Saito A, Tsugawa T (2008) Occurrence characteristics of plasma bubble derived from global ground-based GPS receiver networks. I Geophys Res 113:A05301. https://doi.org/10.1029/2007JA012605

Oberheide J, Shiokawa K, Gurubaran S, Ward WE, Fujiwara H, Kosch MJ, Makela JJ, Takahashi H (2015) The geospace response to variable inputs from the lower atmosphere: a review of the progress made by Task Group 4 of CAWSES-II. Prog Earth Planet Sci 2:2. https://doi.org/10.1186/s40645-014-0031-4

Obridko V, Georgieva K (2018) Solar activity in the following decades. J Atmos Solar-Terrestrial Phys 176:1-4. https://doi.org/10.1016/j.jastp.2018.08.001

Otsuka Y (2018) Review of the generation mechanisms of post-midnight irregularities in the equatorial and low-latitude ionosphere. Prog Earth Planet Sci 5:57. https://doi.org/10.1186/s40645-018-0212-7

Otsuka Y, Shiokawa K, Ogawa T, Wilkinson P (2004) Geomagnetic conjugate observations of medium-scale traveling ionospheric disturbances at midlatitude using all-sky airglow imagers. Geophys Res Lett 31:L15803. https://doi.org/10.1029/2004GL020262

Ozaki M, Miyoshi Y, Shiokawa K, Hosokawa K, Oyama S-1, Kataoka R, Ebihara Y, Ogawa Y, Kasahara Y, Yagitani S, Kasaba Y, Kumamoto A, Tsuchiya F, Matsuda S, Katoh Y, Hikishima M, Kurita S, Otsuka Y, Moore RC, Tanaka Y, Nosé M, Nagatsuma T, Nishitani N, Kadokura A, Connors M, Inoue T, Matsuoka A, Shinohara I (2019) Visualization of rapid electron precipitation via chorus element wave-particle interactions. Nat Commnun 10:257. https:/doi.org/10.1038/s41467-018-07996-z

Pal S, Gopalswamy N, Nandy D, Akiyama S, Yashiro S, Makela P, Xie H (2017) A Sun-to-Earth analysis of magnetic helicity of the 2013 March 17-18 interplanetary coronal mass ejection. Astrophys J 851(2):123

Pal S, Nandy D, Srivastava N, Gopalswamy N, Panda S (2018) Dependence of coronal mass ejection properties on their solar source active region characteristics and associated flare reconnection flux. Astrophys J 865(1):4

Pala Z, Atici R (2019) Forecasting sunspot time series using deep learning methods. Sol Phys 294(5):50. https://doi.org/10.1007/s11207-019-1434-6

Palmerio E, Kilpua EKJ, James AW, Green LM, Pomoell J, Isavnin A, Valori G (2017) Determining the intrinsic CME flux rope type using remote-sensing solar disk observations. Sol Phys 292(February):39. https://doi.org/10.1007/s11207-017-1063-x

Park S-H, Leka KD, Kusano K, Andries J, Barnes G, Bingham S, Bloomfield DS et al. (2020) A comparison of flare forecasting methods. IV. Evaluating Consecutive-Day Forecasting Patterns. ArXiv:2001.02808 [Astro-Ph], January. Available at http://arxiv.org/abs/2001.02808.

Patsourakos S, Georgoulis MK, Vourlidas A, Nindos A, Sarris T, Anagnostopoulos G, Anastasiadis A, Chintzoglou G, Daglis IA, Gontikakis C, Hatzigeorgiu N, Iliopoulos AC, Katsavrias C, Kouloumvakos A, Moraitis K, Nieves-Chinchilla T, Pavlos G, Sarafopoulos D, Syntelis P, Tsironis C, Tziotziou K, Vogiatzis II, Balasis G, Georgiou M, Karakatsanis LP, Malandraki OE, Papadimitriou C, Odstrči DE, Pavlos G, Podlachikova O, Sandberg I et al (2016) The major geoeffective solar eruptions of 2012 March 7: comprehensive Sun-to-Earth analysis. Astrophys J 817(1):14. https://doi.org/10.3847/0004-637X/817/1/14

Pedatella NM, Liu H-L (2018) The influence of internal atmospheric variability on the ionosphere response to a geo-magnetic storm. Geophys Res Lett 45:4578-4585 https://doi-org.ejgw.nul.nagoya-u.ac. jp/10.1029/2018GL077867

Pesnell WD (2012) Solar cycle predictions. Sol Phys 281:507-532. https://doi.org/ 10.1007/s11207-012-9997-5

Petrovay K (2020) Solar cycle prediction. Living Rev Sol Phys 17:2. https://doi.org/ 10.1007/s41116-020-0022-z

Petrovay K, Nagy M, Gerják T, Juhász L (2018) Precursors of an upcoming solar cycle at high latitudes from coronal green line data. J Atmos Solar-Terrestrial Phys 176:15-20. https://doi.org/10.1016/j.jastp.2017.12.011 
Piša D, Hospodarsky GB, Kurth WS, Santolík O, Souček J, Gurnett DA, Masters A, Hill ME (2015) Statistics of Langmuir wave amplitudes observed inside Saturn's foreshock by the Cassini spacecraft. J Geophys Res Space Physics 120. https://doi.org/10.1002/2014JA020560

Piša D, Santolík O, Hospodarsky GB, Kurth WS, Gurnett DA, Souček J (2016) Spatial distribution of Langmuir waves observed upstream of Saturn's bow shock by Cassini. J Geophys Res Space Physics 121. https://doi.org/10.1002/ 2016JA022912

Pomoell J, Poedts S (2018) EUHFORIA: European heliospheric forecasting information asset. J Space Weather Space Climate 8:A35. https://doi.org/10. $1051 /$ swsc/2018020

Popova E, Zharkova V, Shepherd S, Zharkov S (2018) On a role of quadruple component of magnetic field in defining solar activity in grand cycles. J Atmos Solar-Terrestrial Phys 176:61-68. https://doi.org/10.1016/j.jastp.2017.05. 006

Qian L, Laštovička J, Solomon SC, Roble RG (2011) Progress in observations and simulations of global change in the upper atmosphere. J Geophys Res 116: A00H03. https://doi.org/10.1029/2010JA016317

Qiu J, Hu Q, Howard TA, Yurchyshyn VB (2007) On the magnetic flux budget in low-corona magnetic reconnection and interplanetary coronal mass ejections. Astrophys J 659(1):758-772. https://doi.org/10.1086/512060

Reames DV (2015) What are the sources of solar energetic particles? Element abundances and source plasma temperatures. Space Sci Rev 194:303-327. https://doi.org/10.1007/s11214-015-0210-7

Reeves GD, Friedel RHW, Larsen BA, Skoug RM, Funsten HO, Claudepierre SG, Fennell JF, Turner DL, Denton MH, Spence HE, Blake JB, Baker DN (2016) Energy-dependent dynamics of keV to MeV electrons in the inner zone, outer zone, and slot regions. J Geophys Res-Space Phys 121:397-412. https:// doi.org/10.1002/2015JA021569

Riley P, Caplan RM, Giacalone J, Lario D, Liu Y (2016) Properties of the fast forward shock driven by the 2012 July 23 extreme coronal mass ejection. Astrophys J 819:57. https://doi.org/10.3847/0004-37X/819/1/57

Rotter T, Veronig AM, Temmer M, Vršnak B (2012) Relation between coronal hole areas on the sun and the solar wind parameters at 1 AU. Sol Phys 281:793813. https://doi.org/10.1007/s11207-012-0101-y.

Rozanov E, Calisto M, Egorova T, Peter T, Schmutz W (2012) Influence of the precipitating energetic particles on atmospheric chemistry and climate. Surv Geophys 33(3-4):483-501. https://doi.org/10.1007/s10712-012-9192-0

Sabarinath A, Anilkumar AK (2018) Sunspot cycle prediction using multivariate regression and binary mixture of Laplace distribution model. J Earth System Sci 127, 84(6). https://doi.org/10.1007/s12040-018-0987-3

Sarp V, Kilcik A, Yurchyshyn V, Rozelot J-P, Ozguc A (2018) Prediction of solar cycle 25: a non-linear approach. Mon Not R Astron Soc 481(3):2981. https:// doi.org/10.1093/mnras/sty2470

Sato K, Tsutsumi M, Sato T, Nakamura T, Saito A, Tomikawa Y, Nishimura K, Kohma M, Yamagishi H, Yamanouchi T (2014) Program of the Antarctic Syowa MST/IS radar (PANSY). J Atmos Solar-Terrestrial Phys 118:2-15. https:// doi.org/10.1016/j.jastp.2013.08.022

Schaefer BE, King JR, Deliyannis CP (2000) Superflares on ordinary solar-type stars. ApJ 529(2):1026-1030. https://doi.org/10.1086/308325

Schmieder B (2018) Extreme solar storms based on solar magnetic field. J Atm Solar-Terr Phys 180:46-51. https://doi.org/10.1016/j.jastp.2017.07.018

Schmieder B, Vincent B, Baumjohann W, Ono T, Basu S, Lean J (2004) Climate and weather of the Sun-Earth system: CAWSES. Adv Space Res 34(2):443-448. https://doi.org/10.1016/.asr.2003.12.010

Scolini C, Rodriguez L, Mierla M, Pomoell J, Poedts S (2019) Observation-based modelling of magnetised coronal mass ejections with EUHFORIA. Astron Astrophys 626(June):A122. https://doi.org/10.1051/0004-6361/201935053

Seif A, Liu J-Y, Mannucci AJ, Carter BA, Norman R, Caton RG, Tsunoda RT (2017) A study of daytime L-band scintillation in association with sporadic E along the magnetic dip equator. Radio Sci 52. https://doi.org/10.1002/2017RS006393

Seif A, Liu J-Y, Mannucci AJ, Carter BA, Norman R, Caton RG, Tsunoda RT (2018) Equatorial ionospheric scintillation during daytime. Eos 99. https://doi.org/10. 1029/2018EO106297

Seif A, Tsunoda RT, Abdullah M, Hasbi AM (2015) Daytime gigahertz scintillations near magnetic equator: relationship to blanketing sporadic $E$ and gradientdrift instability. Earth Planets Space J 67(177):1-13. https://doi.org/10.1186/ s40623-015-0348-2.67:177

Seki K, Miyoshi Y, Ebihara Y et al (2018) Theory, modeling, and integrated studies in the Arase (ERG) project. Earth Planets Space 70:17. https://doi.org/10.1186/ s40623-018-0785-9
Seppälä A, Matthes K, Randall CE, Mironova IA (2014) What is the solar influence on climate? Overview of activities during CAWSES-II. Prog Earth Planet Sci 1. article id.24. https://doi.org/10.1186/s40645-014-0024-3

Share GH, Murphy RJ, White SM, Tolbert AK, Dennis BR, Schwartz RA, Smart DF, Shea MA (2018) Characteristics of late-phase > $100 \mathrm{MeV}$ gamma-ray emission in solar eruptive events. ApJ 869:182. https://doi.org/10.3847/1538-4357/ aaebf7

She C-Y, Krueger DA, Yuan T (2015) Long-term midlatitude mesopause region temperature trend deduced from quarter century (1990-2014) Na lidar observations. Ann Geophys 33:363-369 www.ann-geophys.net/33/363/2015/

Shen F, Feng XS, Wu ST, Xiang CQ, Song WB (2011) Three-dimensional MHD simulation of the evolution of the April 2000 CME event and its induced shocks using a magnetized plasma blob model. J Geophys Res 116(A4). CitelD A04102. https://doi.org/10.1029/2011JA016584

Shen C, Chi Y, Wang Y, Xu M, Wang S (2017) Statistical comparison of the ICME's geoeffectiveness of different types and different solar phases from 1995 to 2014. J Geophys Res 122:5931-5948

Shen C, Mengjiao X, Wang Y, Chi Y, Luo B (2018) Why the Shock-ICME complex structure is important: learning from the early 2017 September CMEs. Astrophys J $861(9 \mathrm{pp}): 28$

Shen F, Shen C, Zhang J, Hess P, Wang Y, Feng X, Cheng H, Yang Y (2014) Evolution of the 12 July 2012 CME from the Sun to the Earth: dataconstrained three-dimensional MHD simulations. J Geophys Res 119:71287141. https://doi.org/10.1002/2014JA020365.

Shinagawa H, Jin H, Miyoshi Y, Fujiwara H, Yokoyama T, Otsuka Y (2018) Daily and seasonal variations in the linear growth rate of the Rayleigh-Taylor instability in the ionosphere obtained with GAIA. Prog Earth Planet Sci 5:16. https://doi.org/10.1186/s40645-018-0175-8

Shinagawa H, Miyoshi Y, Jin H, Fujiwara H (2017) Global distribution of neutral wind shear associated with sporadic E layers derived from GAIA.J Geophys Res Space Physics 122:4450-4465. https://doi.org/10.1002/2016JA023778.

Shiokawa K, Lu G, Otsuka Y, Ogawa T, Yamamoto M, Nishitani N, Sato N (2007) Ground observation and AMIETIEGCM modeling of a storm-time traveling ionospheric disturbance. J Geophys Res 112:A05308. https://doi.org/10.1029/ 2006JA011772.

Shiokawa K, Katoh Y, Hamaguchi Y, etal, (2017) Ground-based instruments of the PWING project to investigate dynamics of the inner magnetosphere at subauroral latitudes as a part of the ERG-ground coordinated observation network. Earth Planets Space 69:160. https://doi.org/10.1186/s40623-017$0745-9$

Shirokov EA (2018) Application of the method of moments for calculating electrodynamic characteristics of a quasistatic antenna in an anisotropic medium. Radiophys Quantum Electron 61(5):350-361. https://doi.org/10. 1007/s11141-018-9896-1

Shirokov EA, Demekhov AG, Chugunov YV, Larchenko AV (2017) Effective length of a receiving antenna in case of quasi-electrostatic whistler mode waves: application to spacecraft observations of chorus emissions. Radio Sci 52(7): 884-895. https://doi.org/10.1002/2016RS006235

Sindhuja G, Gopalswamy N (2020) A study of the observational properties of coronal mass ejection flux ropes near the Sun, Research Gate. https://doi.org/ 10.13140/RG.2.2.28853.42725

Solomon SC, Liu HL, Marsh DR, McInerney JM, Qian L, Vitt FM (2019) Whole atmosphere climatechange: dependence on solar activity. J Geophys Res Space Physics 124:3799-3809. https://doi.org/10.1029/2019JA026678

Stober G, Chau JL (2015) A multistatic and multifrequency novel approach for specular meteor radars to improve wind measurements in the MLT region. Radio Sci:431-442. https://doi.org/10.1002/2014RS005591

Stober G, Chau JL, Vierinen J, Jacobi C, Wilhelm S (2018) Retrieving horizontally resolved wind fields using multi-static meteor radar observations. Atmos Meas Tech Discuss 11:4891-4907. https://doi.org/10.5194/amt-11-4891-2018

Stober G, Matthias V, Brown P, Chau JL (2014) Neutral density variation from specular meteor echo observations spanning one solar cycle. Geophys Res Lett 41:6919-6925. https://doi.org/10.1002/2014GL061273

Svalgaard L, Cliver EW (2007) Long-term geomagnetic indices and their use in inferring solar wind parameters in the past. Adv Space Res 40:1112-1120. https://doi.org/10.1016/j.asr.2007.06.066.

Takeo D, Shiokawa K, Fujinami H, Otsuka Y, Matsuda TS, Ejiri MK, Nakamura T, Yamamoto M (2017) Sixteen year variation of horizontal phase velocity and propagation direction of mesospheric and thermospheric waves in airglow images at Shigaraki. Japan. J Geophys Res Space Phys 122(8):8770-8780. https://doi.org/10.1002/2017JA023919 
Temmer M, Hinterreiter J, Reiss MA (2018) Coronal hole evolution from multiviewpoint data as input for a STEREO solar wind speed persistence model. J Space Weather Space Climate 8:A18. https://doi.org/10.1051/swsc/2018007

Temmer M, Thalmann JK, Dissauer K, Veronig AM, Tschernitz J, Hinterreiter J, Rodriguez L (2017) On flare-CME characteristics from Sun to Earth combining remote-densing image data with in situ measurements supported by modeling. Sol Phys 93. https://doi.org/10.1007/s11207-017-1112-5

Teramoto M, Hori T, Saito S, Miyoshi Y, Kurita S, Higashio N, Matsuoka A, Kasahara Y, Kasaba Y, Takashima T, Nomura R, Nosé M, Fujimoto A, Tanaka Y-M, Shoji M, Tsugawa Y, Shinohara M, Shinohara I, Blake JB, Fennell JF, Claudepierre SG, Turner DL, Kletzing CA, Sormakov D, Troshichev O (2019) Remote detection of drift resonance between energetic electrons and ultralow frequency waves: multisatellite coordinated observation by Arase and Van Allen probes. Geophys Res Lett. https://doi.org/10.1029/2019GL084379

Thalmann JK, Veronig A, Su Y (2016) Temporal and spatial relationship of flare signatures and the force-free coronal magnetic field. Astrophys J 826:143

Thiéblemont R, Matthes K, Omrani N-E, Kodera K, Hansen F (2015) Solar forcing synchronizes decadal North Atlantic climate variability. Nat Commun 6:8268. https://doi.org/10.1038/ncomms9268

Thomas N, Shiokawa K, Vichare G (2019) Comprehensive study of low-latitude Pi2 pulsations using observations from multi-satellite Swarm mission and global network of ground observatories. J Geophys Res 124. https://doi.org/10.1029/ 2018JA026094

Thomas N, Vichare G, Sinha AK (2016) Spatial frequencies associated with the latitudinal structures of ionospheric currents seen by CHAMP satellite. Astrophys Space Sci 361:205. https://doi.org/10.1007/s10509-016-2787-z

Thomas N, Vichare G, Sinha AK, Rawat R (2015) Low-latitude Pi2 oscillations observed by polar low earth orbiting satellite. J Geophys Res Space Physics 120. https://doi.org/10.1002/2014JA020958.

Toriumi S, Wang H (2019) Flare-productive active regions. Living Rev Solar Phys 6(1):3. https://doi.org/10.1007/s41116-019-0019-7

Toriumi S, lida Y, Kusano K, Bamba Y, Imada S (2014) Formation of a flareproductive active region: observation and numerical simulation of NOAA AR 11158. Sol Phys 289(9):3351-3369. https://doi.org/10.1007/s11207-014-0502-1

Toriumi S, Takasao S (2017) Numerical simulations of flare-productive active regions: $\delta$-sunspots, sheared polarity inversion lines, energy storage, and predictions. Astrophys J 850:39. https://doi.org/10.3847/1538-4357/aa95c2

Trinh QT, Ern M, Doornbos E, Preusse P, Riese M (2018) Satellite observations of middle atmosphere-thermosphere vertical coupling by gravity waves. Ann Geophys 36(2):425-444. https://doi.org/10.5194/angeo-36-425-2018

Trinh QT, Kalisch S, Preusse P, Chun H-Y, Eckermann SD, Ern M, Riese M (2015) A comprehensive observational filter for satellite infrared limb sounding of gravity waves. Atmos Meas Tech 8(3):1491-1517. https://doi.org/10.5194/amt8-1491-2015

Trinh QT, Kalisch S, Preusse P, Ern M, Chun H-Y, Eckermann SD, Kang M-J, Riese M (2016) Tuning of a convective gravity wave source scheme based on HIRDLS ob- servations. Atmos Chem Phys 16(11):7335-7356. https://doi.org/10.5194/ acp-16-7335-2016

Tschernitz J, Veronig AM, Thalmann JK, Hinterreiter J, Pötzi W (2018) Reconnection fluxes in eruptive and confined flares and implications for superflares on the sun. Astrophys J 853(1):41. https://doi.org/10.3847/15384357/aaa199.

Tsuchiya S, Shiokawa K, Fujinami H, Otsuka Y, Nakamura T, Connors M, Schofield I, Shevtsov B, Poddelsky I (2019a) Three-dimensional fourier analysis of the phase velocity distributions of mesospheric and ionospheric waves based on airglow images collected over 10 years: comparison of Magadan, Russia, and Athabasca. Canada. J Geophys Res Space Phys 124(10):8110-8124. https://doi. org/10.1029/2019JA026783

Tsuchiya S, Shiokawa K, Otsuka Y, Nakamura T, Yamamoto M, Connors M, Schofield I, Shevtsov B, Poddelsky I (2019b) Wavenumber spectra of atmospheric gravity waves and medium-scale traveling ionospheric disturbances based on more than 10-year airglow images in Japan, Russia, and Canada. J Geophys Res Space Phys 125(3):e26807. https://doi.org/10. 1029/2019JA026807

Tsuda T, Fujii R, Shibata K, Geller MA (eds) (2009) Climate and Weather of the Sun-Earth System (CAWSES) selected papers from the 2007 Kyoto Symposium. TERRAPUB, 2009, Tokyo

Tsuda T, Shepherd M, Gopalswamy N (2015) Advancing the understanding of the Sun-Earth interaction - the Climate and Weather of the Sun-Earth System (CAWSES) II program. Prog Earth Planet Sci 2(1):28. https://doi.org/10.1186/ s40645-015-0059-0
Tsugawa T, Nishioka M, Ishii M, Hozumi K, Saito S, Shinbori A, Otsuka Y, Saito A, Buhari SM, Abdullah M, Supnithi P (2018) Total electron content observations by dense regional and worldwide international networks of GNSS. J Disaster Res 13:535-545. https://doi.org/10.20965/jdr.2018.p0535

Tsugawa T, Saito A, Otsuka Y, Nishioka M, Maruyama T, Kato H et al (2011) lonospheric disturbances detected by GPS total electron content observation after the 2011 off the Pacific coast of Tohoku earthquake. Earth Planets Space 63:875-879. https://doi.org/10.5047/eps.2011.06.035

Tsurutani BT, Gonzalez WD, Lakhina GS, Alex S (2003) The extreme magnetic storm of 1-2 September 1859. J Geophys Res 108:1268. https://doi.org/10. 1029/2002JA009504

Tsurutani BT, Lakhina GS (2014) An extreme coronal mass ejection and consequences for the magnetosphere and Earth. Geophys Res Lett 41:287292. https://doi.org/10.1002/2013GL058825

Tulasi Ram S, Yokoyama T, Otsuka Y, Shiokawa K, Sripathi S, Veenadhari B, Heelis R, Ajith KK, Gowtam VS, Gurubaran S, Supnithi P, Le Huy M (2015) Duskside enhancement of equatorial zonal electric field response to convection electric fields during the St. Patrick's Day storm on 17 March 2015. J Geophys Res Space Physics 120. https://doi.org/10.1002/2015JA021932

Turunen E, Kero A, Verronen PT, Miyoshi Y, Oyama SI, Saito S (2016) Mesospheric ozone destruction by high-energy electron precipitation associated with pulsating aurora. J Geophys Res Atmos 121:11,852-11,861. https://doi.org/10. 1002/2016JD025015

Turunen E, Verronen PT, Seppälä A, Rodger CJ, Clilverd MA, Tamminen J, Enell CF, Ulich T (2009) Impact of different precipitation energies on NOx generation during geomagnetic storms. J Atmos Sol Terr Phys 71:1176-1189. https://doi.org/10.1016/j.jastp.2008.07.005

Tziotziou K, Georgoulis MK, Raouafi N-E (2012) The magnetic energy-helicity diagram of solar active regions. Astrophys J Lett 759:L4. https://doi.org/10. 1088/2041-8205/759/1/L4

Upton LA, Hathaway DH (2018) An updated solar cycle 25 prediction with AFT: the modern minimum. Geophys Res Lett 45:8091-8095. https://doi.org/10. 1029/2018GL078387

Usoskin IG (2018) Comment on the paper by Popova et al. On a role of quadruple component of magnetic field in defining solar activity in grand cycles. J Atmos Solar-Terrestrial Phys 176:69-71. https://doi.org/10.1016/j. jastp.2017.09.018

Vadas SL, Becker E (2019) Numerical modeling of the generation of tertiary gravity waves in the mesosphere and thermosphere during strong mountain wave events over the Southern Andes. J Geophys Res-Space Phys 124:76877718. https://doi.org/10.1029/2019JA026694

Vadas SL, Crowley G (2010) Source of the traveling ionospheric disturbances observed by the ionospheric TIDDBIT sounder near Wallops Island on 30 October 2007. J Geophys Res 115:A07324. https:/doi.org/10.1029/2009JA015053

Vadas SL, Xu S, Yue J, Bossert K, Becker E, Baumgarten G (2019) Characteristics of the quiet-time hot spot gravity waves observed by GOCE over the Southern Andes on 5 July 2010. J Geophys Res-Space Phys 124:7034-7061. https://doi. org/10.1029/2019JA026693

van de Kamp M, Seppälä A, Clilverd MA, Rodger CJ, Verronen PT, Whittaker IC (2016) A model providing long-term data sets of energetic electron precipitation during geomagnetic storms. J Geophys Res Atmos 121:12,52012,540. https://doi.org/10.1002/2015JD024212

Vourlidas A, Patsourakos S, Savani NP (2019) Predicting the geoeffective properties of coronal mass ejections: current status, open issues and path forward. Philos Trans R Soc A 377(2148):20180096. https://doi.org/10.1098/ rsta.2018.0096

Vršnak B, Temmer M, Veronig AM (2007) Coronal holes and solar wind highspeed streams: II. forecasting the geomagnetic effects. Sol Phys 240:331-346. https://doi.org/10.1007/s11207-007-0311-X.

Wang Y, Zhuang B, Hu Q, Liu R, Shen C, Chi Y (2016) On the twists of interplanetary magnetic flux ropes observed at $1 \mathrm{AU}$. J Geophys Res Space Physics 121:9316-9339. https://doi.org/10.1002/2016JA023075.

Ward W, Seppälä A, Erdal Yigit3, Nakamura T, Stolle C, Laštovička J, Woods TN, Tomikawa Y (2021) Role of the sun and the middle atmosphere/ thermosphere/ionosphere in climate (ROSMIC): a retrospective and prospective view. Progress in Earth and Planetary Science (this issue)

Watanabe T, lyemori T, Shiokawa K, Zhang J, Kanekal SG, Nishitani N (2017) Special issue "Global data systems for the study of solar-terrestrial variability.". Earth Planets Space 69(1):155. https://doi.org/10.1186/s40623-017-0742-z

Webb D, Nitta N (2017) Understanding problem forecasts of ISEST campaign flare-CME events. Sol Phys 292:142. https://doi.org/10.1007/s11207-017-1166-4 
Wenzel D, Jakowski N, Berdermann J, Mayer C, Valladares C, Heber B (2016) Global ionospheric flare detection system (GIFDS). J Atm Sol-Terr Phys 138139:233-242. https://doi.org/10.1016/j.jastp.2015.12.011

Werner R, Guineva V (2020) Forecasting sunspot number for solar cycle 25 using autoregressive model for both hemispheres of the Sun. C R Acad Bulg Sci 73:82-82. https://doi.org/10.7546/CRABS.2020.01.10

Wijsen N, Aran A, Pomoell J, Poedts S (2019) Modelling three-dimensional transport of solar energetic protons in a corotating interaction region generated with EUHFORIA. A\&A 622:A28. https://doi.org/10.1051/0004-6361/201833958

Wiltberger M, Rigler EJ, Merkin V, Lyon JG (2017) Structure of high latitude currents in magnetosphere-ionosphere models. Space Sci Rev 206:575-598. https://doi.org/10.1007/s11214-016-0271-2

Wood BE, Wu C-C, Lepping RP, Nieves-Chinchilla T, Howard RA, Linton MG, Socker DG (2017) A STEREO survey of magnetic cloud coronal mass ejections observed at Earth in 2008-2012. Astrophys J Suppl 229(2):29. https://doi.org/ 10.3847/1538-4365/229/2/29

Woods TN, Caspi A, Chamberlin PC, Jones A, Kohnert R, Mason JP, Moore CS, Palo S, Rouleau C, Solomon SC, Machol J, Viereck R (2017) New solar irradiance measurements from the miniature X-ray solar spectrometer cubesat. Astrophys J 835:122. https://doi.org/10.3847/1538-4357/835/2/122

Xu H, Shiokawa K, Oyama S, Otsuka Y (2019) Thermospheric wind variations observed by a Fabry-Perot interferometer at Tromsø, Norway, at substorm onsets. Earth Planets Space 71:93. https://doi.org/10.1186/s40623-019-1072-0

Yadav S, Sridharan R, Sunda S (2016) Impact of the 17 March 2015- St. Patrick's Day storm on the evolutionary pattern of equatorial ionization anomaly over the Indian longitudes using high resolution spatio-temporal TEC maps - new insights. Space Weather 14(10):786-801. https://doi.org/10.1002/ 2016SW001408

Yamamoto M, Shiokawa K, Nakamura T, Gopalswamy N (2016) Special issue "International CAWSES-II Symposium.". Earth Planets Space 68(1):26. https:/ doi.org/10.1186/s40623-016-0392-6

Yeo KL, Krivova NA, Solanki SK (2017) EMPIRE: a robust empirical reconstruction of solar irradiance variability. J Geophys Res Space Physics 122:3888-3914. https://doi.org/10.1002/2016JA023733

Yermolaev YI, Lodkina IG, Nikolaeva NS (2018) Geoeffectiveness of solar and interplanetary structures and generation of strong geomagnetic storms. In: Buzulukova N (ed) Extreme events in geospace. Origins, predictability, and consequences. Elsevier, Amsterdam

Yiğit E (2018) Dynamics of the atmosphere-ionosphere system meteorological influences, variability, and space weather. In: Atmospheric and space sciences: ionospheres and plasma environments, vol 2. Springer, New York, pp 103-133

Yiğit E, Aylward AD, Medvedev AS (2008) Parameterization of the effects of vertically propagating gravity waves for thermosphere general circulation models: sensitivity study. J Geophys Res 113:D19106. https://doi.org/10.1029/ 2008JD010135

Yiğit E, Koucká Knižová P, Georgieva K, Ward W (2016) A review of vertical coupling in the Atmosphere-lonosphere system: effects of waves, sudden stratospheric warmings, space weather, and of solar activity. J Atmos SolarTerrestrial Phys 141:1-12. https://doi.org/10.1016/j.jastp.2016.02.011

Yoshida A (2014) Difference between even- and odd-numbered cycles in the predictability of solar activity and prediction of the amplitude of cycle 25 Ann Geophys 32:1035-1042. https://doi.org/10.5194/angeo-32-1035-2014

Zhang J, Blanco-Cano X, Nitta N, Srivastava N, Mandrini CH (2018) Editorial: Earthaffecting solar transients. Sol Phys 293(5):80. https://doi.org/10.1007/s11207018-1302-9

Zhang J, Richardson IG, Webb DF, Gopalswamy N, Huttunen E, Kasper JC, Nitta NV, Poomvises W, Thompson BJ, Wu C-C, Yashiro S, Zhukov AN (2007) Solar and interplanetary sources of major geomagnetic storms (Dst $<100 \mathrm{nT}$ ) during 1996-2005. J Geophys Res 112:A10102. https://doi.org/10.1029/ 2007JA012321

Zhang J et al (2021) Earth-affecting solar transients: a review of progress in solar cycle 24. Progress in Earth and Planetary Science (this issue)

Zharkova V, Popova E, Shepherd S, Zharkov S (2018) Reply to comment on the paper " on a role of quadruple component of magnetic field in defining solar activity in grand cycles" by Usoskin. J Atmos Solar-Terrestrial Phys 176: 72-82. https://doi.org/10.1016/j.jastp.2017.09.019

\section{Publisher's Note}

Springer Nature remains neutral with regard to jurisdictional claims in published maps and institutional affiliations.

\section{Submit your manuscript to a SpringerOpen ${ }^{\circ}$ journal and benefit from:}

- Convenient online submission

- Rigorous peer review

- Open access: articles freely available online

- High visibility within the field

- Retaining the copyright to your article

Submit your next manuscript at $\boldsymbol{\nabla}$ springeropen.com 